\title{
WestVirginiaUniversity
}

THE RESEARCH REPOSITORY @ WVU

Graduate Theses, Dissertations, and Problem Reports

2006

\section{Composite suspension member analysis}

Bruce M. Schlicker

West Virginia University

Follow this and additional works at: https://researchrepository.wvu.edu/etd

\section{Recommended Citation}

Schlicker, Bruce M., "Composite suspension member analysis" (2006). Graduate Theses, Dissertations, and Problem Reports. 1745.

https://researchrepository.wvu.edu/etd/1745

This Thesis is protected by copyright and/or related rights. It has been brought to you by the The Research Repository @ WVU with permission from the rights-holder(s). You are free to use this Thesis in any way that is permitted by the copyright and related rights legislation that applies to your use. For other uses you must obtain permission from the rights-holder(s) directly, unless additional rights are indicated by a Creative Commons license in the record and/ or on the work itself. This Thesis has been accepted for inclusion in WVU Graduate Theses, Dissertations, and Problem Reports collection by an authorized administrator of The Research Repository @ WVU. For more information, please contact researchrepository@mail.wvu.edu. 
Composite Suspension Member Analysis

Bruce M. Schlicker

Thesis submitted to the

College of Engineering and Mineral Resources

at West Virginia University

in partial fulfillment of the requirements

for the degree of

Master of Science

in

Mechanical Engineering

Chairman

Dr. Ken Means

Committee Members

Dr. Xingbo Liu

Dr. Jacky Prucz

Department of Mechanical Engineering

Morgantown, West Virginia

2006

Keywords: Hybrid composite, Aluminum/epoxy interface 


\section{ABSTRACT \\ Composite Suspension Member Analysis}

\section{Bruce M. Schlicker}

As research has developed advancement in composites, they are increasingly being used as components in dynamic situations, e.g. suspension members. Previously used alloy materials are being replaced. Current research has led to developments in attaching aluminum to the composite. This new material is often referred to as a hybrid composite.

Hybrid composites used as suspension components become popular for their increased design flexibility. In this thesis, the shock mounting point was of the concern. It was found that the weak link in the hybrid aluminum/composite attachment is the bond between the aluminum and the epoxy.

Experiments and research led to advancements and conclusions on maximizing the strength of attaching an aluminum plate to a carbon/epoxy composite. As research continues the benefits of composites are seen. Specifically enhanced properties and weight reduction of these modern hybrid components offer the advantages worthy of researching this topic. 


\section{ACKNOWLEDGEMENTS}

I would like to express my sincere appreciation to all of my family and friends for their continuing support. It has been a long road in pursuing my education filled with numerous challenges. My parents, Rick and Vala, deserve a special thank you for never doubting me and always encouraging me. Thank you mom and dad!

Dr. Ken Means became a very important advisor and friend to me through my involvement with the Mini-Baja program and this thesis. I would like to thank Dr. Means for always being available and offering his time.

I would also like to thank Dr. Xingbo Liu for all his knowledge and answers provided both in and out of the classroom.

It should be mentioned I began engineering at WVU in Dr. Prucz's ENGR 101 classroom and it seems appropriate to complete my MSME under his guidance. 


\section{TABLE OF CONTENTS}

Abstract

$\begin{array}{ll}\text { Acknowledgements } & \text { iii }\end{array}$

List of Tables vii

List of Figures viii

1. Introduction 1

1.1 Background 1

1.2 Suspension Members 1

2. Composite Materials 4

2.1 Introduction 4

$\begin{array}{ll}2.2 \text { Matrix } & 4\end{array}$

2.3 Reinforcement Fibers 5

2.4 Lay-up Processes and Matrix Curing 5

2.4.1 Hand Lay-up 6

$\begin{array}{ll}\text { 2.4.2 Prepreg Lay-up } & 7\end{array}$

$\begin{array}{ll}\text { 2.4.3 Bag Molding } & 7\end{array}$

2.4.4 Autoclave 8

2.5 Material Effects and Unidirectional Reinforcement 9

$\begin{array}{ll}\text { 2.6 Multidirectional Composite Laminates } & 10\end{array}$

$\begin{array}{ll}2.7 \text { Environmental Effects } & 11\end{array}$

$\begin{array}{ll}2.8 \text { Creep and Modulus Decay } & 12\end{array}$ 
3.2 Composite Failure Prediction 13

3.2.1 Truncated-Maximum-Strain Criterion $\quad 14$

3.3 Composite Fatigue 15

3.3.1 Fatigue Behavior of Unidirectional Composites 15

3.3.2 Fatigue Behavior of Multidirectional Laminate Composites 18

3.3.3 Effect of Stress Concentrators $\quad 20$

3.3.4 Compressive Fatigue Loading 20

3.3.5 Flexural Loading and Fatigue $\quad 21$

3.3.6 Comparison with Metals 21

3.4 Damage Accumulation 23

4. Hybrid Composites 25

4.1 Investigation of the Aluminum/Epoxy Interface 25

4.2 Surface Treatments on Enhancing the Aluminum/Epoxy Bond 26

4.2.1 Adhesive Films 26

4.2.2 Phosphoric Acid Anodization (PAA) 26

4.2.3 Silane Coupling Agents $\quad 26$

4.3 Surface Treatment Effects on Interfacial Loading 27

$\begin{array}{lr}\text { 4.3.1 Interfacial Shear } & 27\end{array}$

4.3.2 Interfacial Tension $\quad 28$

4.4 Coefficient of Friction $\quad 29$

4.4.1 Wear Mechanisms 31 
4.5.1 Shear Strength Research $\quad 32$

4.5.2 Fracture Surface of Laminated Composites 32

5. Interface Stress Intensity Factor

$\begin{array}{ll}5.1 \text { Introduction } & 34\end{array}$

5.2 Fracture Toughness of Epoxy Plate 34

$\begin{array}{ll}\text { 5.3 Discussion } & 35\end{array}$

6. Aluminum/Carbon Hybrid Composite Experiment 36

6.1 Introduction 36

6.2 Experimental Procedure 36

6.3 Experimental Results and Discussion 42

6.4 Experimental Verification $\quad 66$

7. Conclusions

$\begin{array}{ll}\text { References } & \mathbf{7 4}\end{array}$

$\begin{array}{ll}\text { Appendix } & 76\end{array}$ 


\section{List of Tables}

$\begin{array}{lll}\text { Table } 1 \text { Carbon fiber properties. } & 37\end{array}$

Table 2 Filament/Tow properties. $\quad 38$

Table 3 Properties of E-Z Lam 60 epoxy resin. 38

Table 4 Strain gage dimensions. 57

Table 5 Experimental failure data. $\quad 60$

Table 6 Calculated aluminum/epoxy interfacial failure data. $\quad 67$

Table 7 Typical epoxy composite properties. 68 


\section{List of Figures}

Fig. 1 Hybrid composite swing arm. 2

Fig. 2 Vacuum bag curing. $\quad 8$

Fig. 3 Composite stress-strain curve predicted by the volume fraction rule. $\quad 10$

Fig. 4 Comparison of the S-N tensile fatigue behavior of three different 16 unidirectional composite materials.

Fig. 5 Comparison of the S-N tensile fatigue behavior of four composite $\quad 17$ materials based on the same epoxy resin matrix but with different carbon fibers.

Fig. 6 Comparison of the S-N tensile fatigue behavior of three composite materials with the same carbon fiber reinforcement but in three different epoxy resin matrices.

Fig. 7 Plots of peak tensile stress normalized to the static strength versus $\log$ cycles to failure for carbon fiber composites with varying percentages of unidirectional fibers.

Fig. 8 A comparison of the S-N fatigue behavior of a standard carbon fiber laminate with $50 \%$ unidirectional fibers in both zero-tension and tension-compression loading.

Fig. 9 Sketched fatigue damage accumulation.

Fig. 10 Coefficient of friction as a function of normal force. 30

Fig. 11 Experimental sample molds. 37

Fig. 12 Two part epoxy resin system used. 38

Fig. 13 Composite beam sample under vacuum. $\quad 40$

Fig. 14 Laminate surface imperfections where the aluminum is to be attached. 40

Fig. 15 Corrected laminate surface using sandable putty. 41

Fig. 16 Experimental set-up. $\quad 42$

Fig. 17 Sample preparation using c-clamps. 43

Fig. 18 Vacuum curing process. 44

Fig. 19 Composite failure surface for the vacuum cured sample. 45

Fig. 20 Composite sample with additional wrap of carbon fiber fabric 46 after vacuum curing.

Fig. 21 View of the sharp corner at the aluminum/composite interface. 47

Fig. 22 Damage which occurred at a 1,432 lb. load. 48

Fig. 23 Failure surfaces at the interface. 49

Fig. 24 Partially wetted carbon fabric during initial stage of lay-up process. $\quad 50$

Fig. 25 Saturated peel-ply fabric. 51

Fig. 26 Sample deformation at 2200 lbs. 52

Fig. 27 Aluminum plate deformation. 53

Fig. 28 Interfacial fracture surface. $\quad 54$

Fig. 29 Epoxy failure surface on the composite sample. 55

Fig. 30 Data acquisition experimental set-up. 56

Fig. 31 Strain gage configuration used for EXP 1. 57

Fig. 32 Strain gage configuration used for EXP 2. 58

Fig. 33 Load vs. Displacement for EXP 1 and EXP 2. 59

Fig. 34 EXP 1 Strain vs. Time at top gage location. 61 
Fig. 35 EXP 1 Strain vs. Time at side gage location. 62

Fig. 36 EXP 2 Strain vs. Time at top gage location. 63

Fig. 37 Fibers cut away for inspection. 64

Fig. 38 EXP 1 Interfacial fracture surface. $\quad 65$

Fig. 39 EXP 2 Interfacial fracture surface. $\quad 66$

$\begin{array}{ll}\text { Fig. } 40 \text { EXP } 1 \text { strain vs. calculated strain. } & 69\end{array}$

Fig. 41 Orientation of strain gages in EXP 1. 70

Fig. 42 EXP 2 strain vs. calculated strain. 71

Fig. 43 Orientation of strain gage in EXP 2. 71

\section{Appendix Figures}

$\begin{array}{ll}\text { Fig. 1A Experiment sample. } & 77\end{array}$

Fig. 2A Area under load. $\quad 78$ 


\section{CHAPTER ONE}

\section{INTRODUCTION}

\subsection{Background}

The use of composites in the vehicle industry has become very popular due to the vehicle weight reduction that is achieved. A light weight vehicle ultimately requires less engine demand and increases the vehicle fuel efficiency. With the evident increase in fueling costs, this gain in efficiency is a welcome addition to the design process. Furthermore, in racing applications, where speed and performance is of greater concern, the gain from composites becomes more obvious in the suspension system. The ability to shave a mere tenth of a second off a lap time is a huge advantage in such a competitive sport.

Composite materials also offer the unique advantage in being able to tailor their properties to specific design requirements. This allows for less material in low stress regions and a bulk of material in higher stressed regions to meet design requirements. It is during the design process, software programs can be used to model the part and analyze reactions due to applied forces. This knowledge is applied in using only the required amount of properly aligned fibers to meet demands, helping to again reduce the overall weight of the part.

Because composites are fairly new to high demand applications like the suspension system, research continues to help understand how composites behave. The failure of composite materials is unlike the metal part it often replaces. The effect the environment has on composites can be more severe and can be often linked to damage accumulation. Fatigue of composites is also more complicated when designing with composites. With the added behavioral complications associated with composites, more complicated and sometimes unpredictable failure patters can occur.

It is not always the case where a composite can be made from fiber reinforcement and the matrix alone. These composites are often referred to as hybrid composites. Hybrid composites consist of the fibers, matrix and a foreign material such as a metal. With the designing of a composite suspension member, often is the case where aluminum would be chosen because of its strength-to-weight ratio. Shock and frame mounts, along with the bearing carrier in a swing arm are all points of interest in using aluminum/composite attachments. In the case of these hybrid composites, attention must also be given to the epoxy-aluminum interface and its failure modes.

\subsection{Suspension Members}

The expansion of composite applications continues to grow and is reaching into the area of suspension member components. The attraction of lightweight composites is popular due to the unsprung weight associated with suspension members. As rebound occurs in the shock, the connected suspension member is "reset" as shock compression releases. The rate at which this member is reset is dependent on the rebound settings on the shock along with the weight of the member itself. A lighter weight composite member will rebound quicker allowing the tires to make ground contact sooner. The increased tire contact is crucial in improving handling, acceleration and braking. 
These unsprung members are designed to transmit loading from the tires of the vehicle into the vehicle's rigid frame. The ability to control and predict this reaction can be linked to such things as vehicle chassis twisting. For race applications, this has a critical effect on the handling of the vehicle. By allowing the suspension to control the majority of the vehicle's kinematics, the torsional stiffness of the chassis improves. This results in greater handling and predictability of the vehicle. With this in mind, a designed composite suspension component must be able to withstand the dynamic loading that occurs in the suspension system. Dynamic impact research has shown that maximum loads can occur as much as 4.8 times the static load for a Mini-Baja car under free fall, a four wheel vehicle built for an SAE off-road race. However, the percent of maximum load increase is directly proportional to vehicle weight and impact speed increase.

The suspension system can be designed with many different configurations. The typical set-up includes a shock tower connected to the frame at one end and a rigid link at the other end. The two major link components in dealing with these suspension members are a swing arm and a control arm (a-arm). A swing arm is located at the rear of a vehicle in which the axle is connected via a bearing carrier. This U-shaped component is mechanically fastened to the main frame at its open ends. This allows for suspension travel and rotation of the swing arm relative to the frame. The "arms" act as a linkage between the axle and the frame mount. Located on each arm, between the frame mount and the rear wheel, are mount points for the rear shock absorber. The swing arm has proven to be an effective design in the transmission of loading from the tires to the frame. Fig. 1 shows a hybrid composite swing arm that was built for use on a Baja car. The points where mechanical fastening to the vehicle and axle occur can be seen.

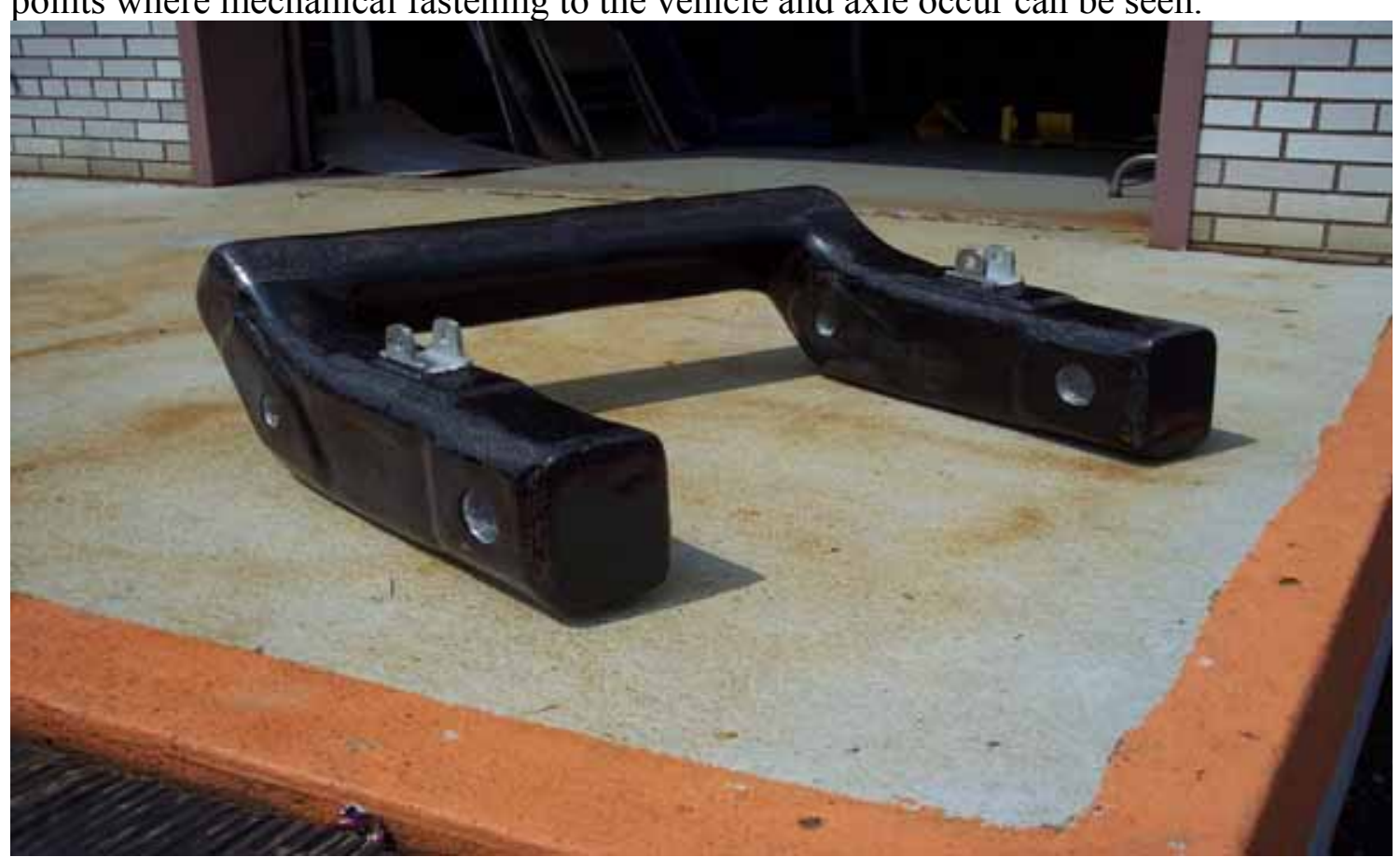

Fig. 1 Hybrid composite swing arm.

Apart from the swing arm, a control arm system is used for the front suspension. It can also be used when an independent rear suspension is desired. A control arm acts as a suspension link in the shape of an " $A$ ". The link is mechanically fastened to the frame 
at its two open points. This again prevents displacement in the $\mathrm{x}, \mathrm{y}$ and $\mathrm{z}$-directions relative to the frame. At these points, loads are distributed away from the tire, through the longer link arms and into the rigid frame. The suspension system also includes the shock absorber which is mechanically fastened on the shorter cross member of the "Aarm". This design has again proven effective in the transfer of any terrain induced loads that occur in the tire.

The vehicle's suspension components play a critical role in the handling and overall performance. With both designs mentioned, it can be understood how any weight reduction and improved stiffness using composites can be beneficial. First, any weight reduction will increase the horsepower-to-weight ratio. Therefore, the efficiency of the engine and its horsepower output increases. This will allow for improved performance in acceleration and top speed, critical in any race applications. The unsprung weight reduction in the suspension member is just as important. By increasing tire contact with the terrain, greater maneuvering and overall control will result. Another advantage is the enhanced stiffness properties of a composite suspension member helping to control chassis twisting. This again results in improved handling and performance. 


\section{CHAPER TWO}

\section{COMPOSITE MATERIALS}

\subsection{Introduction}

A composite material is made by combining two or more materials. These materials are often referred to as the reinforcement and the matrix. When combined and cured, they form a composite material with enhanced properties. Of these make-up materials, the reinforcement element consists of design specified oriented fibers. These fibers can be used in continuous, discontinuous and particle or whisker form. The fibers can have superior strength, however unable to sustain multidirectional loads, fibers cannot be used alone. This is where the matrix becomes crucial. After curing, the surface matrix first acts to protect the imbedded fibers from environmental conditions and damage. The main function of the matrix is to hold the fibers in place and allow load transfer between the fibers. It is important to point out that matrix properties are negligible compared to fibers so the mechanical properties of the composite are lower than the properties of the reinforcement fibers.

\subsection{Matrix}

A matrix is formed by the irreversible chemical transformation of a resin system often referred to as a thermoset matrix. One common thermoset matrix used in advanced composite materials is created with an epoxy resin system. Depending on the lay-up method and the reactivity of the resin, cure cycles can vary from minutes to hours. Curing usually takes place either at room temperature or higher. The reactions are exothermic and gel form of the resin can sometimes occur rapidly. This occurs when the resin viscosity has increased to the point where the resin hardly moves when probed. At this point the resin becomes unusable in the lay-up process. During the curing process the resin mixture thickens, gives off heat, solidifies and shrinks. Because the fiber reinforcement will not shrink, internal stress may be induced during matrix curing. This can cause matrix cracking, fiber misalignment, dimension inaccuracies and surface roughness. Initial imperfections like these can lead to failure of the composite as it stressed during use.

Among these matrices, epoxy resin systems are widely used because they are very versatile. They have high mechanical properties and high resistance to corrosion. Epoxies also shrink less than other materials during curing. The resistance for epoxy to shrink can be from $1.2-4 \%$ by volume better than other matrix resins such as the $8 \%$ for polyester matrices. This allows epoxies to also have excellent bond characteristics when used as adhesives. Epoxy resins are less affected by temperature and water than other polymer matrices. This is a crucial property when designing a composite suspension member, given their typical outdoor operating environments. Epoxy systems are also popular for their simple cure process that can be achieved at temperatures between $5^{\circ} \mathrm{C}$ to $150^{\circ} \mathrm{C}$. However, in most situations, the manufacture will provide a recommend cure environment. The epoxy resin system used in the following experiment has a recommended cure of 24 hours at $75^{\circ} \mathrm{F}$ to $80^{\circ} \mathrm{F}$ for example. 


\subsection{Reinforcement Fibers}

Carbon fibers, also referred to as graphite fibers, are lightweight and very strong fibers. They are a popular choice as reinforcement in composites for many reasons. Carbon fibers are available in a broad range of stiffness values. Being stiffer than other fibers allows carbon fibers to provide better fatigue characteristics to the composite by reducing the amount of strain in the matrix under loading. The properties of carbon fibers depend on the raw material and the process used for its manufacture.

One of the earliest materials used to make carbon fibers was rayon, which are derived from cellulosic materials. The major disadvantage is a high weight loss, or low conversion yield to carbon fiber during processing, on average only $25 \%$ of the initial fiber mass remains after carbonization. This means that carbon fiber made from these materials is reasonably more expensive than carbon fibers made from other materials.

The more common raw material used in carbon fibers are polyacrylonitrile (PAN). PAN precursors are the source for the majority of carbon fibers commercially available today. They provide a carbon fiber conversion yield that is $50-55 \%$. These precursors can be thermally rearranged before thermal decomposition. This allows them to be oxidized and stabilized before the carbon fiber conversion process, while maintaining the same filamentary configuration. The chemical composition of PAN precursors defines the thermal characteristics that the material displays throughout the oxidation/stabilization portion of the conversion process. These thermal characteristics influence the processing sequences that are used to convert PAN precursors to carbon fiber. Carbon fiber based on a PAN precursor generally has a higher tensile strength than a fiber based on any other precursor. This is due to a lack of surface defects which act as stress concentrators and consequently reduce tensile strength.

Pitch precursor base on petroleum asphalt, coal tar and polyvinyl chloride can also be used to produce carbon fiber. Pitches are relatively low in cost and comparatively high in carbon yield during processing. They due however have lower strength values than PAN fibers. The most significant drawback is nonuniformity from batch to batch. This can result in inconsistencies in fiber strength and unpredicted composite failure.

Carbon fibers have excellent chemical resistance. This is crucial in the case the protective matrix becomes damaged and can no longer provide protection from environmental conditions. The maximum operating temperature of carbon fibers can vary from $300^{\circ} \mathrm{C}$ to as much as $550^{\circ} \mathrm{C}$. However, this can be further limited by the operating temperature of the matrix which is often less than that of the reinforcement fibers.

With the enhanced properties of carbon fibers over other fibers does come a higher cost. However, as mentioned before, for applications in the race industry the cost of high strength carbon fibers can be justified when compared to the strength-to-weight payoffs. Carbon fibers can offer high temperature performance, corrosion resistance, high fatigue strength and long term strength retention making them ideal for use in suspension member composites.

\subsection{Lay-up Processes and Matrix Curing}

The manufacturing process used depends on various situations. It becomes dependent on the type of matrix and fibers used. The required temperature to form the part and to cure the matrix must be known. The cost effectiveness of the process can also 
become a concern. The designer must be aware of the advantages, limitations, cost production rate and volume, and typical uses of the various manufacturing lay-up processes. For designing a complex hybrid composite suspension member it is often the hand lay-up, prepreg lay-up, bag molding and autoclave processing that become popular choices.

\subsubsection{Hand Lay-up}

The hand lay-up technique, also known as wet lay-up, is the simplest process. It involves manual placement of the dry reinforcement fibers in or around the mold and manual application of the resin. The resin is brushed or rolled on the fibers, ensuring complete wetting. Uniform distribution of the resin is important to imbedding all fibers into the resin matrix. This process is repeated until the desired thickness and fiber orientations are reached. The layered structure is then cured according to resin specifications. In summary, the hand lay-up process can be divided into four basic steps. It starts with mold preparation, then resin coating, lay-up around the mold and finally the curing process.

Mold preparation begins the critical steps in the lay-up process. The mold can be made from a variety of materials. Materials like foam board, plastics, plaster, wood and other choice materials may be used depending on the number of times the mold will be used along with the resin cure temperature and pressure used. The mold can be designed to remain a non-structural part of the finished composite or it can be removed. For this case, a release agent can be applied to the mold allowing for easy removal of the finished composite part without damage. Some common release agents are wax, release fabric and silicones. The choice of the release agent depends on the type of mold material used and the quality of the finished product desired.

Resin coating can begin with the application of resin to the mold first. The coating is a nonreinforced layer of resin applied to the mold before the reinforcement fibers are added. This method, used along with a release agent will again produce a smooth clean surface appearance. The resin can also contain pigments to add color and appearance. The layer of resin becomes the outer surface of the composite once curing is complete. This outer surface acts as the protective layer through which the fiber reinforcements do not penetrate and therefore are not exposed to environmental conditions.

The final steps in the hand lay-up process involve fiber placement and resin curing. The reinforcement fibers can be applied in the form of strand mat, woven fabric or chopped fibers. The resin is next applied to the fibers, completely wetting or impregnating all fibers with resin. The resin can be applied using brushes or rollers to press the fiber material against the mold to ensure complete air removal. Once the reinforcement fibers are in place, curing can be completed according to resin specifications. The final molded composite part is then released from the mold.

The production rates and cost of the hand lay-up technique vary widely. They depend on the fibers and matrix used, the size of the part to be manufactured and the methods used. The hand lay-up process is also affected by the part quality required because of the need for either semiskilled or skilled workers. The cost per part can be minimized by choosing the appropriate mold construction and adjusting production to the available equipment. 


\subsubsection{Prepreg Lay-up}

Prepreg is referred to as a preimpregnated fiber reinforcement material where the resin is already partially cured or thickened around the fibers. The fibers can be arranged in a unidirectional manner, a woven fabric or random chopped fiber sheets. A common prepreg is made from epoxy resin systems using carbon fibers as the popular reinforcement. The essential difference between the prepreg lay-up and hand lay-up processing is that using prepreg, the impregnation of the fibers is complete prior to molding.

Prepregs are widely used for making high performance parts and complex geometries, where the hand lay-up becomes difficult. In most of the prepreg systems, the resin content is higher than desired for the final part. Allowing for the removal of this excess resin is crucial in eliminating any entrapped air and volatiles, which can produce voids in the final part if not removed. This is important because it was discovered for each $1 \%$ of voids there can be as much as a $7 \%$ reduction in the interlaminar shear strength. There is also a significant reduction in the compressive strength for a void content above $2 \%$. Lower resin content also reduces the overall weight and cost of the part without affecting the strength. Modern prepregs can be made with near-net resin content to avoid the removal of excess resin, which can become costly. The near-net resin content refers to the amount of resin in the prepreg being maintained near to the resin content desired in the final part. These modern prepregs are made using a hot melt impregnation method that minimizes the volatiles present.

The prepreg fabric or sheets are usually supplied in convenient lengths and widths. They are again cut to fit in or around the mold and laminated layer by layer until the desired thickness and fiber orientation is achieved. Because the resin is already partially cured, prepregs do have a limited shelf life. The shelf life can be extended by storing them in a chilled environment. An autoclave or vacuum is often required to assist in the curing of the laminate layers because of the higher temperatures required for complete resin curing.

\subsubsection{Bag Molding}

During bag molding a uniform pressure is applied to the laminate(s) before during the cure cycle. This method improves consolidation of the fibers and resin and the removal of any excess resin, air and volatiles from the matrix. The pressure is applied with the use of a flexible diaphragm or bag to conform around the mold.

The laminate layers are first placed in or around the mold using a choice of lay-up processes. A release film or fabric is then used to prevent the laminates from sticking to the bag. In some cases a peel-ply fabric can be used to leave an imprint or pattern on the surface to enhance adhesive bonding when multiple lay-up sessions are necessary. Perforated peel-ply can also be used to allow excess resin that is squeezed out during vacuum bagging to escape the laminates. For this case, a breather cloth is wrapped around the laminate to act as a sponge and soak up excess resin which has leaked through the perforated peel-ply. The breather cloth and bleeder combination also helps distribute the vacuum pressure across the laminates helping to ensure consistent properties. The mold is then covered with the flexible bag. The bag is then perfectly sealed around the mold and connected to the vacuum pump. Vacuum is applied and the part is then cured with pressure and heat as seen in Fig 2. By applying this vacuum under the bag, the 
atmospheric pressure acts uniformly over the laminate. The vacuum is also very effective in withdrawing excess volatile compounds. After the curing process is complete the vacuum is released and the part is removed.

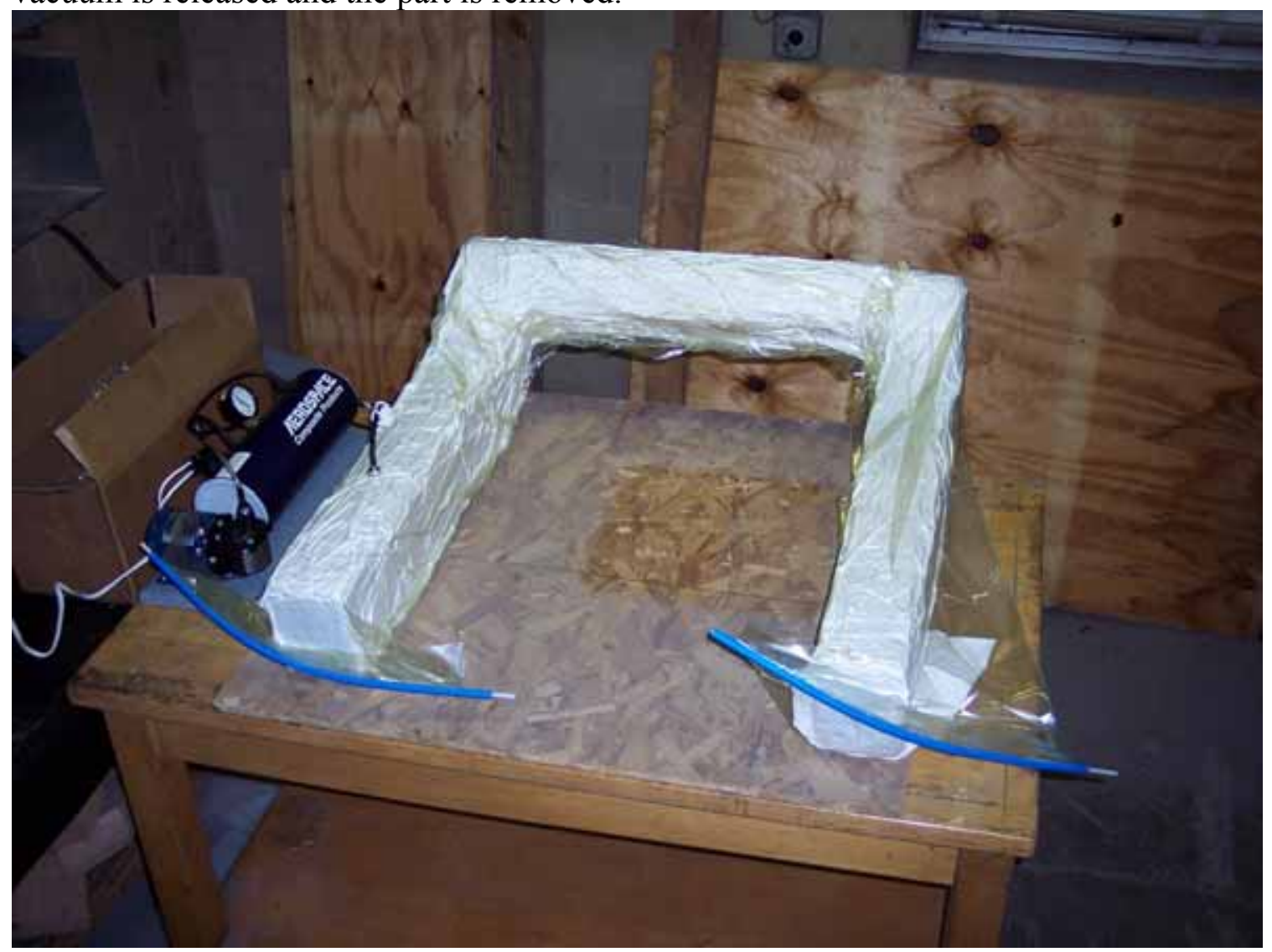

Fig. 2 Vacuum bag curing.

The disadvantage is that vacuum bags do allow for the production of large, lower cost composite parts. The size of the part that can be made using bag molding is limited only by the curing equipment. This includes the size of the curing oven or autoclave available. Using this method, vacuum and curing equipment can become quite large and expensive.

\subsubsection{Autoclave}

Autoclave processing of composites is an extension of the vacuum bag process. Autoclaves are pressure vessels that contain compressed gas during the curing process. The compressed gas in an autoclave provides higher pressure than a vacuum would and gives greater mold compression and elimination of voids. They are often used for the production of high quality, complex geometry parts. This method is better for parts with moderate production quantities given the added cost of the autoclave.

The complete mold is first prepared and sealed in a vacuum bag as previously discussed. Full or partial vacuum is drawn within the bag and sealed. Gas pressure within the autoclave, greater than atmospheric, is then applied on the exterior of the bag. The part temperature is raised to initiate the curing process of the resin. The higher temperature also helps decrease the viscosity of the resin allowing greater flow and 
wetting of the reinforcement. Using this higher temperature and pressure technique, porosity and voids are minimized when compared to vacuum bagging alone.

\subsection{Material Effects and Unidirectional Reinforcement}

Insight can be gained on the behavior of composites by understanding the concepts of fiber and matrix domination of composite properties. Fiber domination occurs when the principal stresses in the composite are carried by reinforcement fibers. Matrix domination of properties is referred to when the stresses in the composite are carried mainly by the matrix material.

Fiber or matrix domination is determined by both the material and the loading mode. All unidirectional and highly unidirectional composites subjected to tensile loading in the fiber direction are fiber dominated under equal strain conditions. Unidirectional composites loaded in any direction other than the fiber direction are matrix dominated under equal fiber/matrix stress conditions. Thickness properties such as interlaminar tension, compression and shear are always matrix dominated. Varying degrees of fiber and matrix domination can occur in complex materials such as composites.

Because fiber fatigue properties are better than those of the matrix, it is desirable to have fiber domination in fatigue whenever possible. This is normally accomplished by using continuous or highly oriented fibers in the principal stress direction of the composite. In general, high modulus fibers such as graphite and carbon exhibit outstanding fatigue properties in unidirectional composites. This is because matrix strains in these composites are very low, resulting in fatigue performance almost totally dominated by the fibers. It is for this reason, when fatigue is critical, it is better to choose a continuous fiber composite. Chopped fiber reinforced composites mainly rely on the matrix for load transfer from fiber to fiber. This will result in a much lower, partially matrix dominated fatigue performance. Continuous fibers can be added to a chopped fiber reinforced composite to improve the fatigue performance by increasing fiber domination.

For a fiber-reinforced composite with a tensile load applied in the fiber direction the uniaxial stress-strain response can be divided into stages. In the first stage the strain is small and both the fiber and matrix deform elastically. At the end of this stage the matrix begins to deform plastically while the fiber remains elastic. As a result, the stressstrain slope is reduced. During the second stage since many high strength fibers do not permanently deform prior to fracture the tensile strength of the composite is found at the end of this stage. Assuming all the fibers fail at the same strain, the stages of composite behavior can be represented by the illustration in Fig 3 [Courtney]. The volume fraction rule used to produce the curve below states that the stress carried by the composite at a specific strain is a volume fraction weighted average of the stresses found in the fiber and the matrix at the same strain. 


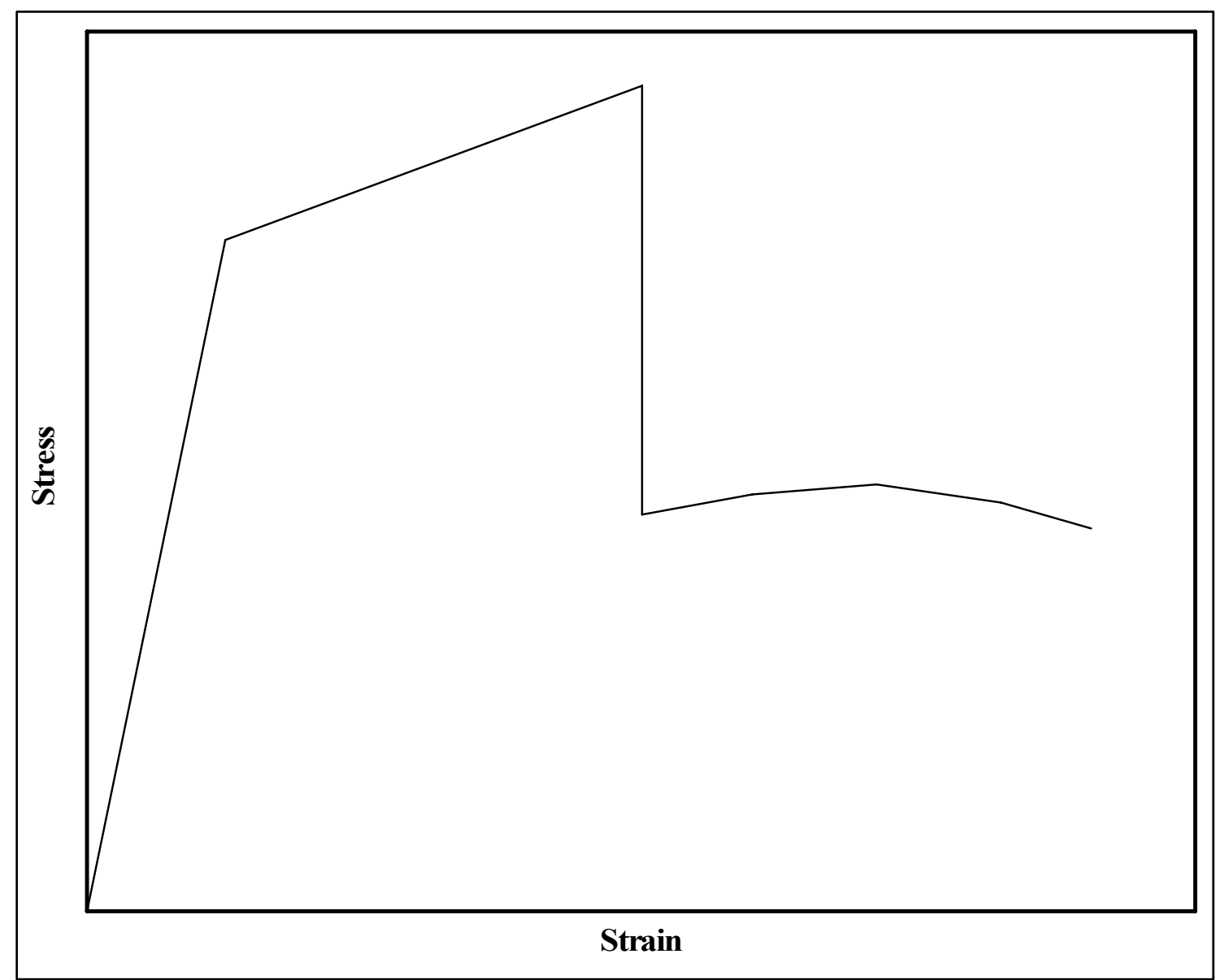

Fig. 3 Composite stress-strain curve predicted by the volume fraction rule.

Matrix failure is not necessarily concurrent with fiber failure in that the matrix is still capable of carrying a tensile load after fiber failure has occurred, although minimal in comparison to the ultimate tensile strength. Tensile failure in fiber dominated composites is usually controlled by fiber failure and pullout from the matrix. However, tensile loading in any direction other than the fiber direction normally results in matrix and fiber/matrix interface failure. This occurs when the matrix cracks and/or separates from the fibers.

Compressive failure in the fiber direction can be fiber dominated in some cases, with the fibers actually failing in compression. In other cases, the matrix or fiber/matrix interface can dominate failure. However, compressive loading in any direction is generally dominated by the matrix and its properties. Shear failure is normally matrix and fiber/matrix interface dominated in unidirectional composites.

\subsection{Multidirectional Composite Laminates}

The mechanical properties of unidirectional composite materials are very anisotropic, high strength and stiffness properties are confined to the fiber directions. Fibers do not contribute to the strength transversely to the fiber direction. It becomes necessary to add layers of a fiber/matrix laminate with various fiber orientations to 
account for multidirectional loads. To achieve more isotropic properties, composites are usually laminated with many stacked layers, each having fiber strength in different orientations to improve fiber domination. Layers are arranged so that the fibers are oriented in the principal loading directions. Fibers are oriented in the $0^{\circ}$ direction to support tensile and compressive loads. The $\pm 45^{\circ}$ fibers carry torsional loads while the $90^{\circ}$ fibers strengthen the transverse rigidity and limit lateral shrinkage on axial loading.

Another solution to handle multidirectional loads is to incorporate bidirectional reinforcement in each layer. This bidirectional reinforcement is obtained by using a woven fabric of fibers. There are various methods in which to weave the fibers resulting in various bidirectional mechanical properties of the fabric.

A different type of hybrid composite can also be used to achieve desired multidirectional properties. A fiber of one material can be oriented in the direction of loading corresponding to its strength property. A lighter or less expensive fiber can be incorporated into the laminates in the strength directions where it is unnecessary to use the previous fiber. There is again the concern with hybrid composites at the interface between the individual fibers because they have different properties. Reactions at any and all interfaces must be considered.

\subsection{Environmental Effects}

Moisture expansion is particularly important to address provided the composite part will be exposed to moist weather conditions. Moisture is primarily absorbed by the matrix with the exception of organic fibers which can also absorb moisture. Inorganic fibers such as carbon however will not absorb moisture. Once moisture is absorbed, it produces swelling of the matrix and reduced strength and stiffness properties of the composite. Moisture is also known to cause corrosion and adhesion deteriation. The absorption rate of the composite is controlled by its diffusivity coefficient. The diffusion of moisture in the composite part is often slower than thermal conduction. This results in the part reaching thermal equilibrium much faster than moisture equilibrium when exposed to a changing environment.

The amount of moisture and the rate at which it is absorbed can be obtained easily by monitoring the weight of the composite part. Careful consideration needs to be given to the void content in the composite since water that fills up voids does not contribute to the induced swelling. If the void content is known, and if it can be assumed that all voids will be filled by water, the weight of the water in the voids can be subtracted to get the weight of water actually absorbed by the composite part.

Thermal expansion must also be considered when utilizing composites. Composite materials have two coefficients of thermal expansion. In the fiber direction, the thermal expansion behavior is dominated by the fibers. In the perpendicular direction, the matrix dominates the thermal expansion behavior. The thermal expansion coefficient of the resin matrix is positive. However, expansion coefficients in reinforcement materials such as carbon fiber may differ in given directions. Carbon fibers have a negative expansion in the fiber direction and a large expansion in the transverse direction. This material property can be beneficial to the designer. Depending on the amount of fibers, it is possible to tailor the coefficient of thermal expansion of the composite to the design requirements. It is certainly possible to design a composite 
material part with a very low coefficient of thermal expansion. This is useful when dimensional stability of the part is required.

\subsection{Creep and Modulus Decay}

It is known the mechanical properties of composites depend strongly on environmental conditions. Among the effected properties that become crucial is creep. Unlike metals, composites can begin to creep at room temperature. Creep is the continuous growth of deformation with time under constant load. Material creep is one result of the viscoelastic behavior of polymer matrices associated with temperature dependence.

One simple creep test consists of loading a composite sample with a constant tensile load and recording the elongation over time. First there is an instantaneous elastic deformation followed by the primary creep region where deformation grows fast. The primary creep region occurs over a short period of time and for this reason it is of interest during processing. The secondary creep region is typically characterized by a constant slope. This slope is defined as the creep rate. This creep region extends over a long period of time. This region is of interest in design because it encompasses the range of time for which the part will be in operation. If the creep rate is not a function of the stress level, the material is referred to as viscoelastic.

The load-rate effects of polymers are further evidence of viscoelastic behavior. If the load is not applied suddenly but over time, the stress-strain plots change as a function of the loading rate, the slower the application of the load, the larger the strain. This is because slower loading time allows the polymer to accumulate more creep strain. The initial portion of the stress-strain plots is linear, while the behavior is viscoelastic. The plot then becomes nonlinear at higher stress levels indicating viscoplastic behavior where the creep rate now becomes a function of the stress level. One of the main reasons for using fiber reinforcements is to limit the creep of polymer matrices so that structures can take loads over a longer period of time.

Beyond creep under simple loading, modulus decay and cyclic creep are associated to fatigue damage. For this case one can expect the decrease in the modulus of stress-strain leading to permanent deformation. Modulus decay is defined at the ratio of modulus after $\mathrm{N}$ fatigue cycles to the initial stress-strain modulus on the first cycle of loading. Cyclic creep is the increase in strain at the minimum fatigue stress compared to the first cycle strain at the minimum stress. Fatigue modulus decay and cyclic creep are common in composites whose properties are not dominated by reinforcing fibers. This means they have no fibers in the loading direction and are matrix dominated. Modulus of decay and cyclic creep are both functions of stress level, temperature and other environmental conditions. 


\section{CHAPTER THREE}

\section{COMPOSITE STRENGTH DESIGN}

\subsection{Design Process}

The design process for composites is often much more involved and complex. The process can begin first by defining the operating environment of the part. The design engineer must first define the operating environment since we know how exposure to elements can result in composite damage. Temperature ranges, moisture exposure and chemical exposure conditions should all be specified.

The expected loading, including fatigue, on the structure should be defined in terms of load magnitude, direction, number of cycles and frequency. It can also be important to define minor, secondary fatigue loading as these may have a significant effect on structure durability. Next, failure criteria for the structure must be established based on its performance requirements. Failure may occur within the composite, especially in the matrix, that may not be considered a structural failure. In this case, the part is still considered operational. However, this minor damage may accumulate over time and result in eventual structural failure. Usually, either separation failure at the matrix interface or minimum stiffness failure criteria is selected.

Only after all of the design requirements have been fully defined can a material and process be selected. This requires an understanding of the relations between the complexity of the chosen design and the material and processing that will be used. Items such as process limitation and process effects on material performance should be considered at this point.

Once the considered materials and processing are decided on, finite element analysis or other analysis techniques are used to estimate the stress state of the material throughout the structure. For multiple layer reinforced composite materials, interlaminar stresses must be considered. It may be found that additional material data is needed to complete the design procedure. With all of the required test data and analysis results available, a design decision can be made. If the calculated fatigue stresses in the material are low enough to assure adequate life, then the deign is satisfactory. Otherwise, the material and possibly the lay-up process will have to be redefined to meet the design requirements. This requires reiteration of the stress analysis and material comparison steps of the design procedure until a satisfactory design is attained.

The final step is to build and evaluate a prototype of the final design. This is done to assure that production material and process conditions are suitably simulated. If an unforeseen development arises in prototype production and testing, a reiteration in part of the design procedure may become necessary. With a successful prototype, design of the composite part is complete.

\subsection{Composite Failure Prediction}

Failure of a composite occurs when it can no longer perform its intended function. Because composites show many modes of failure it is difficult to incorporate all modes into the design. The simplest alternative it to use empirical failure criteria similar to the criteria used in metals, but modified for composites. Some of the more popular options include max stress-strain, Tsai-Hill and Tsai-Wu failure criteria. A limitation of Tsai-Hill 
and Tsai-Wu criteria is that they do not explicitly distinguish matrix failure from fiber failure. This implies there are no abrupt changes in failure mechanism when the various components of stress or strain change sign.

It is important to note, failure criteria are equations with parameters adjusted to fit experimental data of failure of a single-layer composite. The criteria are then used for situations where experimental data is not available. Failure criteria are further complemented with laminate failure analysis techniques to predict laminate failure from single-layer data. The strength of a single-layer composite can be described by numerous strength values which include; tensile and compressive strengths both in the fiber direction and the transverse direction, inplane shear strength, interlaminar shear strength values and biaxial interaction coefficient.

For the prediction of composite laminate failure, there are a couple of approaches. The simplest approach consists of using one of the layer criteria to predict the first ply failure (FPF) load. This is the load at which the first layer failure occurs. To predict FPF, the laminate stresses that result due to a set of reference loads are first computed. Then analysis is conducted to determine the strength ratio at the top and bottom of each laminate. The FPF load can be obtained by multiplying the reference set of loads by the strength ratio. Because the transverse strength of the composite is typically much lower than the tensile strength, FPF is usually associated with matrix cracking only.

When matrix cracking results in layer failure, a stress redistribution will result with a constant applied load. The majority of the stress carried by a layer before it fails is transferred to the remaining intact layers. To find the load at which the next layer fails, the properties of the first failed layer can be degraded. The laminate is reanalyzed to find the new stress and strength ratios. Upon redefining the minimum of all the strength ratios at the top and bottom of all layers, the second-ply failure load can be calculated. This incremental analysis is repeated until all the layers are degraded. Then a final calculation, with all layers degraded, will provide the load at which a layer fails in the fiber direction. This is known as the fiber failure (FF) load. Fiber fracture in a composite will most likely correspond to the final failure of the composite, although in some cases matrix failure may define ultimate failure. FF load only gives an indication of ultimate load when the strength of the laminate is controlled by the fibers. If a laminate fracture is due to a matrix failure, the FF load has no significance. Prediction of matrix failure is important in identifying undesirable laminate designs with fracture controlled by matrix failure. Such laminates could be identified as having a FF $\leq$ FPF.

\subsubsection{Truncated-Maximum-Strain Criterion}

Matrix cracking often occurs at lower loads, however typically it does not lead to catastrophic failure in a composite with properly designed laminates. If the transverse deformation of each layer is constrained by a layer of fibers oriented in the perpendicular direction, the reduction in strength in one layer due to matrix cracking is compensated by a load transfer into the fibers of the perpendicular layer. Furthermore, if the fibers are more brittle than the matrix, it can be assumed that the perpendicular fibers nearly eliminate or at least reduce matrix cracking because the fibers would have to fail first. Based on these observations, the truncated-maximum-strain criterion provides an alternative to the previous methods of composites failure prediction. 
This criterion does assume certain conditions hold true; (a) all layers have a complementary layer with perpendicular fiber orientation, (b) layers with various fiber orientations are separated as much as possible to avoid clusters of layers with the same orientation where a matrix crack can grow, (c) the strains in the fiber are those of the layer, noting this assumption is satisfied in the fiber direction, but it is only approximate in the transverse direction. The truncated-maximum-strain criterion is again applied layer by layer, but it is a laminate failure criterion and can not be used for a single unidirectional layer. In this criterion the FF is found by comparing the strain in the fiber with the strain to failure of the unidirectional composite in tension and in compression.

\subsection{Composite Fatigue}

In modern suspension designs, the desired outcome is to replace typical steel and aluminum suspension components with a lighter composite material. These composite components must again however maintain the required material properties shown by the metal to be replaced. In order to do so successfully, research must be given to the loads the suspension linkage will experience during operation and how the desired composite can withstand. Suspension members are often subjected to constant fatigue due to stress cycling. The extreme fatigue loading that occurs in suspension members must be accounted for when considering composites.

An understanding of the fatigue behavior of composites is essential in assuring that the components are properly designed. Due to fatigue, failure typically occurs below the ultimate strength of the material. A great deal research and development is available when looking at the fatigue loading of common metals. When dealing with composites however the line of attack is complicated with various considerations. Fiber orientation, volume fraction rates, operation temperature and moisture are again all examples of the added concerns. It must also be understood the interfaces between the fibers and the matrix are relatively weak and are potential fracture paths. Because the individual fibers generally perform well in fatigue, it is usually the matrix and the influence of the complex local stresses that determine the development of damage in composites during fatigue loading and thus ultimately the fatigue performance of composite materials.

To acquire fatigue data a repetitive, cyclic stress is applied to the material at a controlled frequency. The cyclic stress is defined by the parameters $\mathrm{S}$ and $\mathrm{R}$. Where $\mathrm{S}$ is the maximum stress and $\mathrm{R}$ is the ratio of minimum to maximum stress applied during each fatigue cycle. This data is generally presented in an S-N curve plot. Each test results in one data point to be used in constructing the curve. This curve becomes essential when selecting fatigue design stresses. The use of very stiff fibers, such as carbon fibers, results in relatively low strains and thus a more desirable shallow S-N curve.

\subsubsection{Fatigue Behavior of Unidirectional Composites}

The simplest form of a composite material is one with all the fibers aligned in the load direction. In these materials static strengths as high as $3 \mathrm{GPa}$ can be achieved. Application of such composites is limited because of the poorer mechanical properties in directions other than along the fibers and the matrix itself. Composites with large fractions of fibers in one direction typically provide a plot of peak stress versus log cycles to failure similar to that found in Fig. 4 [Curtis]. 


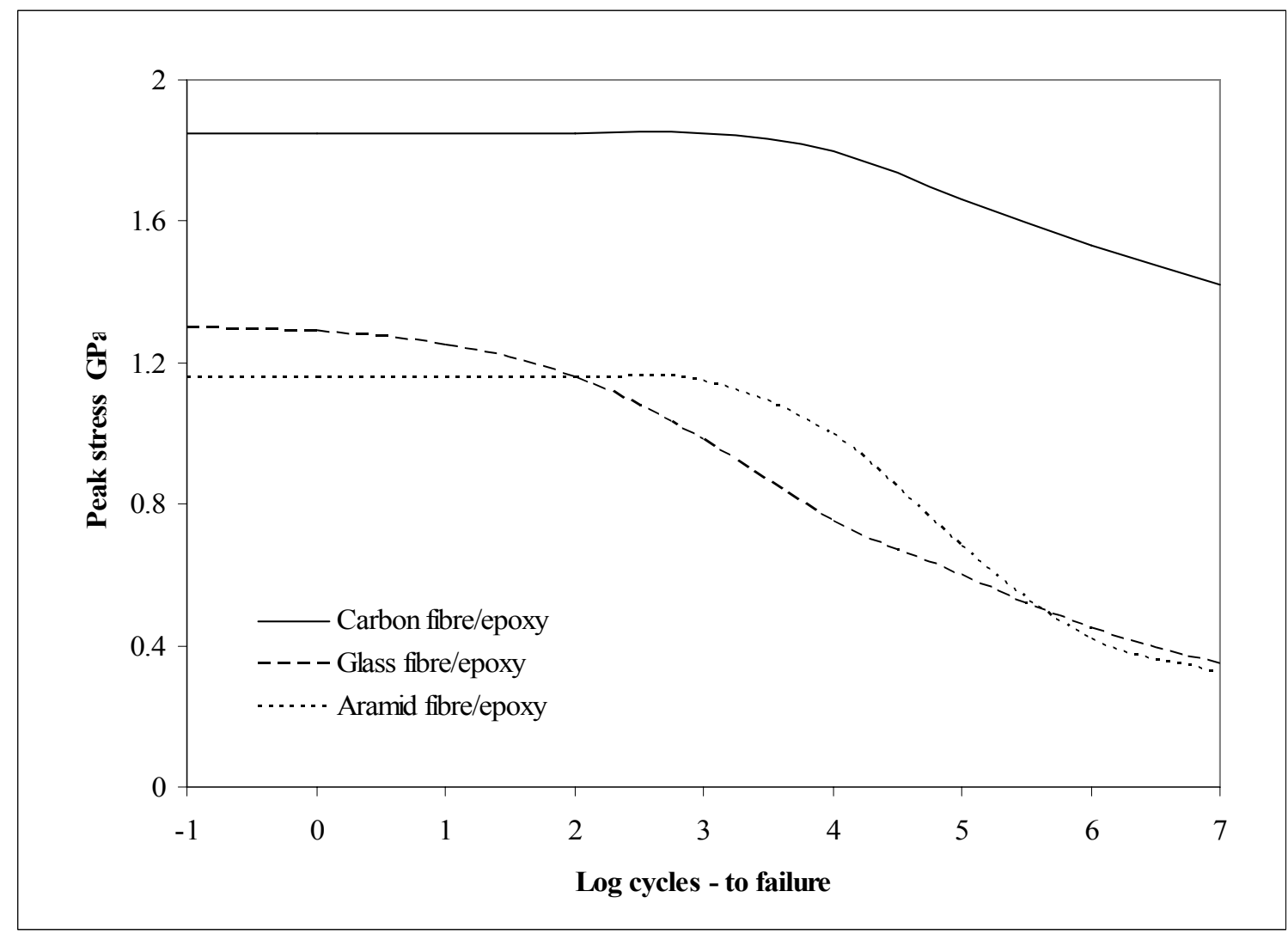

Fig. 4 Comparison of the S-N tensile fatigue behavior of three different unidirectional composite materials.

In the figure above, the $\mathrm{S}-\mathrm{N}$ curve for three unidirectional fiber materials is plotted. An epoxy resin system reinforced with carbon fiber, glass fiber and aramid fiber are displayed. The glass fiber reinforced material has the steepest curve while the carbon fiber reinforced material has the shallowest. This illustrates the superior fatigue property of carbon fibers. Looking at the curve for aramid fibers, the sudden drop in peak stress shows these fibers are more fatigue sensitive and can defibrillate during fatigue loading. In the case where fatigue life is extremely important, carbon fibers are a common choice.

The use of different high performance carbon fibers in the same standard epoxy resin matrices generally results in little change in composite fatigue behavior. This can be seen in Fig. 5 [Curtis] which shows the plot of peak strain versus log cycles to failure for several composites using the same resin matrix with different carbon fiber reinforcements. 


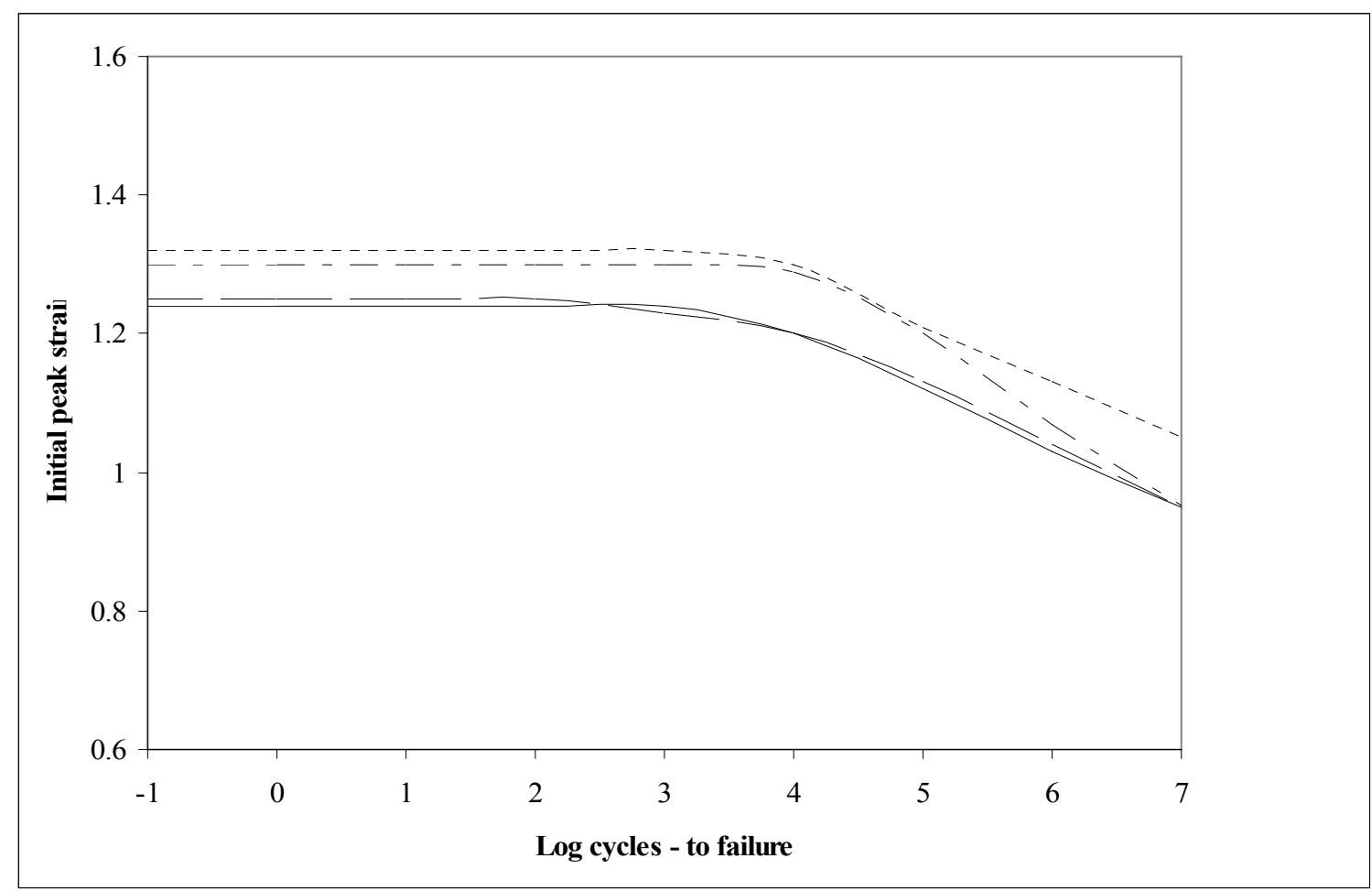

Fig. 5 Comparison of the S-N tensile fatigue behavior of four composite materials based on the same epoxy resin matrix but with different carbon fibers.

Based on the plots seen above, only small changes in the fatigue behavior are observed. This is undoubtedly the result of the fatigue behavior being mainly dependent upon the matrix and interfacial characteristics, rather than the superiority of the fiber strength. This illustrates the importance of both fiber and matrix material selection.

Striving to improve the performance of the composite matrix, manufacturers have tried to increase matrix toughness. The trade off is detriment to the higher temperature properties, especially after moisture absorption. The compromise has lead to improvements in static strength, but usually poorer fatigue behavior with steeper S-N curves, as shown in Fig. 6 [Curtis]. 


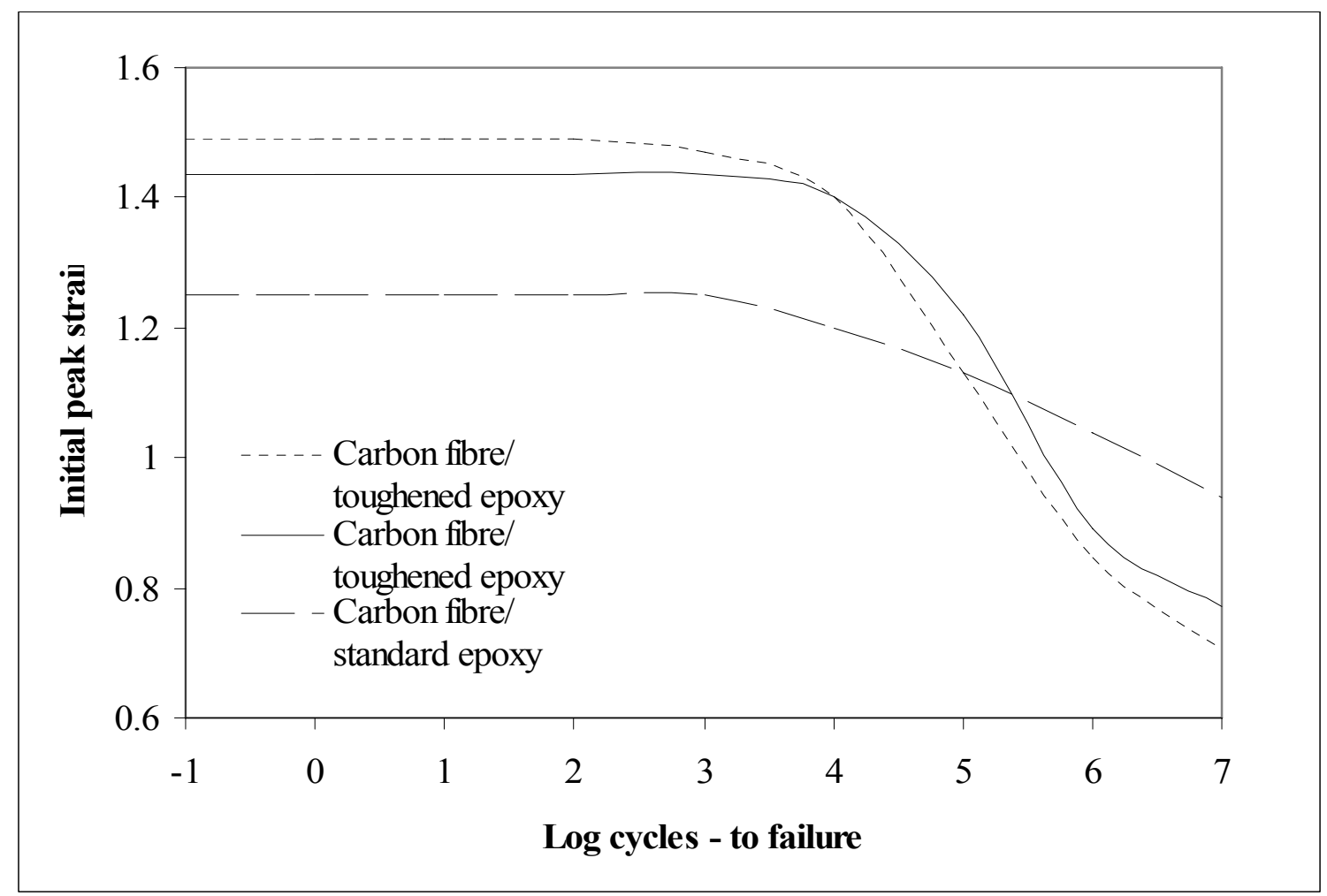

Fig. 6 Comparison of the S-N tensile fatigue behavior of three composite materials with the same carbon fiber reinforcement but in three different epoxy resin matrices.

With the toughened epoxies, the initial peak strain was increased around $25 \%$. Yet, a steep drop in the peak strain is observed. This indicates that as failure begins to occur it will accumulate rapidly to catastrophic failure. In most situations, a shallow S-N curve is desirable therefore the toughened epoxies may not be the best solution to fatigue damage complications.

\subsubsection{Fatigue Behavior of Multidirectional Laminated Composites}

Composite materials are commonly used in laminated form, layers being arranged so that the fibers are oriented in the principal load directions. Upon increasing the percentage of axial fibers in a laminate, the static tensile strength and stiffness are increased since more fibers are available in the $0^{\circ}$ direction to support the mean applied load. Off-axis fiber alignment will result in a more matrix dominate composite in which the matrix does not perform well in fatigue. This can be seen in Fig. 7 [Curtis]. 


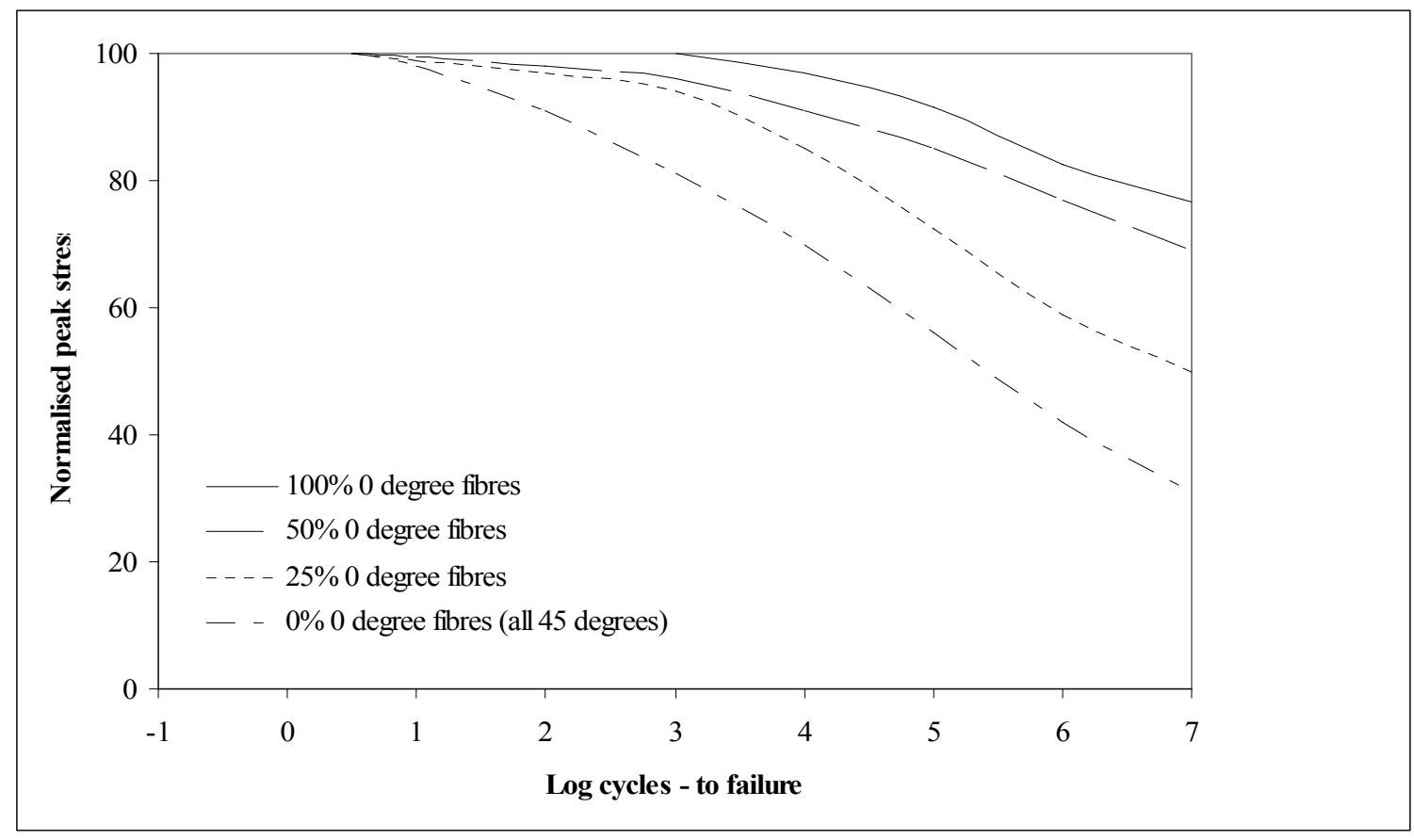

Fig. 7 Plots of peak tensile stress normalized to the static strength versus $\log$ cycles to failure for carbon fiber composites with varying percentages of unidirectional fibers.

The slope of the tensile S-N curve increases in relation the static strength as layers with off-axis fibers increases. The off-axis fibers whose mechanical properties are matrix dominant, are more easily damaged in fatigue. Failure becomes more rapid resulting in an undesirable steeper $\mathrm{S}-\mathrm{N}$ curve. The figure above illustrates the importance of fiber alignment and fiber domination in static strength and how they affect fatigue life.

As fiber domination in the loading direction change, failure modes of the composite also change. Transverse layers, fibers $90^{\circ}$ to the load direction, tend to develop transverse cracks either upon the first tensile load cycle or with increasing numbers of cycles. Because the transverse fibers support little axial load, this has little effect on the axial strength or stiffness of the material. Angled ply layers, with fibers typically at $\pm 45^{\circ}$, can also develop laminate damage. This will also cause small reductions in strength and stiffness during initial loading. However, gradually these cracks can lead to more severe damage.

The stress concentration that occurs at the ends of laminate cracks can lead to the initiation of delamination between stacked layers. This can result in the decoupling of the $0^{\circ}$ principal load bearing layers, which will lead to a loss of integrity. Upon reverse loading, a certain reduction in compressive strength will result. With lessened support in the transverse direction the fibers will buckle more easily as discussed in Section 3.2.4. Also with the resulting damage to the matrix the composite becomes more vulnerable to detrimental environmental attack.

The cracks may occasionally propagate into adjacent primary load bearing layers and critically weaken the material. Ultimate tensile fatigue failure of composite laminates is still determined by the unidirectional layers, thus the tensile $\mathrm{S}-\mathrm{N}$ curves for multidirectional laminated composite materials are still relatively shallow. However, the 
curves are often steeper than for fully unidirectional material showing a more rapid failure.

Multidirectional laminates are also vulnerable to edge induced stresses developed as a consequence of the different elastic properties of the layers. These stresses may appear at any free edges, straight edges and at inserts and holes. This can give rise to edge induced damage, often resulting in delamination between layers.

\subsubsection{Effect of Stress Concentrators}

Stress concentrators like notches, holes, fasteners, impact damage and other imperfections are nearly impossible to avoid. They have shown to have less effect on fatigue strength than they do statically. Depending upon laminate configuration, stress concentrations have been reported to reduce the static tensile strength by up to $50 \%$. In fatigue, however, damage zones develop at stress concentrations which can serve to actually reduce their magnitude. These damage zones usually consist of matrix cracks along the fibers within layers and interlaminar matrix cracking between layers. If the cracks do not damage fibers, this can lead to increased composite strength.

It was reported that indeed if fatigue loading is applied by gradually increasing the applied load from zero to peak load over the course of several hundred cycles, then the apparent strength of composites with stress concentrators may actually increase for notched carbon fiber reinforced epoxy resin samples. Further cycling resulted in some loss in strength, but typically fatigue strength. Calculated on a net stress basis, strength approaches that of the plain unnotched material after longer lifetimes. The explanation is gradual damage zone accumulation leading to failure giving a fairly flat $\mathrm{S}-\mathrm{N}$ curve.

\subsubsection{Compressive Fatigue Loading}

In compression, the fibers remain the principal load bearing element and must remain supported from becoming locally unstable and undergoing a buckling type of failure. This becomes the task of the matrix and the fiber/matrix interface. The integrity of both is of far greater importance in compressive loading than in tensile loading. Because of matrix domination in compressive loading, compressive fatigue loading generally has a greater effect on the strength of composite materials than tensile loading. Additionally, local resin and interfacial damage leads to fiber instability in compressive loading which is more severe than the fiber isolation which occurs in tensile loading. Ultimately, the worst fatigue loading condition for composite materials is fully reversed axial fatigue, or tension-compression loading. The loading comparison can be seen in Fig. 8 [Curtis] in which the S-N curves are plotted for both zero-tension and tensioncompression loading. 


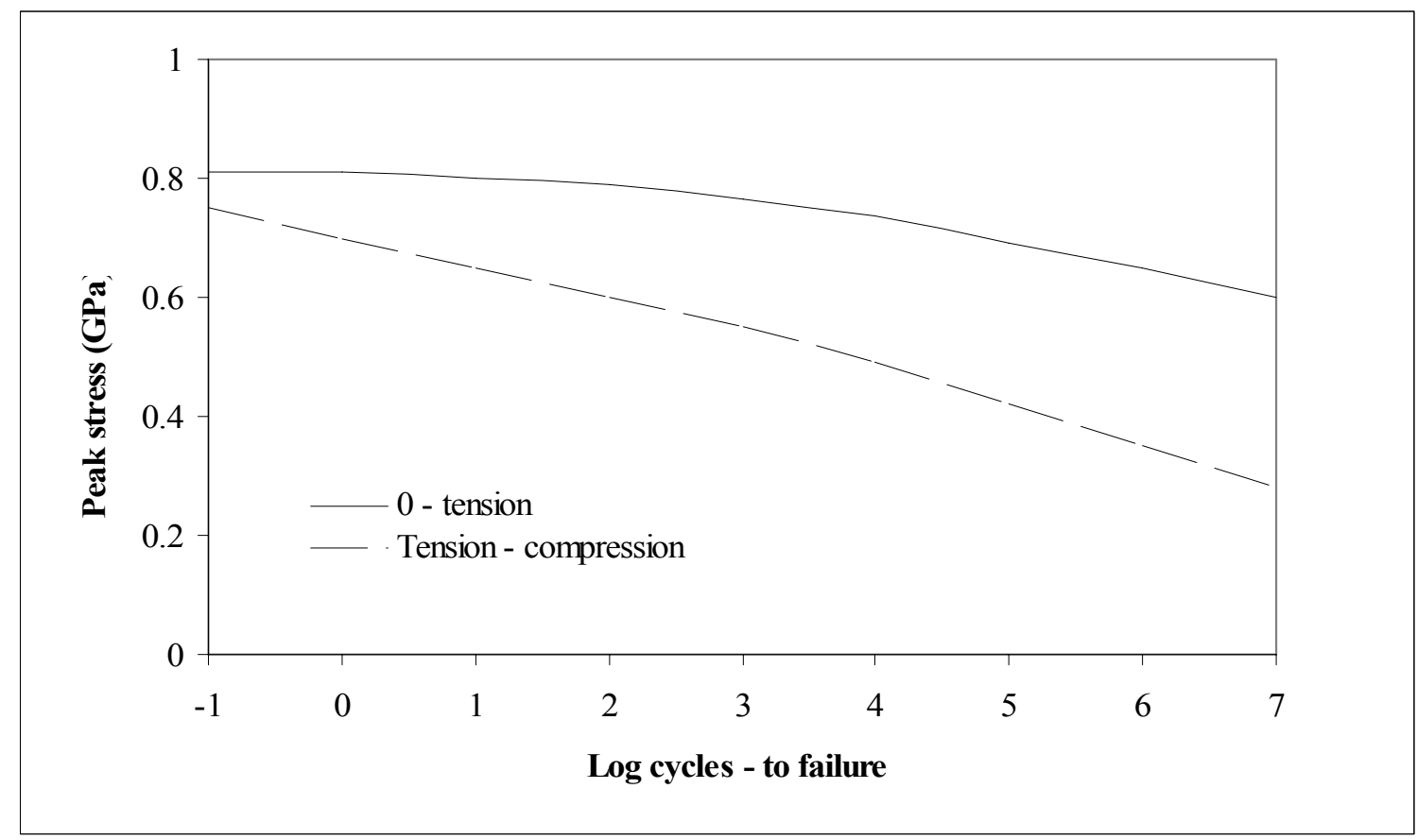

Fig. 8 A comparison of the S-N fatigue behavior of a standard carbon fiber laminate with $50 \%$ unidirectional fibers in both zero-tension and tension-compression loading.

The inferior behavior is because many of the laminate plies, without fibers in the load direction develop damage and cause local layer delamination. The result is fiber isolation and relatively short lifetimes. In tensile loading this is not as serious since the layers containing fibers aligned along the load direction continue to support the majority of the applied load. In compression however, tensile induced damage can lead to local layer instability and layer buckling. This can occur before resin and interfacial damage within the layers has initiated fiber microbuckling in which a portion of the fiber buckles and not the layer. For this reason the fatigue life in reversed loading is usually shorter than for compression-compression loading.

\subsubsection{Flexural Loading and Fatigue}

Flexural loading is a combination of tensile, compression and interlaminate shear modes. During high load flexural fatigue, only a small portion near the surface of the composite is subjected to the maximum tensile stress. The result is flexural fatigue performance exceeding tensile performance under high fatigue loads. For low load flexural fatigue conditions, the interlaminate shear stress component of flexural loading is of greater concern. This shear fatigue stress greatly accelerates matrix cracking and interface failure mechanisms. The fibers become more isolated leading to lower fatigue life and the low load tensile fatigue performance exceeding flexural performance.

\subsubsection{Comparison with Metals}

The advanced research of metals has shown fatigue typically occurs by mechanisms of crack initiation and crack propagation. Failure is the result of reduction of net load bearing area as the crack propagates to the point where the fatigue stress 
exceeds the metal's ultimate strength. This normally occurs by propagation of a single fatigue crack to a critical magnitude.

For composites, fatigue occurs by many different mechanisms. The exact fatigue mechanism is dependent on the material, loading mode and principal loading direction. The damage mechanisms in composite materials consists of matrix cracking, interface debonding, delamination, fiber splitting and breaking. Typically in composites instead of a single crack growth, many small cracks develop and grow. These cracks can eventually join together to the extent that the matrix becomes unstable and can no longer perform in transferring load from one fiber to the next ultimately leading to composite failure.

In metals, crack initiation is often caused by geometric stress concentrations, metal inclusions or voids. The crack propagation is limited to a single crack growing in an unobstructed manner with each fatigue cycle. Final failure in metals often results in a clean fracture surface along the path of the crack propagation.

In composites, crack initiation can be caused by many other factors. Matrix voids, fiber debonding, fiber discontinuities among other stress concentrations are all examples of possible crack initiation zones. Once initiated, matrix cracks may propagate along different paths. Cracks may travel through the matrix and stop when reaching a reinforcement fiber. Cracks may also propagate along a fiber/matrix or filler/matrix interface significantly reducing the strength of the composite. The fracture surface of composites is often a complex assortment of matrix failure coupled with fiber failure and fiber pull-out from the matrix.

With most metals, once a fatigue crack has developed even to a macroscopic size, failure is certain. In general, metals do not lose significant amount of stiffness until just prior to fatigue failure. However, with composites, matrix debonding and cracking can occur relatively early during the fatigue life, with microscopic cracks existing for most of the lifetime. Some cracks may remain stable while others eventually creep and link together until causing failure, therefore composites lose stiffness gradually over their fatigue life. For this reason, fatigue failure of composites is considered to be a more gradual, noncatastrophic event than for metals. Composite fatigue failure can often be monitored by the deflection of the component.

Statistical distribution of strength is of less concern in the more uniform make-up of metals. All fibers in composites have a distribution of strength determined by flaws, thus a few of the weakest fibers will fail first during fatigue loading. If this were to occur, it would give way to locally high stresses in the matrix and at the fiber/matrix interface leading to the development of fatigue damage with increasing numbers of cycle. Damage may also develop at local microdefects, such as misaligned fibers, resin rich regions or voids. Fatigue cracks regularly develop along the fibers, isolating them from adjacent material and rendering them ineffective load carriers. Matrix damage also causes fibers to become locally overloaded and further static fiber failure occurs. Close to failure, the matrix may develop widespread longitudinal splitting parallel to fibers caused by matrix and interfacial damage. This results in the brush-like failure characteristics of most unidirectional materials. The rate of this degradation process in the matrix and at the interface is a function of the strain as well as the nature of the matrix itself. 


\subsection{Damage Accumulation}

Under cyclic loading, damage accumulates in composite materials and causes the fatigue failure of components. For homogeneous materials with isotropic material properties, damage is accumulated at a low growth rate in the beginning with a single crack propagating in the direction perpendicular to the cyclic loading axis. With composites, especially for those with multiple laminates, the fracture behavior is characterized by multiple damage modes, such as matrix cracking, fiber/matrix separation, fiber fracture, delamination, void growth and multidirectional cracking.

The mechanisms of crack initiation and crack growth are also complex for composites. Even for unidirectional reinforced composites under a simple loading case, for instance tension along the direction of fibers, multiple cracks can initiate at different locations and in different directions. The cracks often initiate in the matrix perpendicular to the direction of loading. Cracks may also initiate at the fiber/matrix interface along the direction of the fibers due to debonding. Fatigue test research to study crack grown has shown when there is only one dominant crack propagating, the crack propagates in the same plane and direction as the initial crack.

The concept of damage accumulation may be used as the more suitable approach in predicting the fatigue life of composite components. Young's modulus or the stiffness of composites is often used to evaluate the fatigue damage due to cyclic loading. However, fatigue damage cannot be measured precisely.

The complexity of composites leads to the presence of many modes of damage. These modes often appear at the early stages of the fatigue life. The fatigue damage process can been divided into three stages. The damage will accumulate rapidly during the first few cycles. During this stage microcracks initiate in multiple locations in the matrix and debonding occurs at the weaker interfaces between the fibers and matrix. Also, any flawed fibers with low strength may break at this stage. The next stage of failure shows a slow and steady damage growth rate increase as initiated cracks slowly propagate. In the last stage of failure the damage again grows rapidly as cracks join together and fiber strength is greatly compromised. The duration of the third stage is often short, normally occupying about $20 \%$ of the total fatigue lifetime of the composite material. The different stages of composite failure modes can be seen clearly when compared to the less defined curve of homogeneous materials found in Fig 9 [Mao]. 


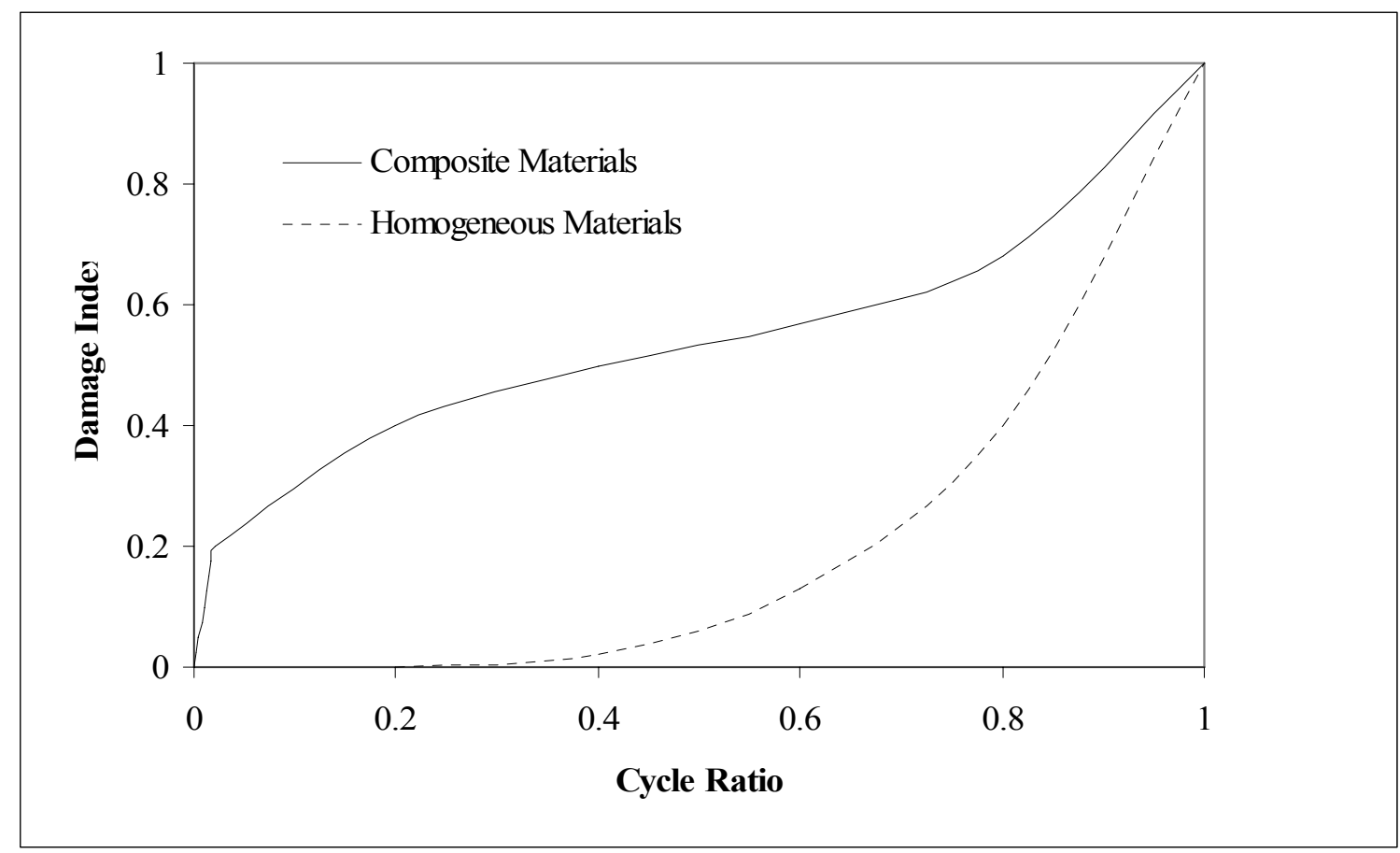

Fig. 9 Sketched fatigue damage accumulation.

The figure above shows the comparison of damage accumulation in composite materials with homogeneous materials as a function of fatigue cycle ratio. The curves are plotted in terms of damage index versus cycle ratio, where the damage index is defined by the equation, $\mathrm{D}=\left(\mathrm{E}_{\mathrm{o}}-\mathrm{E}\right) /\left(\mathrm{E}_{\mathrm{o}}-\mathrm{E}_{\mathrm{r}}\right)$. Where $\mathrm{E}_{\mathrm{o}}$ is the initial Young's modulus of the undamaged material, $\mathrm{E}$ is the Young's modulus of the damaged material and $\mathrm{E}_{\mathrm{r}}$ is defined as Young's modulus when fracture occurs. The cycle ratio is defined as the number of cycles at a given instant divided by the fatigue life.

It is difficult to fully characterize the fatigue failure mechanisms of composite materials simply based on stress analysis alone. However to analyze fatigue behavior of composites, several studies have used the Paris law which can describe the fatigue of metallic alloys very well. For this method, crack initiation followed by crack propagation is the dominant damage mode as is for metals. With composites, the size and number of cracks increases with the number of loading cycles before catastrophic failure occurs. Crack size and number is therefore generally assumed to be proportional to a damage variable used in calculations. 


\section{CHAPTER FOUR}

\section{HYBRID COMPOSITES}

\subsection{Investigation of the Aluminum/Epoxy Interface}

There are many technical issues to address when using hybrid composites. Thermal expansion and stiffness mismatch at the interface are contributors to poor adhesive bonding. The most significant problem with bonded joints is the adhesion strength of the metal/matrix interface. Research shows that an untreated metal surface such as aluminum, does not exhibit adequate bond strength with an epoxy. High-quality bond strength between the aluminum and epoxy is required for adequate load transfer across the interface. With almost all interfacial experiments, the failure plane is not truly interfacial, but is confined to a very small region near the aluminum/epoxy interface. This adhesive bond has the additional requirement that it be hydro-thermally stable to prevent environmental degradation.

The nature of the surface chemistry of both epoxy polymers and aluminum alloys, have been researched. Metals have shown to have an ordered atomic structure with close packing density. The surface energy is therefore high, often with the presence of an oxide layer. In aluminum, the oxide layer is stable and therefore fairly thin. Polymers however are organic macromolecules that are covalently bonded, disordered, loosely packed and have low density. With a low surface energy these polymers are classified as having high wettability meaning the resin mixture spreads evenly on the surface of the metal.

The adhesion strength at the interface of two different materials $(a, b)$ can be defined by the work of adhesion equation, $\mathrm{W}_{\mathrm{a} / \mathrm{b}}=\gamma_{\mathrm{a}}+\gamma_{\mathrm{b}}-\gamma_{\mathrm{ab}}$. This equation gives the work required to separate the interface per unit area. $\gamma_{\mathrm{ab}}$ is defined as the interfacial tension between material $\mathrm{a}$ and $\mathrm{b}$. It is dependent upon the characteristics of molecular bonding at the interface and structural morphology of intermixing of the two materials. From this equation, it is seen that if the surface tension of the epoxy is increased then the work of adhesion, or the adhesion strength is correspondingly increased.

Structural morphology at the interface is greatly influenced by both chemical interactions and cluster formation. It has been shown through research that aluminum atoms react at polymer carbonyl sites by first transferring charges to carbonyl carbon atoms via oxygen. When aluminum is deposited in a thin film onto an epoxy base, it forms a uniform thin film on the surface under slow evaporation at $300^{\circ}$. A closer look showed the atoms formed surface islands. This characteristic indicates that aluminum can be less adhesive with epoxy compared to other metals.

Grain size at the surface of the metal has been shown to affect the metal/epoxy adhesion strength. Large, unoriented grains can be formed during high temperature polymer resin cure cycles. These effects will result in poor adhesion strengths. A low temperature epoxy system is not expected to lead to grain growth resulting in higher adhesion strengths. 


\subsection{Surface Treatments on Enhancing the Aluminum/Epoxy Bond}

Poor adhesion strength of an untreated aluminum/epoxy interface has given way to research on possible bond improvements. Enhancements can include the use of a load bearing adhesive film. Aluminum surface treatment has shown excellent results by creating an interlocking mechanism. This interlocking can be achieved by mechanically deforming the aluminum surface or on a microscopic scale via anodization. The use of silane coupling agents has also proven effective in enhancing stronger interfacial bonding. Ultimately, a combination of treatments can prove the most effective approach.

\subsubsection{Adhesive Films}

Pure epoxy when cured forms a hard, brittle solid that has relatively low shear strength and fracture toughness. Modified epoxies however contain additional polymers in the resin that make the cured solid tougher and capable of absorbing large strain energy. This modification can be especially advantageous when applied in hybrid composites having a weak aluminum/epoxy interface. An adhesive film containing the additional polymers is used to produce this load bearing bond at the interface. The toughness and thickness of the adhesive film can redistribute the high shear stresses experienced at the metal/epoxy interface and reduce stress concentration effects. Fatigue resistance in the metal/composite joint can be enhanced by using a highly damped adhesive.

\subsubsection{Phosphoric Acid Anodization (PAA)}

The motivation for anodizing a metal with an acid is to create a large and active surface area for the polymer resin to flow into and interlock with the metal. The metal is typically immersed in an oxidizing electrolyte of low $\mathrm{pH}$ and a positive dc current is applied. Phosphoric acid is often chosen as the electrolyte over more common acids used in anodizing, such as chromic, sulfuric and oxalic acids. The oxide layer formed from oxidation with phosphoric acid differs from the others in that it is much thinner and produces larger pore sizes that will not hydrate or seal. This oxide layer however does not provide much corrosion protection because it will not seal. Though with the addition of a polymer to the surface, corrosion is typically not a problem and the benefit of larger pore sizes remain advantageous.

The pores created in the surface of the aluminum are large but only on a relative scale. The large molecules in a polymer like epoxy or an adhesive film may still have difficulty completely interlocking with the aluminum surface. Optimal interlocking and the resulting adhesive strength is obtained by utilizing a primer material. The primer increases the oxide attraction for epoxy and makes the surface more reactive. The PAA process along with a primer creates a mechanical interlock as well as primary chemical bonds to increase the adhesive strength of aluminum and epoxies.

\subsubsection{Silane Coupling Agents}

Silane coupling agents were created to increase bond strength between inorganic reinforcements and organic matrices by forming a much stronger covalent bond. They can also help in prevailing over two common obstacles in composite performance. The effects of debonding caused by water and residual stresses due to differential thermal shrinkage are both reduced. 
Debonding by water absorption is initiated by hydration of the bonds at the interface. The covalent bond created by the silane agent is less susceptible to water diffusion therefore minimizing the debonding effect. Residual stresses can develop due to the mismatch in thermal expansion coefficients of the aluminum and epoxy. The silane coupling agent acts to bridge this mismatch and relieve the resulting stress concentrations near the interface. It is however important to properly choose cure cycle parameters when using silane coupling agents. A low temperature cure could actually degrade the bondline when using silane as a coupling agent as discussed in Section 4.3.1.

\subsection{Surface Treatment Effects on Interfacial Loading}

Choosing the optimal surface treatment can depend on the primary method of loading. The effect a surface treatment may display in shear may differ in tension. This is due to the different adhesion enhancement properties related to the surface treatment. Studies were researched on the outcome different surface treatments have on shear and tension loading performance.

\subsubsection{Interfacial Shear}

A rod pull-out experiment was researched where an aluminum rod was cured in an epoxy plug. Specimens range from untreated to various combinations of surface treatments. The use of two different epoxy matrices as well as primers, adhesive films, a silane coupling agent and PAA treatment were studied in hopes to improve the aluminum/epoxy bond strength.

During shear, fracture can occur in characteristic ways. Initially matrix cracks initiate and extended from the rod surface into the epoxy plug at an angle of approximately $45^{\circ}$ in which maximum shear occurs. Upon complete failure of the epoxy plug, some epoxy can remain adhered to the aluminum. In low strength specimens, no cracks in the epoxy plug will develop and the aluminum would separate from the matrix cleanly and easily.

The nature of the matrix has proven to greatly affect adhesion and shear strength. In a comparison between two epoxy matrices, research has shown one can observe a higher strength value. Both two part epoxy systems were initially cured at room temperature for 24 hours. For the low temperature resin a one hour postcure at $90^{\circ} \mathrm{C}$ followed. The high temperature resin was postcured for two hours at $80^{\circ} \mathrm{C}$ followed by two hours at $177^{\circ} \mathrm{C}$. For a resin system requiring curing at a high temperature, this higher temperature may cause the formation of larger grains on the surface as previously discussed. This disruption in the adhesion process may explain why an epoxy cured at a lower temperature would display a higher strength.

It was discovered a low temperature epoxy combined with a knurling process showed the highest shear strength averaging 16.2 MPa. The knurling process involved mechanically deforming the aluminum in a criss-cross pattern to a depth of approximately $0.40 \mathrm{~mm}$. The grooves in the aluminum greatly increase the mechanical interlocking between the epoxy and aluminum. This interlocking mechanism is enhanced by the high wettability of aluminum by epoxy. High wettability allows all the grooves in the aluminum surface to be filled with the epoxy prior to curing. A completely untreated specimen has minimal interlocking in comparison therefore would have a much lower shear value averaging around $7 \mathrm{MPa}$. 
Another surface treatment that appears effective in shear is the PAA process. Even without using a primer system, PAA specimens show strength values nearly as high as knurled specimens. The oxide layer formed during anodization features large pores that extend into the aluminum. The micromechanical adhesion that develops at the aluminum oxide/epoxy interface mimics the mechanical interlock mechanism of knurling, but on a much smaller scale. An approach to further enhance bond strength would be to induce both interlock couplings by performing a PAA process on knurled specimens.

The addition of an adhesive film to the PAA process was shown to actually lower interfacial shear strength. An explanation for this could be that the adhesive film exhibits a shielding effect preventing full development of the PAA micromechanical interlocking. Essentially, the adhesive film does not allow the epoxy resin to flow freely into the oxide pores created by the PAA process. This is most likely due to the presence of the adhesive mesh so that little interlocking between aluminum oxide and epoxy occurs.

Using a silane coupling agent surface treatment in shear was found to improve strength in a higher temperature epoxy system but have the opposite effect on a lower temperature epoxy system. One reason for this could be that silane coupling agents provide a mechanism for covalent bonding between aluminum and epoxy to improve bonding. Research indicates that no chemical interactions will occur between epoxy and aluminum below about $170^{\circ} \mathrm{C}$. Above this temperature the heated aluminum facilitates the breakage of the epoxide ring and the formation of a three-dimensional silane network. If the cure process does not occur above this temperature, the full potential of the silane network is not reached.

\subsubsection{Interfacial Tension}

For the interfacial tension test researched, only the high temperature resin initially placed under $381 \mathrm{~mm} \mathrm{Hg}$ for 15 minutes to remove air bubbles trapped at the interface was used. The high temperature curing process of the resin was again completed with two hours at $80^{\circ} \mathrm{C}$ and two hours at $177^{\circ} \mathrm{C}$ postcure. Research results from tests on multiple surface treatments to 7075-T6 aluminum alloy utilizing the high temperature resin, show the PAA coupled with silane treatment had the highest average tensile strength averaging $10.6 \mathrm{MPa}$. With $3167 \mathrm{~mm}^{2}$ of exposed surface area for bonding, the micromechanical interlocking combined with primary chemical bonding proved most effective to adhesion strength. It was again reported an untreated specimen to have the lowest strength averaging $1.9 \mathrm{MPa}$.

The use of an adhesive film was shown to have a greater effect in tension than it does in shear when compared to the PAA process alone. This is because the pores that develop from the anodization are perpendicular to the surface, meaning they are aligned in the load direction in this case. Micromechanical interlock relies on whiskers that form on the top of the pores, reducing the benefit of this surface treatment. In general, surface treated specimens with optimal interlocking and high tensile strength often show some degree of cohesive failure. Untreated or lower strength specimens experience an adhesive failure in tension. It has also been discovered cohesive failures occur either near the center or as a ring around the outside edge of the aluminum/epoxy interface. 


\subsection{Coefficient of Friction}

Attention to laminate properties is important when designing hybrid composites requiring bonding or mechanical fastening and complex geometries. The coefficient of friction (cof) during shear loading is one important property. The cof at the aluminum/epoxy matrix interface can have many influences such as fiber direction. The maximum cof was found to be when the fibers were arranged perpendicular or transverse to the load direction. With load induced sliding between the aluminum and composite laminate a wear film of composite debris can develop on the surface causing a variation in the cof.

Axen N. developed a model for predicting the cof of composites. In his model the cof is a function of wear resistance, area fraction and cof of the phases in the composite. In 2000 Schön developed a model for predicting the cof from the amount of load carried by the different types of contact and their cof. Studies have shown that no matter how the cof is predicted, for epoxy sliding against metal the cof shows strong temperature dependence. The maximum found at the glass transition temperature region. In the glassy region, the friction is related to the shearing deformation or fracture of the polymer surface. In the transition region, the epoxy is softened and sticks to the metal surface and the friction corresponds to the supposed stick and slip effect.

An experiment was researched in which the objective was to measure the cof for carbon fiber epoxy matrix in contact with aluminum in reciprocal sliding. It was found the typical behavior of the cof during a test is that is initially increases quickly to a high value. After some time, it then begins to decrease until it levels off at a constant value. When there is a high friction force present a stick slip action is often observed. The friction force increases nearly linearly until sliding begins. Sliding does not begin over the complete contact area at the same time. It is a gradual process where sliding most likely begins at the contact edges and travels inwards. This causes a gradual transition from stick to slip. When the peak friction force is reached, sliding begins over the total contact area and the friction force drops quickly together with a rapid increase in displacement.

Research has also shown the cof is nearly independent of normal force. This suggests that the measured cof is a material constant. Fig. 10 [Schön] was made available through experimental research showing a plot of the cof against normal force that agrees with this idea. 


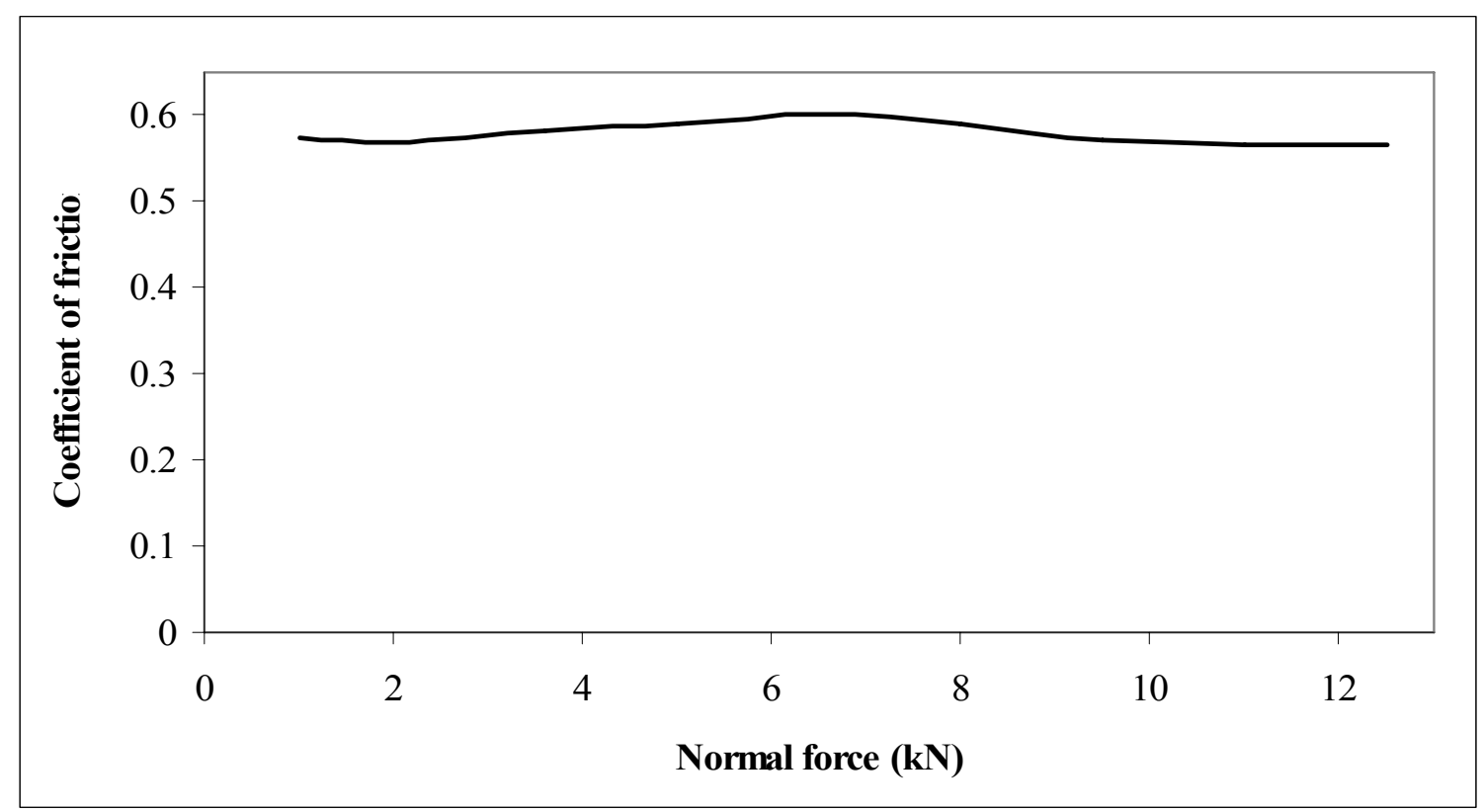

Fig. 10 Coefficient of friction as a function of normal force.

For composite/aluminum specimens the initial coefficient is found to be lower than for composite/composite specimens. Although the maximum cof is only slightly lower for composite/aluminum specimens. This type of initial increase in cof followed by a slow decrease has also been observed for composite delamination surfaces in contact.

The effective cof $(\mu)$, has been predicted with the Schön model as $\mu=1 / \mathrm{P}\left(\mu_{\mathrm{ea}} \mathrm{P}_{\mathrm{ea}}+\mu_{\mathrm{fa}} \mathrm{P}_{\mathrm{fa}}\right) . \mathrm{P}$ is defined as the total normal load, $\mu_{\mathrm{ea}}$ and $\mu_{\mathrm{fa}}$ are the cof of epoxy and carbon fiber in contact with aluminum, respectively, and $\mathrm{P}_{\mathrm{ea}}$ and $\mathrm{P}_{\mathrm{fa}}$ are the load carried by epoxy and carbon fiber in contact with aluminum, respectively. The cof for carbon fiber in contact with aluminum has been assumed lower than the cof for epoxy resin in contact with aluminum. This is primarily because carbon fiber is harder than epoxy therefore sliding becomes easier.

Ordinarily specimens with composite/composite contact and composite/aluminum contact behave in the same manner. The cof increases in the beginning and then decreases slowly. The initial increase in cof during sliding is most likely due to a wear in condition. The surface of the composite specimen is covered with an epoxy layer and initially almost all the load is most likely carried by the stronger epoxy-aluminum contact. This is most likely the reason for the large cof for initial loads. As the epoxy layer on the surface is worn away more load is carried by the carbon fiber/aluminum contact and the effective cof decreases making sliding easier. As sliding persists and fibers are worn, sliding eventually occurs between a layer of composite wear particles and the aluminum. 


\subsubsection{Wear Mechanisms}

Research provided important information after friction tests were completed and composite/aluminum hybrid specimens were taken apart. The worn composite and aluminum plates were ultrasonically cleaned. Fracture surfaces were then coated with gold and studied with a Scanning Electron Microscope (SEM).

During manufacture of the composite specimens, a matrix layer is formed by the epoxy resin on the surface. For the case of reciprocating sliding, the matrix layer will be worn away and fibers will become exposed. Wear of the matrix layer can be largely due to breaking off of matrix fragments at the boundary where the entire matrix layer has been removed and where the matrix layer is fairly unworn. Further wear of the composite surface would require the carbon fibers either be worn down or broken off. Broken fibers would suggest that a crack has initiated and followed the fiber/matrix interface between the damaged fibers and the laminate matrix below. When a crack becomes long enough a piece of the fibers on top is broken off. Along with the fibers, the matrix surrounding them is also removed from the surface. The driving force for the crack is the shear force acting on the surface from the friction contact.

Nearly all the matrix removed comes from the matrix layer on the original surface. The surface matrix is either worn or removed when fibers are broken off from the surface. The remaining matrix is well protected in the valleys between the remaining fibers. Only minor matrix wear can be expected here.

Wear to the aluminum surface would be the result of fiber contact during sliding. The matrix is too soft to cause depressions in the aluminum surface. The carbon fibers however are stiff enough and can scratch the aluminum. During sliding, any wear debris that does develop typically does not attach to the aluminum surface as it does the composite surface.

\subsection{Interfacial Ageing of Hybrid Composites}

For a long time it has proven difficult to prevent the interfacial ageing of carbon fiber reinforced composites. Because carbon fiber can conduct electricity, what is referred to as the micro-battery effect often appears at the interface between the epoxy resin and the metal under wet conditions. The absorption of water by the epoxy resin and the conductivity of carbon fiber result in corrosion of metal surfaces and subsequently reduce the adhesive bond strength.

The poor performance in adhesion strength for untreated samples has been linked to multiple obstacles. In addition to this list is the electrochemical corrosion of metals in the presence of absorbed water or the micro-battery effect. There are two possible permeation paths of water to the adhesion interface. One is the diffusion through the resin and the other is when water is transferred along the metal/resin interface. Once water molecules reach the interface region the metal surface is immediately exposed to dissolved oxygen as well as the water molecules. Electrochemical corrosion inevitably takes place at the interface region resulting in a rapid reduction of adhesive strength.

Research has been studied on surface modification of the aluminum to be in contact with an epoxy matrix. An imidazole derivative-copper polymetric film on the surface of the aluminum was introduced to see if would eliminate the micro-battery effect and ultimately improve shear strength of the aged composite. In the researched experiment, a $\mathrm{NaOH}$ solution was first used to wash the aluminum plates before they 
were immersed in a copper coating solution. This copper coating acts as a water resistant, insulating material on the surface of the aluminum. The specimens were immediately immersed into a MBIH or benzotriazole (BTAH) solution to form surface complexities $\mathrm{Cu}^{+} \mathrm{MBI}^{-}$and $\mathrm{Cu}^{+} \mathrm{BTA}^{-}$respectively.

\subsubsection{Shear Strength Research}

The coupling effect of copper-MBIH modified aluminum plates and epoxy resin was studied by a mechanical test. In this experiment, specimens were made by placing a layer of carbon fibers wetted with resin between two aluminum plates creating a lap joint. Curing took place at $120^{\circ} \mathrm{C}$ for five hours. Excess of any resin after curing was trimmed from the test specimens. The specimens were then pulled apart in tension to obtain strength values. A group of samples were also immersed in boiling or in salt water for a prolonged period of time and their residual strengths were compared.

After immersion in salt water for 10 days, the specimens which were modified with $\mathrm{Cu}-\mathrm{MBIH}$ at the interface showed excellent shear strength $(8.07 \mathrm{MPa})$ and strength retention ratio (91.9\%), while the unmodified samples exhibited low strength (2.71 MPa) and retention ratio $(40.3 \%)$. In addition, it was found that $\mathrm{MBIH}$ is a much more effective coupling agent for adhesion of carbon fiber reinforced epoxy resin onto aluminum plates.

The MBIH chemical make-up creates a stronger atomic bonding than what the BTAH solution is capable. $\mathrm{MBIH}\left(\mathrm{Cu}^{+} \mathrm{MBI}^{-}\right)$contains two nitrogen atoms and one sulfur atom allowing for greater ability to coordinate with metal than the BTAH $\left(\mathrm{Cu}^{+} \mathrm{BTA}^{-}\right)$. The surface complex obtained from a MBIH film is tighter due to the stronger bonding ability of the atom. Because the active hydrogen number contained in the MBIH complex film is also more than that in the BTAH complex film, the MBIH film more easily induces the ring opening reaction of epoxy resin. On this account, the laminated composite modified with MBIH complexities will possess a higher strength. Beyond being a promoter of adhesion for epoxy resins, MBIH is also excellent in acting as an anti-corrosion agent. Furthermore, because of its compactness, the MBIH complex film also has better water resistance reducing the micro-battery effect.

\subsubsection{Fracture Surface of Laminated Composites}

Upon observing the aluminum fracture surface at the aluminum/epoxy interface, light regions and some dark spots can be seen. The light regions represent areas where separation occurs between the aluminum and matrix. The dark spots are the result of the carbon fabric to which remains adhered to the aluminum. The black carbon fiber areas can cover different portions with various thicknesses depending on whether the aluminum plate has been treated.

A SEM is utilized to aid in understanding the interfacial fracture mechanism for different composite samples. For unmodified composites, it was noticed that in the light region the elements present were oxygen, carbon, and aluminum, the majority of which were aluminum indicating aluminum/matrix interface failure. In the few black regions, the experimental result is just the opposite. The elements found are mainly carbon with a trace of oxygen. These findings further suggest the fracture surface of an untreated composite is mainly the interfacial adhesion failure of aluminum and epoxy resin where 
neither the aluminum nor carbon fibers have been damaged. This research again has confirms the adhesion strength of an unmodified composite is poor.

Results of a modified composite under the SEM show the elements copper, oxygen and carbon existing in the light region of fracture surfaces, where interfacial fracture occurs. The enhancement of coating the aluminum plate surface with a MBIH complex film is more easily seen by an increase in the dark regions. A SEM picture of this region can help prove the breakdown of the higher strength carbon fiber occurred. The surface modification used to create stronger atomic bonding results in the carbon element with no oxygen presence, hinting of the tear of carbon fiber itself.

The light and dark regions observed on the aluminum surface indicate there are two similar kinds of breakdown dependent on if the surface was modified. The interfacial failure between the MBIH film and epoxy is again represented by the light regions in modified samples. For unmodified surfaces the light region represents aluminum/epoxy interfacial failure, while the few dark regions indicate slight fiber damage. In modified samples, the numerous dark regions show a more significant tear of carbon fiber. To achieve this degree of fiber damage would require a higher load therefore the adhesion strength must be stronger for modified composites ultimately exhibiting greater lap shear strength. 


\section{CHAPTER FIVE}

\section{INTERFACE STRESS INTENSITY FACTOR}

\subsection{Introduction}

In hybrid materials, epoxy resin adheres to an aluminum plate through a thin layer formed between the resin and plate. This layer locks the two materials tightly together through adhesion. Because of the difficultly in curing a hybrid composite without the presence of an initial interfacial crack, there is ongoing research to test crack effects. Laminate cracks are known to cause multiple failure patterns as previously discussed. Previous research reveals the fracture tensile stress is inversely proportional to $\mathrm{a}^{1 / 2}$ where the crack length is defined as $2 \mathrm{a}$. This indicates crack properties are linked to such things as propagation direction and rate, and the resulting fracture toughness. It is also assumed the facture toughness value of the epoxy resin may be affected by the sharpness of the crack tip.

It has been discovered in tension a matrix crack first propagates into the epoxy plate at an initial crack angle. A 2001 study states the peak value of the stress intensity factor occurs in the epoxy plate at an angle of approximately $40^{\circ}$, as measured from the interface. This is most likely due to the maximum tensile stress around a crack tip having a maximum value for the plane in the $-25^{\circ} \sim-45^{\circ}$ direction into the epoxy plate. One thing is clear in that the specimens separate into two pieces under the brittle fracture. Experimental analysis dating back over 40 years will verify that crack extension in brittle materials initiates in a plane perpendicular to the plane in which maximum tensile stress appears.

One experiment researching this topic uses epoxy cast around a piece of teflon tape to create a crack in an epoxy plate. A tensile test was conducted to determine the fracture toughness value of the epoxy plate. A second sample consists of an aluminum plate having teflon tape attached cast in an epoxy resin to represent an aluminum/epoxy composite weakened by an interface crack. It was assumed the artificial crack is considered to behave in the same manner as a naturally occurring crack. This is because the fracture toughness value can be successfully predicted regardless of the crack length ratio. The composite material is fractured upon increasing the tensile load. Failure initiates as the maximum value of the stress intensity factor approaches the fracture toughness value of the epoxy plate. Once the maximum value is reached, catastrophic brittle failure occurs.

\subsection{Fracture Toughness of Epoxy Plate}

In 2000, Tada, Paris and Irwin proposed an equation for calculating the stress intensity factor for a crack of width $2 \mathrm{a}$ existing in an elastic strip of $2 \mathrm{~h}$ perpendicular to a tensile stress $\sigma$. The stress intensity factor $\mathrm{K}_{1}$ was given by the equation $\mathrm{K}_{1}=\sigma(\pi \mathrm{a})^{1 / 2} \mathrm{~F}(\mathrm{a} / \mathrm{h})$, where the variable $\mathrm{F}(\mathrm{a} / \mathrm{h})$ is defined as $\mathrm{F}(\mathrm{a} / \mathrm{h})=\left[1.0-0.025(\mathrm{a} / \mathrm{h})^{2}+0.06(\mathrm{a} / \mathrm{h})^{4}\right](1 / \cos [\pi \mathrm{a} /(2 \mathrm{~h})])^{1 / 2}$. If a plate having a centrally located crack is fractured by a tensile stress $\sigma_{\mathrm{f}}$, the fracture toughness value $\mathrm{K}_{1 \mathrm{c}}$ can be defined by the equation $\mathrm{K}_{1 \mathrm{c}}=\sigma_{\mathrm{f}}(\pi \mathrm{a})^{1 / 2} \mathrm{~F}(\mathrm{a} / \mathrm{h})$. 


\subsection{Discussion}

If an interface crack is detected in a composite material, it must be decided if the crack is harmless for the present period or that the crack is unstable and dangerous.

Instability would mean that rapid failure is certain. It is for this reason stress intensity factors for an interface crack must be determined. .

If the adhesive strength is low and if fracture toughness value of the interface is lower than that of the epoxy plate, the interface crack will propagate along the interface. Defects such as voids or inclusions are inevitably present at the interface. Under the application of a load, high stresses are generated around such defects. If the adhesion between the two materials is insufficient the defect grows and propagates slowly along the interface by the fatigue mechanism. If the crack comes to a strong adhesion area, the extension of the interface crack along the interface is interrupted and the crack propagates into the epoxy plate at the angle defined by the maximum tensile stress at the crack tip. 


\section{CHAPTER SIX}

\section{ALUMINUM/CARBON HYBRID COMPOSITE EXPERIMENT}

\subsection{Introduction}

When designing a suspension component, a composite made up from fiber and matrix alone may become difficult. In any suspension design there must be some points in which to attach the composite to the frame as well as the shock tower. A mechanical fastener is the popular choice in which to achieve this attachment. At this point utilizing a material such as aluminum or steel would provide the easiest as well as the strongest means for mechanical attachment. Therefore, a hybrid composite consisting of fibers, a matrix and aluminum would be considered. Aluminum becomes a popular choice because of it strength-to-weight ratio as structural weight remains of primary importance in suspension design.

With this hybrid composite suspension member many areas must be addressed. We will have to consider fiber alignment and required number of laminates to provide the strength necessary for carrying multidirectional suspension loads. The addition of a metal/matrix interface and the method of attaching the aluminum to the composite must also be analyzed. For this study, improving on this aluminum/composite attachment is the goal.

An experiment was set up to help better understand the shear-tensile interfacial reactions between a plate made from 7075 aluminum and a high strength epoxy resin. The 8 " x 3" aluminum plate was designed to act as a shock mount point on a carbon reinforced swing arm designed for a Baja car. Tests were set up to represent a combined tensile and shear failure at the attachment location during shock rebound. As predicted by research, the aluminum/epoxy interface strength was found to be the weakest link. In hopes to strengthen the attachment, carbon fibers were laminated over the aluminum plate and into the composite beam. Different configurations of reinforcement laminates were used to see the effect on the attachment strength. As expected, the addition of the reinforcement laminate over the plate greatly improved the attachment strength.

\subsection{Experimental Procedure}

A hand lay-up method was used for sample processing as detailed in Section 2.4.1. Samples were prepared to conduct a simple combined loading experiment. The mold for the beam samples was made from three layers of white foam board glued together to give a four inch by six inch cross section. This beam will represent a support arm section cut from a swing arm. All corners of the foam mold were sanded down to eliminate any sharp corners. A sharp corner on the mold would ultimately create an undesired stress concentration in the carbon/epoxy composite sample. Fig. 11 illustrates the prepared foam sample molds before composite lamination. From this figure, it can be seen, the surface imperfections in the mold surface which are mentioned later in the section. 


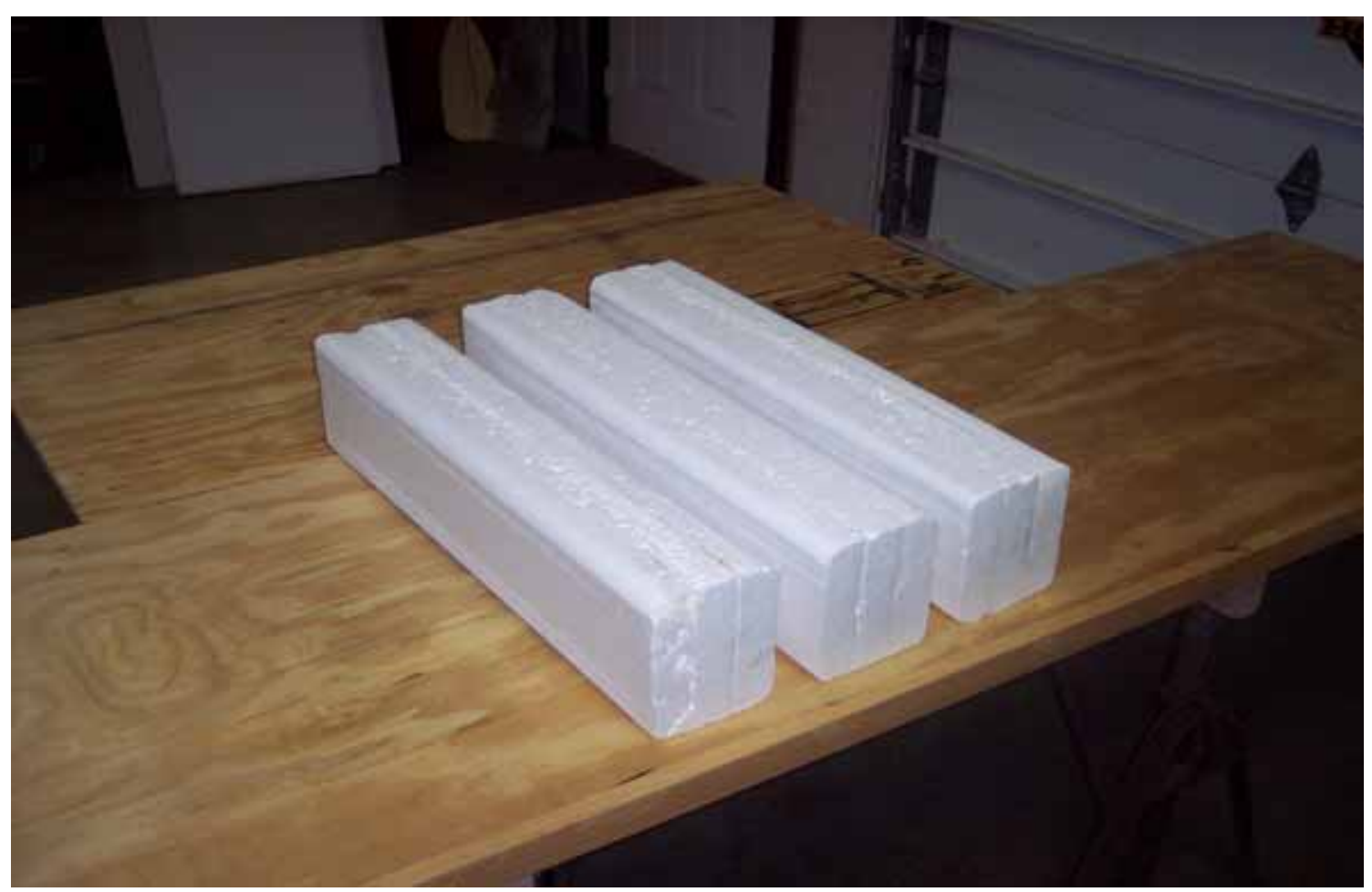

Fig. 11 Experimental sample molds.

A bidirectional carbon fiber fabric woven in the $0^{\circ}$ and $90^{\circ}$ directions was chosen as the reinforcement in the composite for its high strength characteristics. The fabric used was a balanced 4 Harness Satin weave. This weave style has 12.5 yarns/inch in both the $0^{\circ}$ direction as well as the $90^{\circ}$ direction. The fabric weight is given as $5.8 \mathrm{oz} / \mathrm{yd}^{2}(197$ $\left.\mathrm{g} / \mathrm{m}^{2}\right)$ with a thickness of 8.7 mils $(0.22 \mathrm{~mm})$. The PAN based fiber tows used in the fabric has a $3 \mathrm{~K}$ filament count. Magnamite ${ }^{\circledR} A S 4$ carbon fiber properties can be found in Table 1 below, while filament and tow characteristics are found in Table 2.

Table 1 Carbon fiber properties.

\begin{tabular}{|c|c|c|}
\hline Properties & U.S. Units & SI Units \\
\hline Tensile strength & $620,000 \mathrm{psi}$ & $4,278 \mathrm{MPa}$ \\
\hline Tensile modulus & $33.1 \times 10^{6} \mathrm{psi}$ & $228 \mathrm{GPa}$ \\
Chord 6000-1000 & $1.87 \%$ & $1.87 \%$ \\
\hline Ultimate elongation $^{(\mathrm{a})}$ & $94.0 \%$ & $94.0 \%$ \\
\hline Carbon content & $0.0646 \mathrm{lb} / \mathrm{in}^{3}$ & $1.79 \mathrm{~g} / \mathrm{cm}^{3}$ \\
\hline Density & $0.22 \mathrm{Btu} / \mathrm{lb},{ }^{\circ} \mathrm{F}$ & $0.22 \mathrm{cal} / \mathrm{g},{ }^{\circ} \mathrm{C}$ \\
\hline $\begin{array}{c}\text { Specific heat } \\
\text { at } 167^{\circ} \mathrm{F}\left(75^{\circ} \mathrm{C}\right) \\
\text { at } 347^{\circ} \mathrm{F}\left(175^{\circ} \mathrm{C}\right)\end{array}$ & $0.27 \mathrm{Btu} / \mathrm{lb},{ }^{\circ} \mathrm{F}$ & $0.27 \mathrm{cal} / \mathrm{g},{ }^{\circ} \mathrm{C}$ \\
\hline Electrical resistance, $12 \mathrm{~K}$ & $9.6 \mathrm{ohms} / \mathrm{ft}$ & $0.32 \mathrm{ohm} / \mathrm{cm}$ \\
\hline Electrical resistivity, $12 \mathrm{~K}$ & $5.03 \times 10^{-5} \mathrm{ohm}-\mathrm{ft}$ & $1.53 \times 10^{-3} \mathrm{ohm}-\mathrm{cm}$ \\
\hline
\end{tabular}

(a) Calculated from tow test data. 
Table 2 Filament/Tow properties.

\begin{tabular}{|c|c|c|}
\hline Properties & U.S. Units & SI Units \\
\hline Filament diameter & $0.281 \mathrm{mil}$ & 7.1 microns \\
\hline Filament shape & Round & Round \\
\hline Tow cross-sectional area, 3K & $1.82 \times 10^{-4} \mathrm{in}^{2}$ & $0.12 \mathrm{~mm}^{2}$ \\
\hline Approximate yield, 3K & $7,100 \mathrm{ft} / \mathrm{b}$ & $4.76 \mathrm{~m} / \mathrm{g}$ \\
\hline Weight/length, 3K & $11.8 \times 10^{-6} \mathrm{~b} / \mathrm{b}$ & $0.210 \mathrm{~g} / \mathrm{m}$ \\
\hline
\end{tabular}

The polymer matrix used in this experiment was made of a two part epoxy system, illustrated in Fig. 12, purchased from Aerospace Composites Products. E-Z Lam 60 , a room temperature epoxy resin, was used for its high strength properties as well as for is ease in processing. E-Z Lam 60 has a pot life or gel time of approximately 60 minutes at $75^{\circ} \mathrm{F}$. Again, this is the time in which it takes the mixed resin to reach the point were it can no longer be used in processing. The resin system has a mix ratio of two parts by volume epoxy resin with one part by volume hardener. The recommended cure time for this resin system is 24 hours at $75-80^{\circ} \mathrm{F}$. The mechanical properties of the laminating resin used can be found in Table 3.

Table 3 Properties of E-Z Lam 60 epoxy resin.

\begin{tabular}{|c|c|}
\hline Viscosity, mixed & $700 \mathrm{CPS}$ \\
\hline Durometer D & 88 Shore \\
\hline Specific Gravity (Laminate Data 7781 10 ply) & $1.10 \mathrm{gm} / \mathrm{cc}$ \\
\hline Tensile & $55,000 \mathrm{psi}$ \\
\hline Flexural & $63,500 \mathrm{psi}$ \\
\hline Compression & $44,000 \mathrm{psi}$ \\
\hline
\end{tabular}

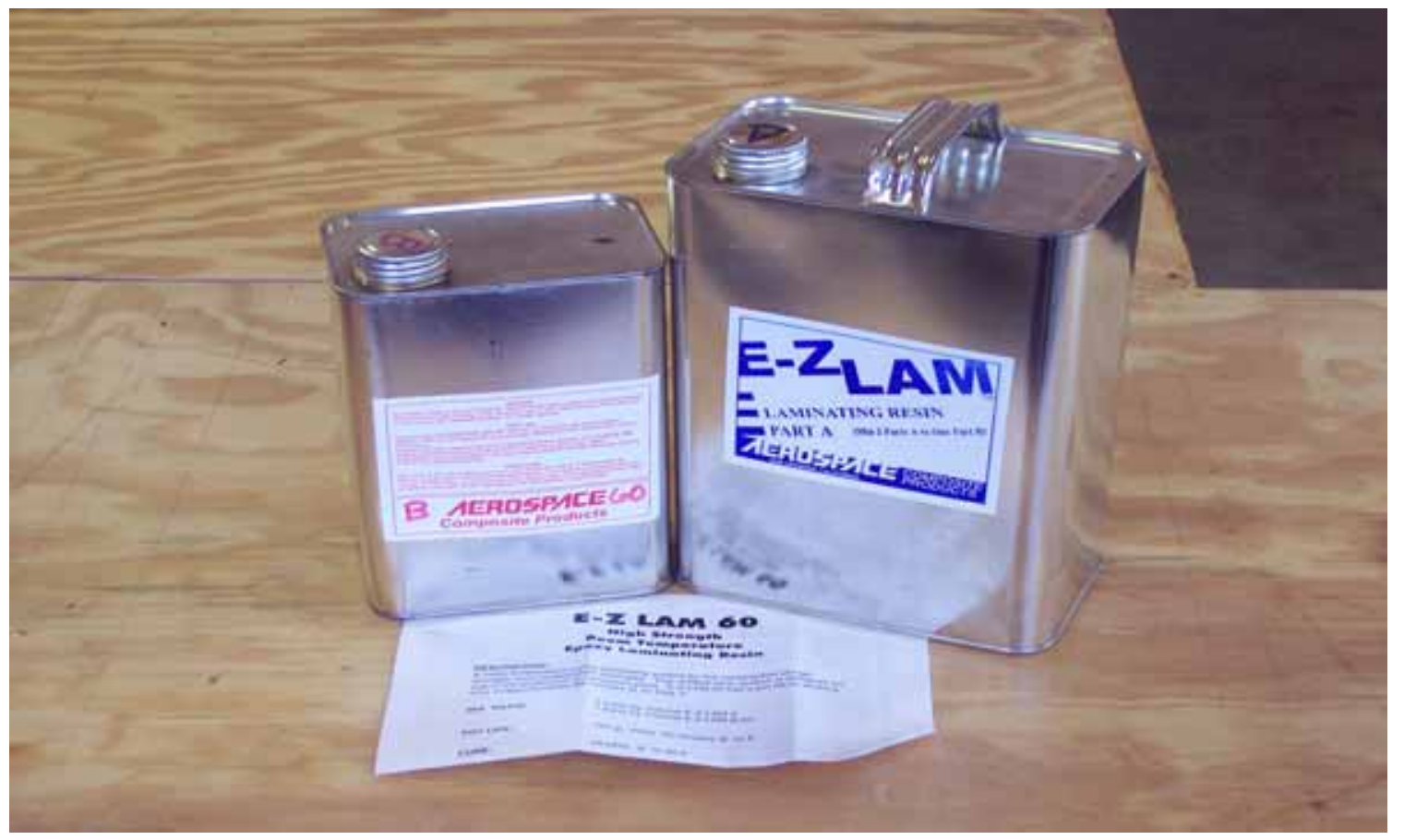

Fig. 12 Two part epoxy resin system used. 
The hand lay-up process continues with the dry carbon fabric being pre-cut to wrap around the foam mold one time with a slight overlap. The dry fabric was then wetted with resin enough to remain in place as the fabric was hand worked around the foam mold. Once the mold was completely wrapped with the reinforcement fabric, complete fiber wetting was ensured by brushing the resin over the entire fabric surface. The resin was hand worked into the fabric helping it to further conform to the mold and remove as much trapped air as possible by hand.

At this stage, human error can become a detail. Because the fibers are being placed manually, fabric misalignment is a certain possibility. As the resin is being worked into the matrix, the fibers will slide around in the wet resin and can become misaligned. Another potential oversight could be in not applying an adequate amount of resin to completely impregnate the fabric. Misaligned fibers and matrix voids will certainly lead to premature or unpredicted failure of the composite part. Before this stage in the hand lay-up process is complete, visual inspection of the laminate should be done. Any areas where the fibers seem dry or misaligned must be corrected before the resin begins to gel and cure.

The next stage is to prepare the sample for the curing process as detailed in Section 2.4.3. A peel-ply fabric was used to first wrap around the wetted carbon fabric. This is the mesh fabric that allows any excess of resin to escape away from the laminates during curing. This perforated peel-ply fabric is also designed to prevent it from adhering to the surface laminate during matrix curing. Once removed it leaves a sandable rough surface which helps to provide matrix interlocking when separate lay-up sessions are desired.

A separate fabric, known as a breather cloth, was then wrapped around the peelply fabric. The breather cloth acts as a sponge and soaks up the excess resin that has escaped through the perforated peel-ply fabric. Multiple layers of this fabric can be used to allow for adequate absorption of the excess resin preventing it from reaching the bag used in vacuum bagging. The breather cloth and the bleeder combination also help to distribute the vacuum pressure across the laminate evenly.

Once all fabrics are tightly wrapped around the sample, it was then placed in a vacuum bag. The bag tube was sealed at both ends and plumbed into the vacuum pump. This was a self monitoring pump capable of reaching 18 in $\mathrm{Hg}$ of vacuum pressure, also purchased from Aerospace Composites Products. The average pressure used in the vacuum curing process of experimental samples was between 13-15 in Hg. All samples were cured under this vacuum pressure for 24 hours to ensure complete resin cure time. Fig. 13 shows a composite beam sample under vacuum during the bag molding process. 


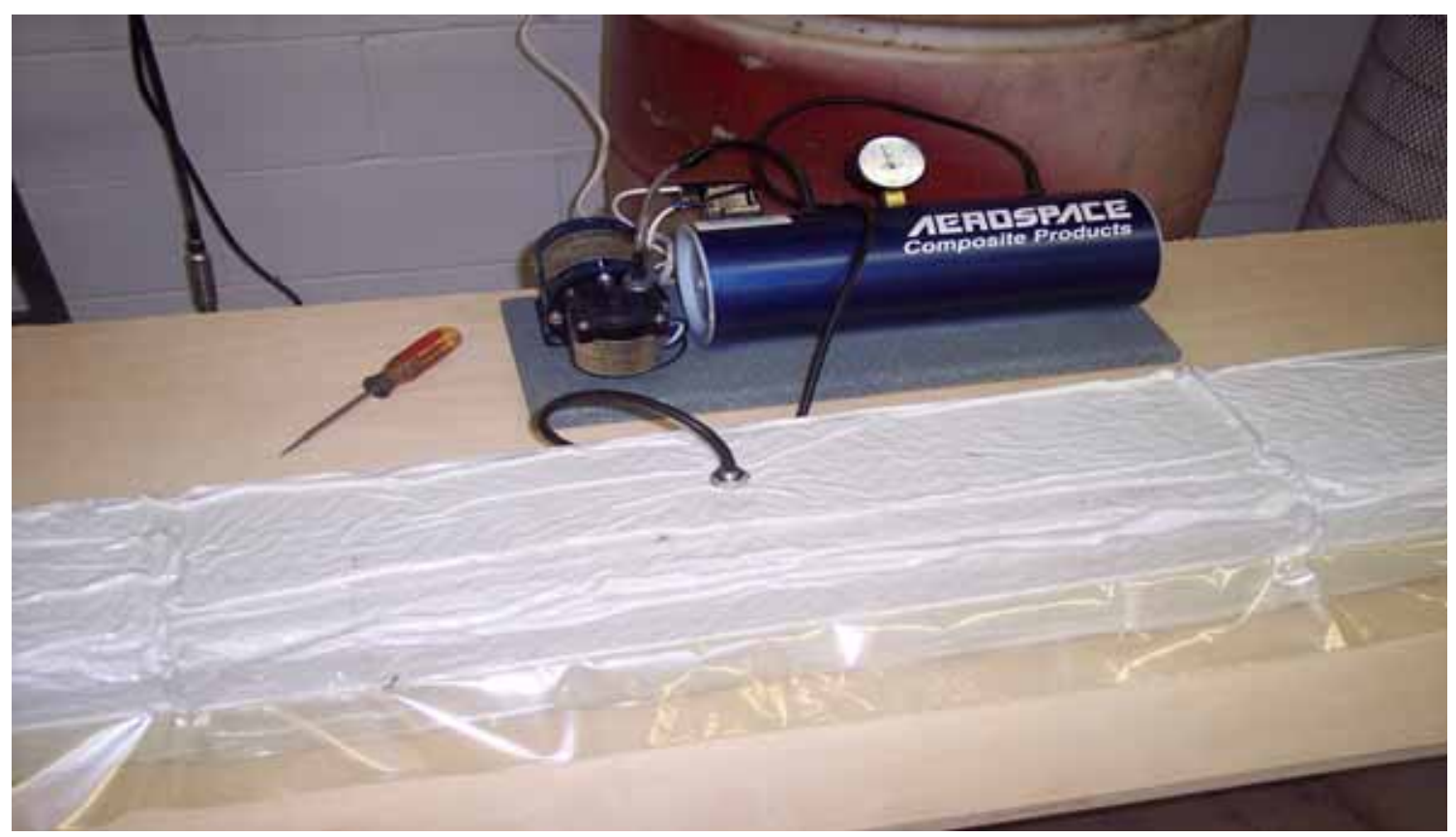

Fig. 13 Composite beam sample under vacuum.

After a complete cure cycle, the peel-ply fabric was carefully removed. It was found that the vacuum pressure was enough to cause the fibers to conform to the mold imperfections mentioned earlier and seen in Fig. 11. This illustrates the importance of a smooth mold surface in obtaining a smooth uniform laminate surface. Because it is known an even contact area is crucial at the interface between aluminum and the epoxy, this initial surface was unacceptable. To correct this problem putty was used to fill the surface valleys and then sanded to obtain a smooth surface. Fig. 14 and Fig. 15 below show the imperfections created in the laminate and the corrected surface using the sandable putty respectively.

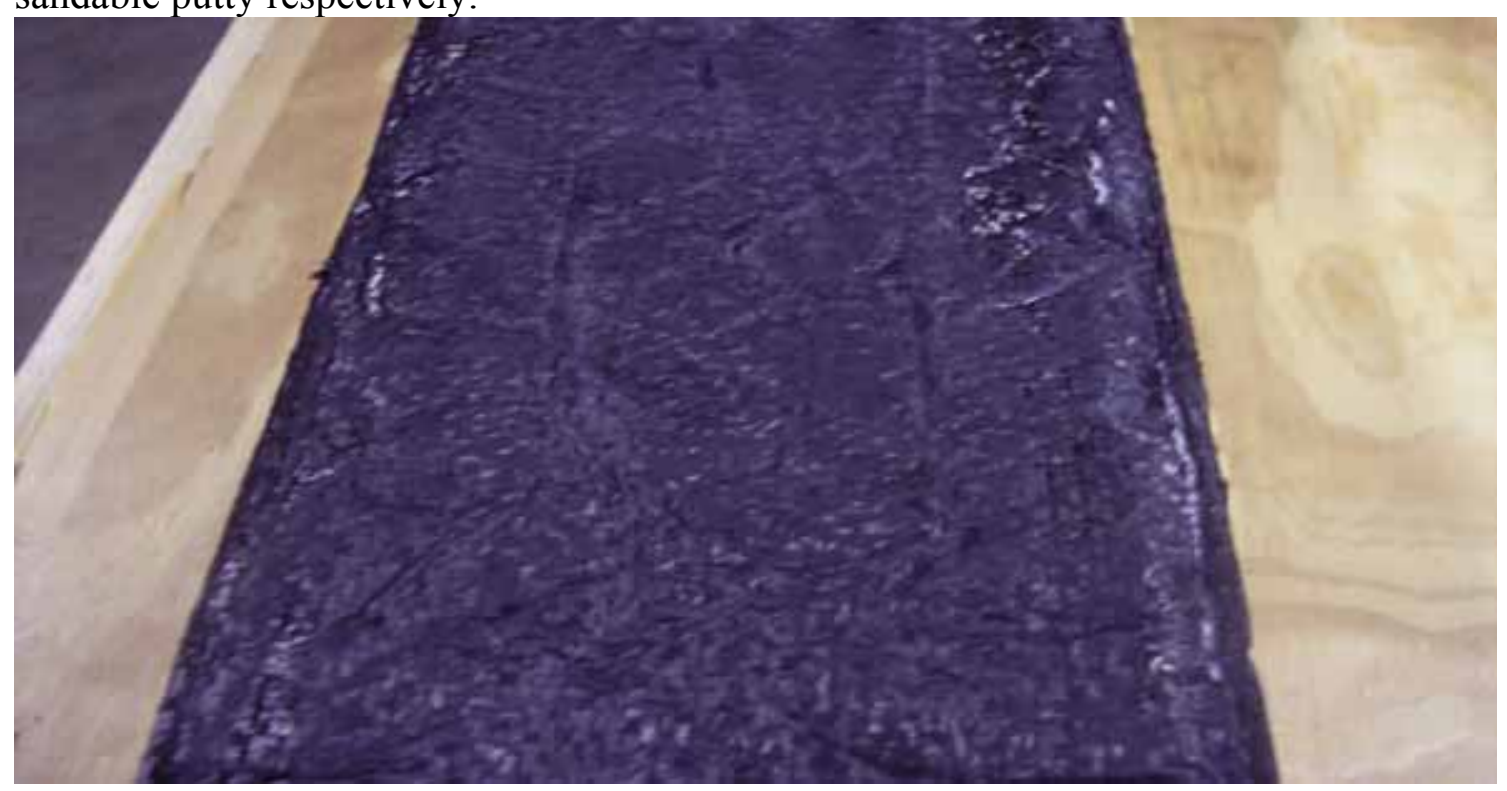

Fig. 14 Laminate surface imperfections where the aluminum is to be attached. 


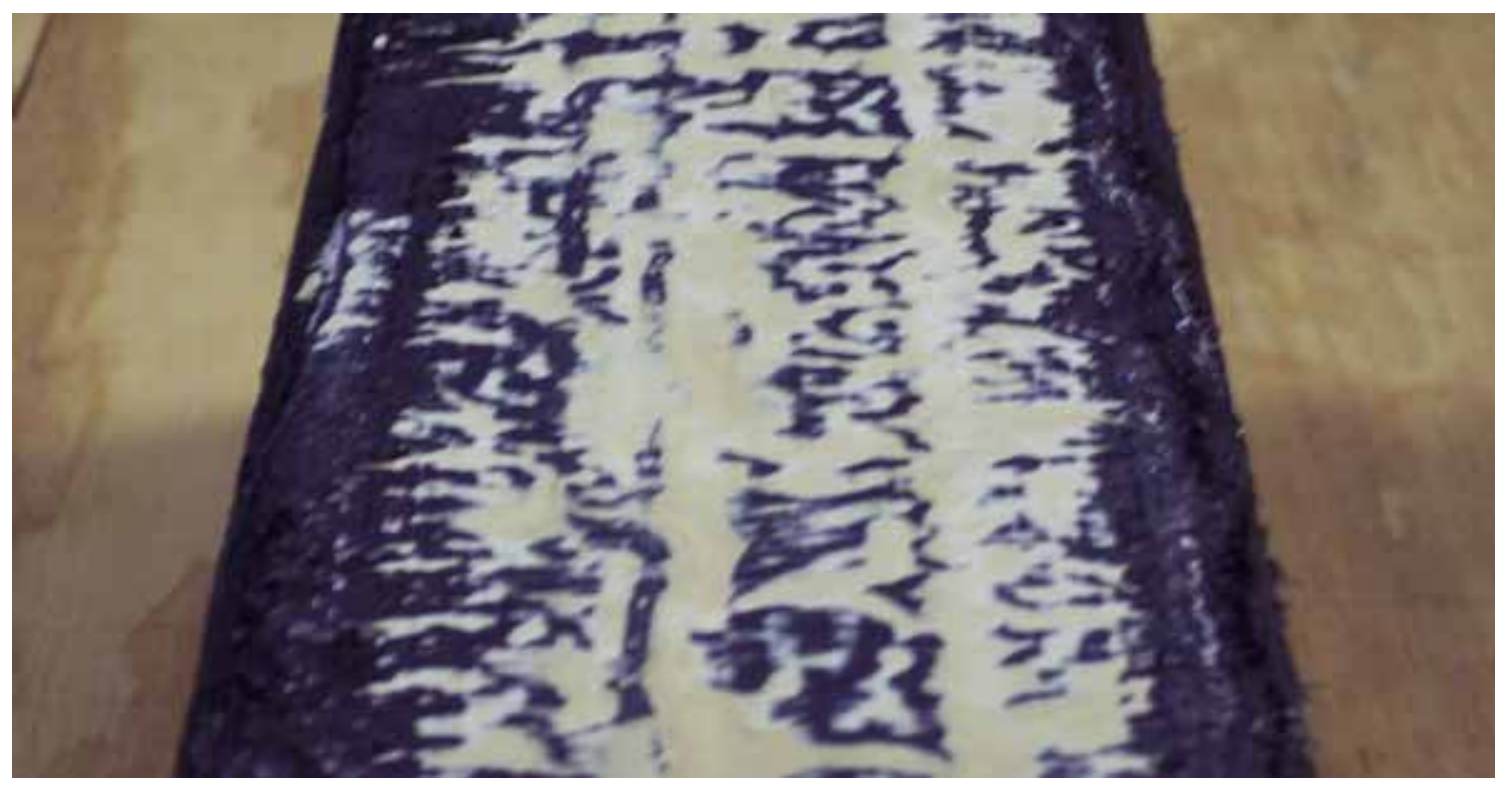

Fig. 15 Corrected laminate surface using sandable putty.

The step that followed was to rewrap the beam sample with another layer of carbon fabric in the same manner as discussed before. The corrected mold surface will allow for the desired even laminate surface. Before the lay-up process began however, dust from the sanding process was removed using high pressure air. After complete cure of this lay-up process, a level, acceptable surface was obtained. The aluminum plate was now ready to be adhered to the fiber/matrix beam sample via different methods.

A surface treatment on the aluminum was always completed to ensure a clean bond between it and the epoxy. The aluminum surface in contact was lightly sanded and wiped with muratic acid. Surface treatment to the aluminum plate remained the same throughout the experiment to ensure its consistency. The light sanding process used was to remove a surface layer of aluminum and expose a clean layer for adhesion. The muratic acid surface treatment helps to ensure the surface is clean from any debris. Aluminum surface treatments used for experiments are not expected to have the highest adhesion strengths obtainable, but because steps remain constant and simple, the results remain accurate from experiment to experiment.

With an aluminum plate attached to a composite beam, testing could begin. The machines used to conduct testing could only pull perpendicular to its sample mounting table. Since actual loading that would occur in shock rebound will create combined loading of tension and shear at the aluminum/composite interface, the sample mounting table had to be modified to simulate this. A modified steel mounting surface was built to secure the samples to the test machine table at a specific angle determined by suspension geometry. Once the mounting frame was attached to the table, a composite sample could be secured to the frame. This was done using two 1/2" bolts and a 3.5" x 2" steel washer to help distribute the clamping load across the top of the composite beam. For this research the load was applied at a $60^{\circ}$ angle relative to the mounting surface resulting in a desired shear-tension loading situation in shock rebound. A piece of $1 / 2$ " threaded rod, acting as the shock tower, was then mechanically coupled to the aluminum plate in the same manner as a shock would be bolted. The opposite end of the threaded rod was 
attached to the upper arm of the loading machine. Fig. 16 illustrates the experimental setup for testing.

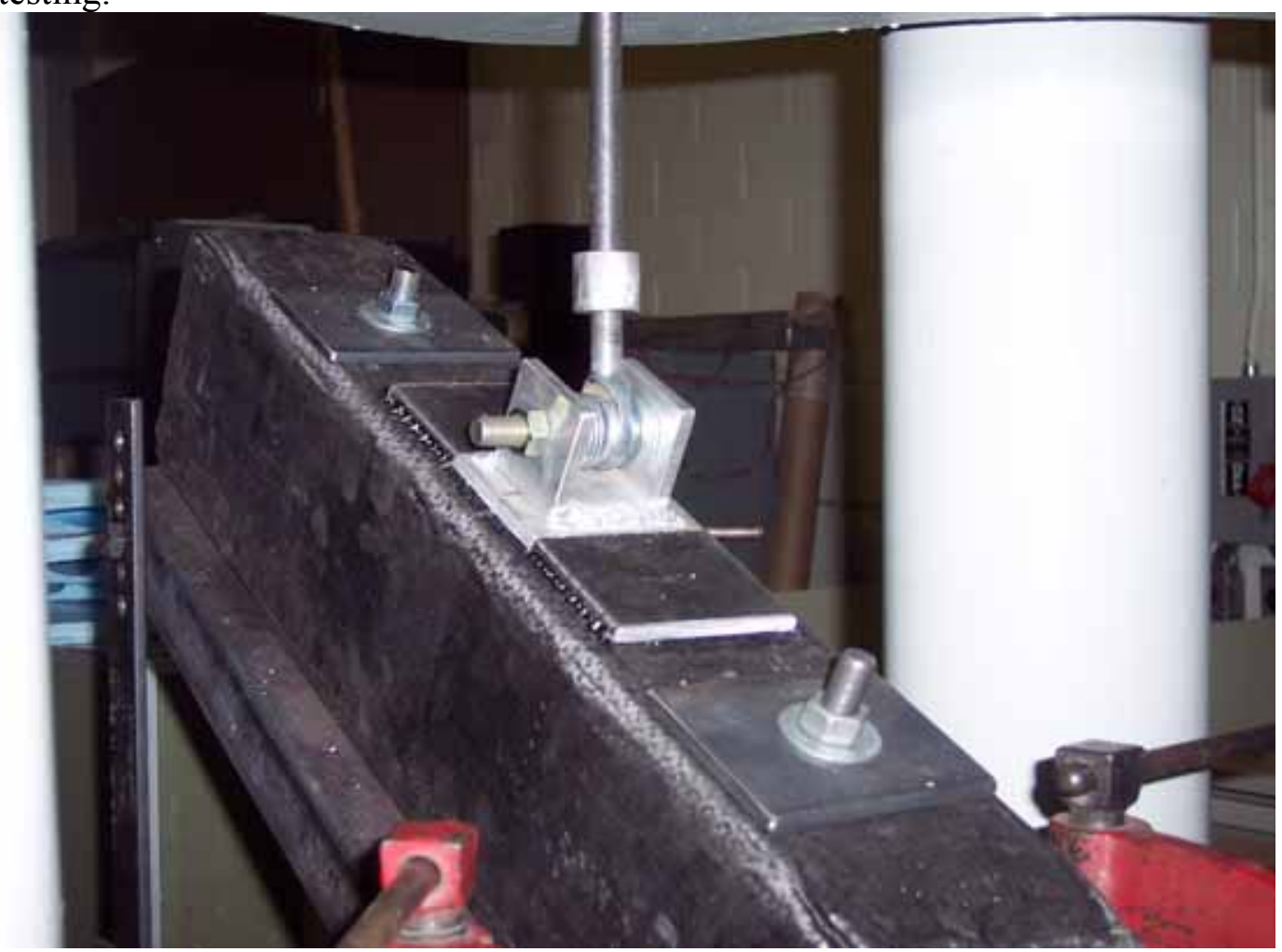

Fig. 16 Experimental set-up.

\subsection{Experimental Results and Discussion}

The better understanding of the reactions and an improvement on bond attachment at the interface between the aluminum and the composite is the conclusion we hope to reach. To do so, different means of attaching the aluminum plate to the composite sample were evaluated. With the obtained experimental results, further design modifications were made and evaluated. All loading conditions for the different samples were applied in the same manner.

The initial stage of testing began on evaluating the difference the curing cycle will have on the adhesion strength. The first sample was prepared by wetting the surface of both the composite and the aluminum plate and ensuring complete epoxy wetting at the interface. The plate was then placed on the composite and two c-clamps were used to apply the compressive force holding the plate during 24 hour curing at room temperature. Fig. 17 shows the sample preparation for this experiment. 


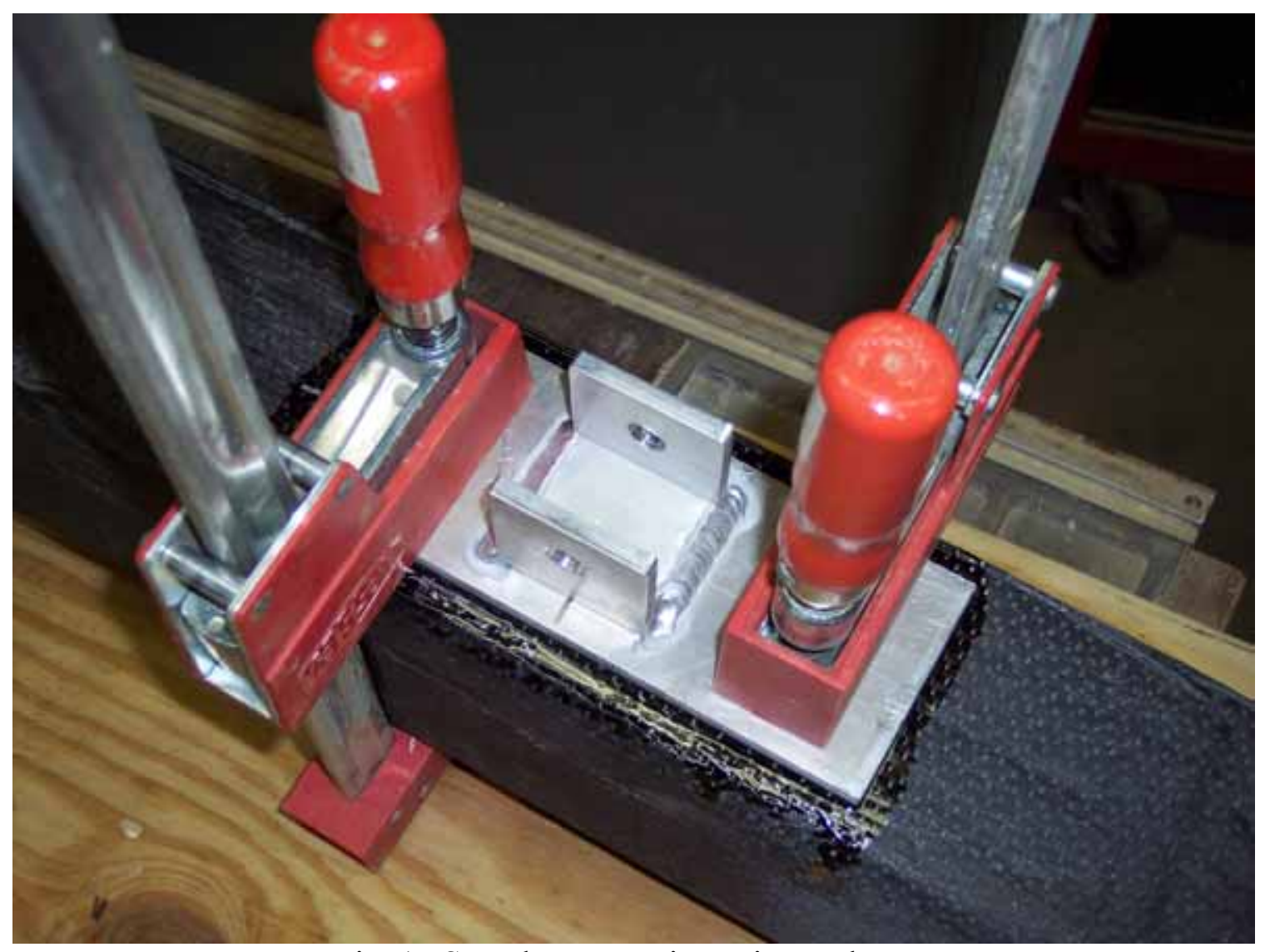

Fig. 17 Sample preparation using c-clamps.

Upon testing of the sample shown above, it was confirmed that this method of attachment is very unstable and weak. This specimen actually began to fail upon bolting it to the test frame. The initial failure, cracking in the matrix, could be heard as the cracks propagated across the aluminum/epoxy interface. As load was applied by the test machine, the plate rapidly separated from the composite beam under a very low, undetectable load.

The next specimen was prepared in the similar manner as the previous sample, although for this experiment the cure cycle used was different. Instead of using c-clamps and curing at room temperature, the sample was cured at room temperature under the vacuum pressure for 24 hours. Using this more effective way of distributing uniform pressure across the interface and the removal of a greater number of interface voids is expected to provide greater strength results. Another advantage is the higher temperature cure environment provided by the vacuum further enhancing the epoxy strength properties. Fig. 18 illustrates the vacuum curing process. 


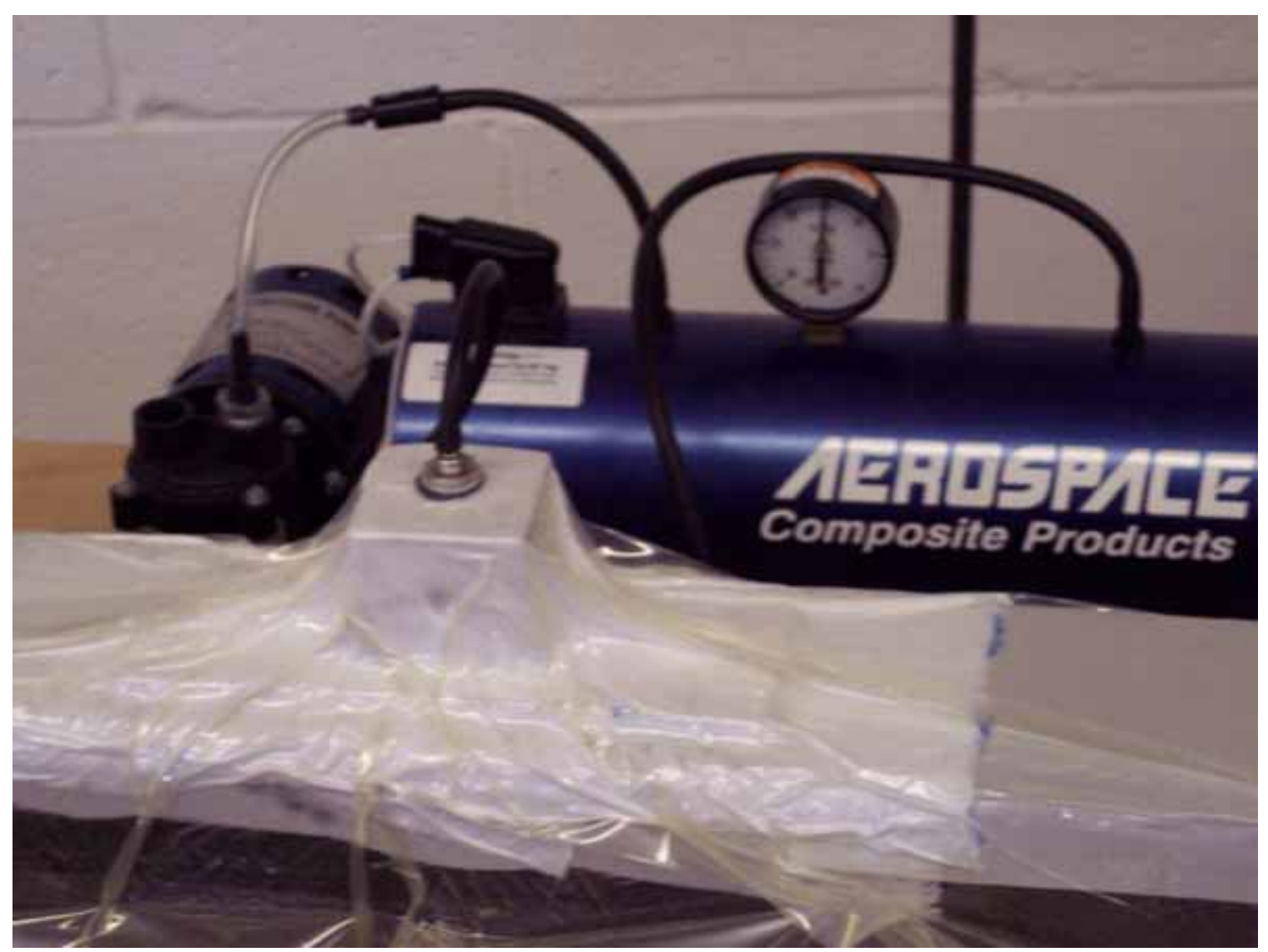

Fig. 18 Vacuum curing process.

The sample was then bolted to the test machine with no evidence of premature matrix cracking occurring. Once secure, a slowly increasing load was applied to the sample. As loading was increased, the sound of interfacial matrix cracking was again the first indication of failure. Loading continued until complete separation between the aluminum and the composite beam occurred. At this point the maximum load to achieve this catastrophic failure was recorded at $250 \mathrm{lb}$. For future reference, this will be referred to as experiment $\mathrm{A}$.

Upon inspection of the failure surfaces for the samples mentioned above, one thing became clear. Failure occurred at the interface between the aluminum plate and the composite beam only. The aluminum separated from the epoxy cleanly with no damage to the carbon fibers underneath. Fig. 19 illustrates the composite failure surface observed for the specimen prepared using the vacuum cure process. 


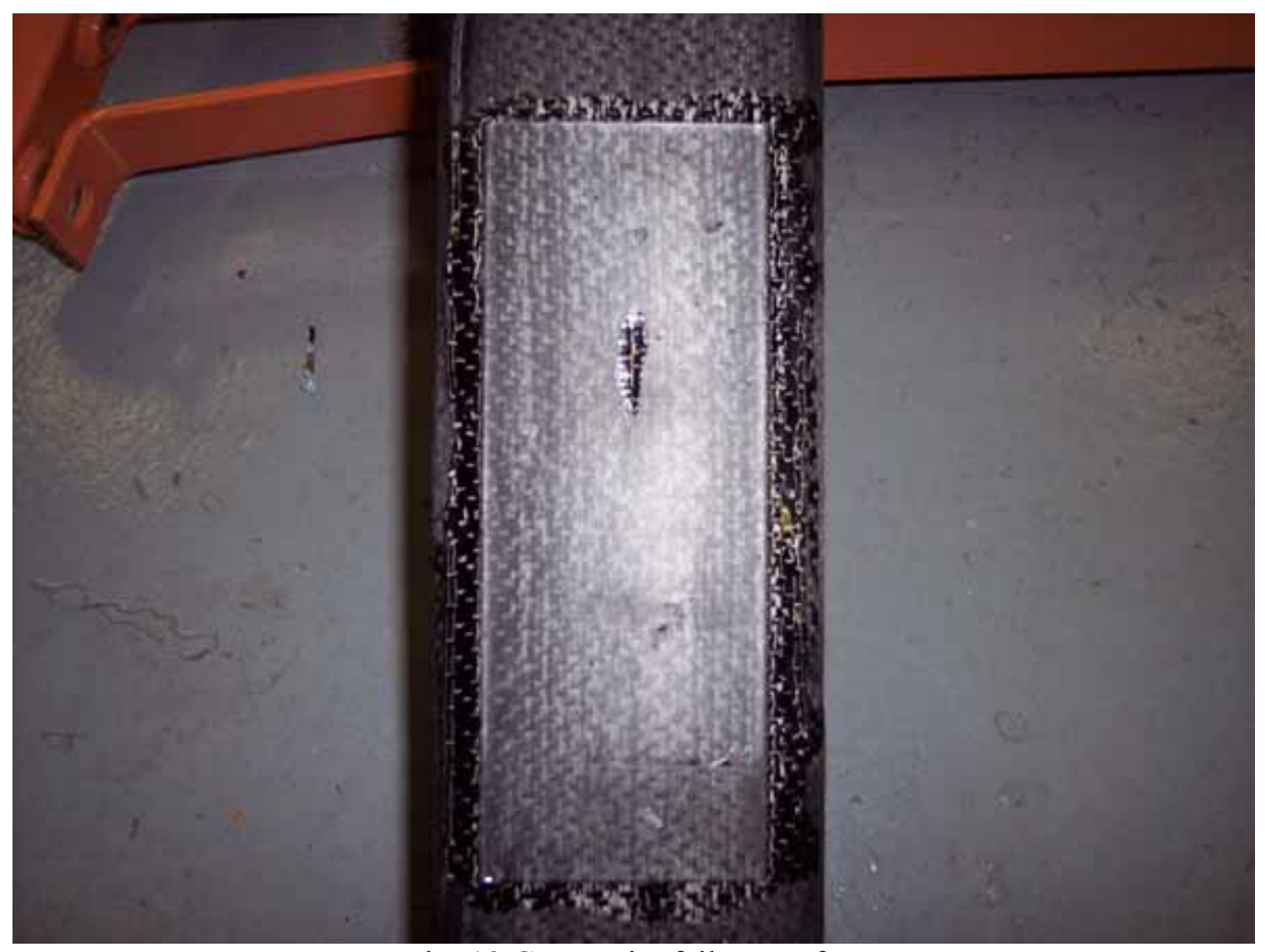

Fig. 19 Composite failure surface for the vacuum cured sample.

The light region observed in the majority of figure above illustrates the smooth surface of epoxy left adhered to the composite sample after separation. This is evidence of interfacial adhesion failure linked to the tensile loading conditions. There is the dark valley that can be seen in the upper-middle of the interface area. Inspection of the aluminum plate in this corresponding area showed that the epoxy remained adhered to the aluminum. This may indicate the possibility of a matrix void created during processing resulting in crack initiation in the matrix and propagation along the composite/epoxy interface. Because the tensile reaction of the applied load is at a maximum in this downhill region, another assumption may be that this area is where initial debonding occurred. Once this initial debonding took place, the overall bond strength became greatly compromised and complete debonding occurred very rapidly. This may be the explanation for the remaining areas where the epoxy did not remain adhered to the aluminum, but tore away cleanly.

The results found above are an improvement, however they show that relying on the interfacial bond alone to provide attachment is insufficient. Knowing that the reinforcement fibers are much stronger than the epoxy matrix, further experimental tests were conducted to see how these fibers can be effectively used to strengthen the aluminum/epoxy bond strength. Previously, it was the strength of the epoxy matrix alone which determined failure. By incorporating a single layer wrap of carbon fibers 
laminated over the aluminum plate the attachment failure strength is expected to increase dramatically.

The sample for these tests would require a slightly modified lay-up process. For the sample in this test, there was an additional two inch wide strip of fabric to be laminated over the two outer edges of the aluminum plate. The carbon fabric strip was cut long enough to effectively wrap down each side of the composite bema as illustrated in Fig. 20, which shows the sample after vacuum curing. Upon inspection you can see the change in fiber orientations which represents the additional single layers of fabric.

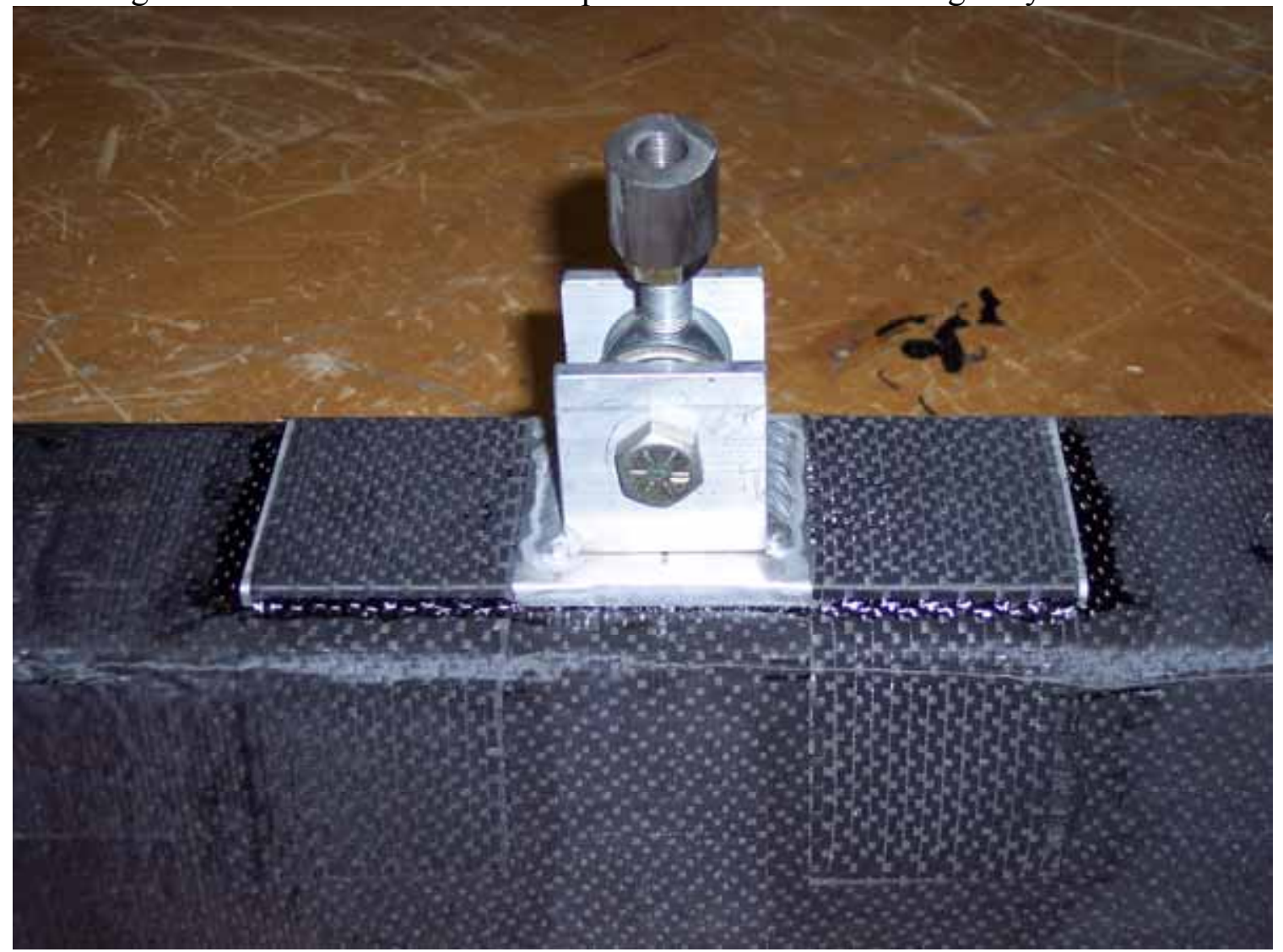

Fig. 20 Composite sample with additional wrap of carbon fiber fabric after vacuum curing.

Upon inspection of the new sample some preliminary concerns were addressed. First was to explain the dark region in the epoxy/fiber laminate that was observed around the edges of the contact area between the aluminum and composite surface. This can be seen closely in Fig. 20 above. At first glance it appeared there was no matrix present in this region leaving exposed surface fibers. Further inspection showed the sandable layer created by the peel-ply was not left behind upon its removal. An explanation for this would be that the peel-ply did not conform tightly to the fiber fabric in this area.

However, there is still adequate matrix impregnating the fibers and it was determined the experiment was not compromised by this effect.

Better seen in Fig. 21, is that the fibers themselves do not conform perfectly to the area around the aluminum and composite interface. This is again the result of the sharp corner that occurs in this area. This observation should raise concerns of a stress 
concentration at this laminate edge location created. A high stress concentration would ultimately cause laminate failure to first occur in that region. For this situation, it can be expected the matrix to fail first, developing cracks that will propagate and combine together along the laminate interface. Ultimately the laminate strength will be compromised and will begin to fail most likely due to delamination.

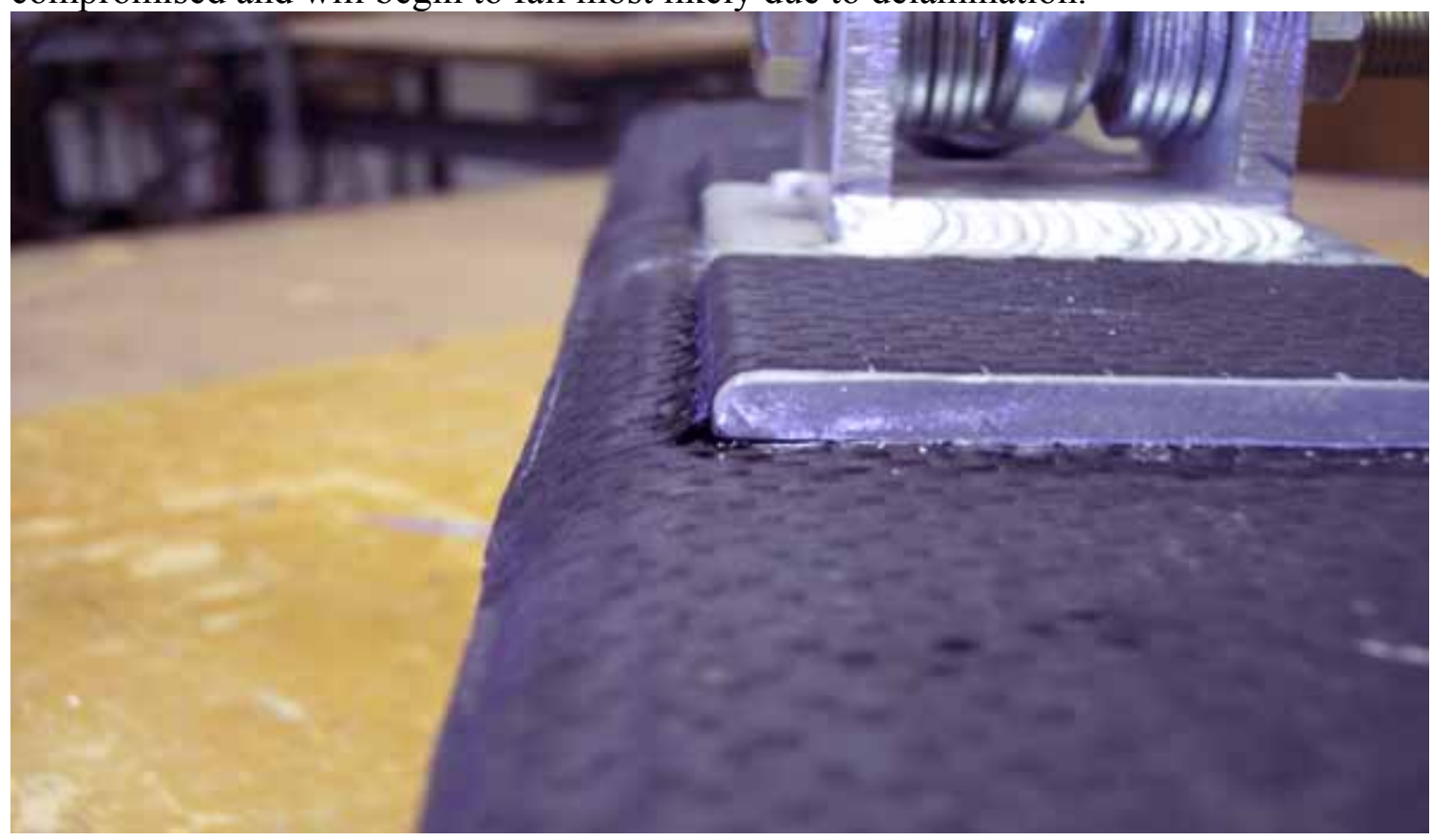

Fig. 21 View of the sharp corner at the aluminum/composite interface.

The sample shown in Fig. 20 and Fig. 21 was bolted to the test frame and a slowly increasing load was again applied. During loading, initial failure patterns were again observed in hearing the matrix cracking underneath the aluminum plate. It is assumed that the interface between the composite sample and the aluminum plate was strengthened. This is because a greater load was recorded before the sound of matrix cracking was heard for this experiment.

As the load continued to increase to the point where the fibers carry all the load, laminate failure of the fabric strip was expected to occur. This would lead to a catastrophic separation failure where the plate would break loose from the composite beam. This failure would generally begin on the downhill side of this specimen in relation to the mounting table. At this point the maximum tensile load in the sample would be reached first. However, the layer of carbon fiber fabric strip remained intact during the loading. Ultimate failure was determined in the composite sample itself.

During loading it could be seen that the aluminum plate initially became separated from the sample beam, first initiating on the downhill (tension) side. At this point the load is now being carried by the laminate strip wrapped over the plate. Because this laminate strip remained adhered to the composite beam sample during loading, deformation in the sample itself began to occur. The downhill side, which saw the highest levels of tensile loading, began to elongate. It was also observed that the aluminum plate was beginning to deform. The plate began to arch in the middle where 
there were no carbon reinforcement fibers to prevent such an occurrence. At this point it was decided to stop the test and consider failure. With this type of damage, this component would certainly be on edge of catastrophic failure upon further loading. It was seen from this experiment just how strong the laminate wrap over the aluminum can be. The final damage results that were recorded occurred at a load of 1,432 lb., which can be seen below in Fig. 22.

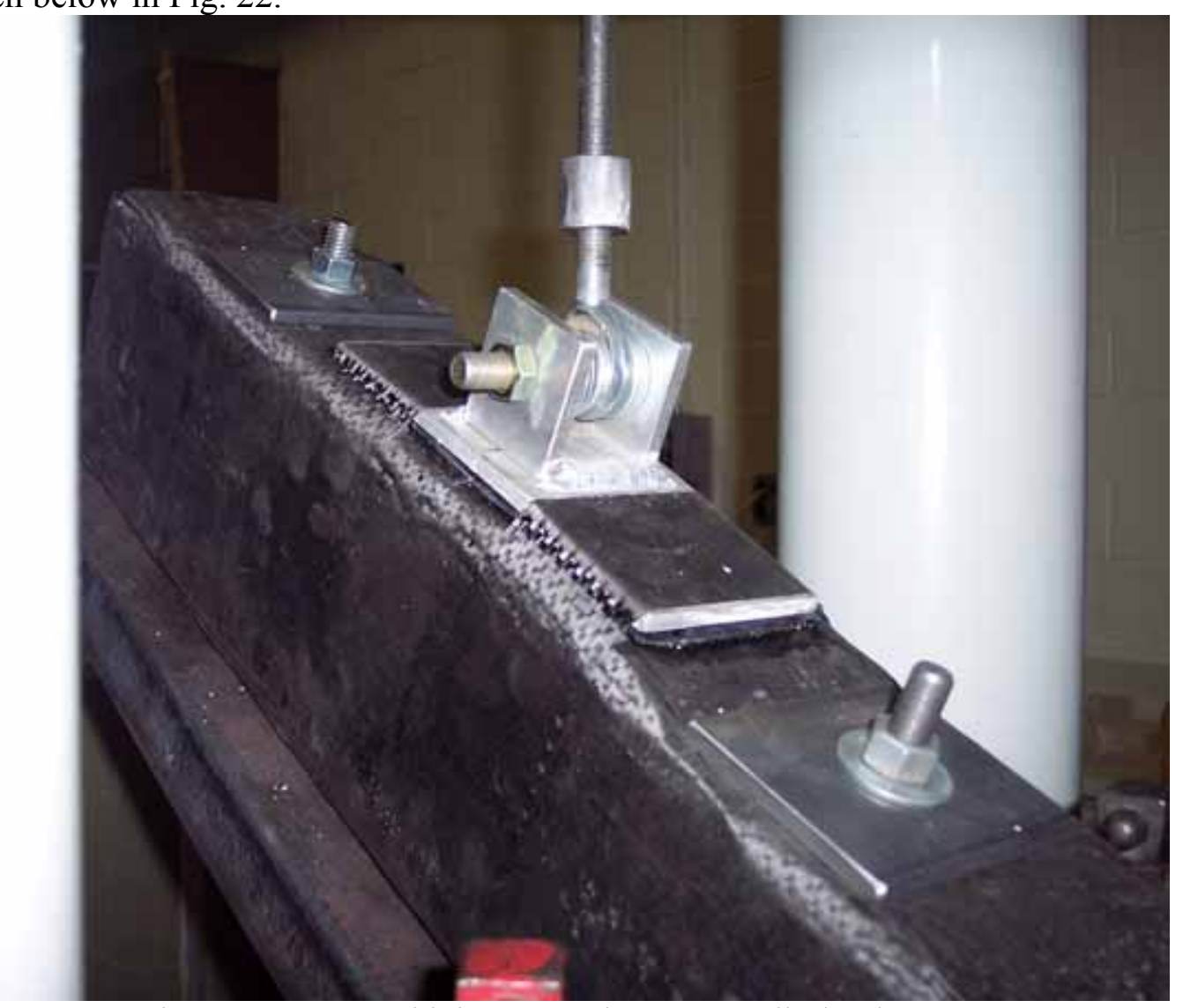

Fig. 22 Damage which occurred at a 1,432 lb. load.

To observe the interfacial fracture surfaces, the aluminum plate was separated from the composite beam by carefully cutting away all the fibers attaching the plate. By hand, a pulling force was required to completely separate the aluminum plate. This indicated that there was still some interfacial bond present on the uphill end of the plate, where the downhill side of the interface had separated completely as seen above. Further observation of the fracture surfaces at the aluminum/epoxy interface revealed an interesting characteristic.

For this experiment using the reinforcing fiber wrap, there was a greater total area in which the epoxy remained adhered to the aluminum as seen in Fig. 23. Again the dark spots on the composite sample represent where the epoxy remained adhered to the aluminum plate. Previously this dark region seen on the epoxy failure surface was linked to a possible matrix void during processing. However careful sample preparation in this experiment would indicate voids are most likely not the cause for this type of failure behavior. 


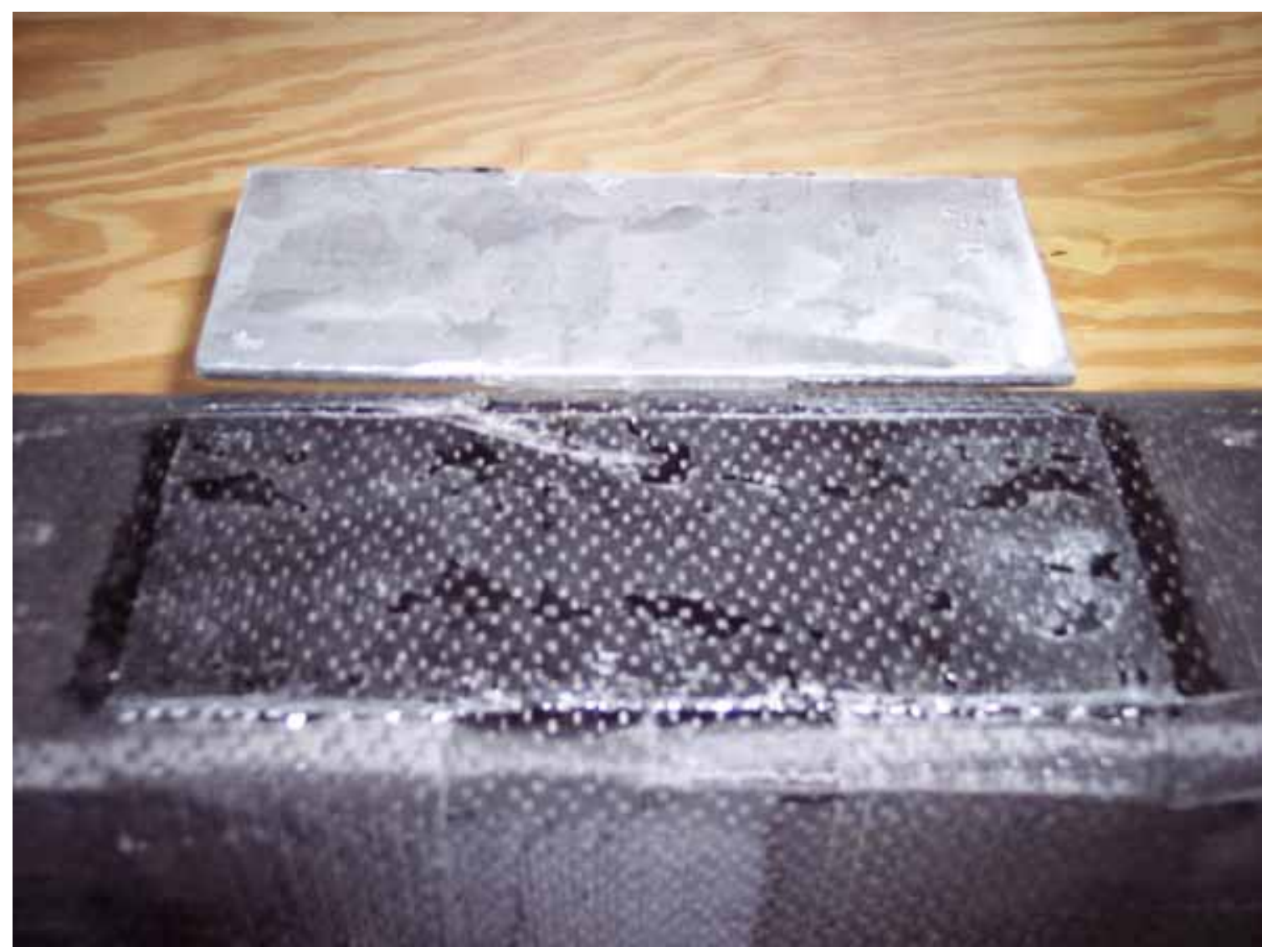

Fig. 23 Failure surfaces at the interface.

In previous experiments, with only the aluminum/epoxy for bonding, adhesion failure and complete debonding is linked to one area. The failure characteristics shown above imply more of a load distribution effect occurred. The initial concentrated load was redistributed from one location to the four dark corners seen around the middle to the downhill end of the composite sample above. This conclusion would indicate the addition of the fiber fabric strips over the aluminum improved the bonding strength area by better distributing the same combined shear-tension load. With these additional fibers, once debonding occurred in an area, other areas can remained adhered allowing for further ability to carry load.

With the results concluded from the previous tests, further advancements were taken to better optimize the transfer of applied load. The improved strength displayed by the laminate strip in distributing the load across the interface suggests that additional load transferring fibers would further increase interfacial bond strength. For the following experiment, a $0^{\circ} / 90^{\circ}$ carbon fiber fabric laminate that would tie as much of the aluminum plate to the composite beam was used. These additional fibers are expected to continue to improve the attachment strength.

Sample preparation began by cutting a piece of bidirectional carbon fiber fabric that would lie over the aluminum shock plate. Again the fibers will extend down the side of the composite beam bonding the two. To achieve as much coverage of the aluminum as possible, fibers were cut away from the fabric to only allow for the vertical uprights to 
protrude. The fabric was made from an individual piece so not to compromise the strength of the fabric weave.

Hand lay-up was again used in the same manner as previously discussed with the newly designed pre-cut carbon fabric added. The dark region across this fabric seen in Fig. 24 illustrates the partial resin wetting of the fabric during the initial steps of the layup process. It is also seen the stiffness of the fabric prior to epoxy impregnation.

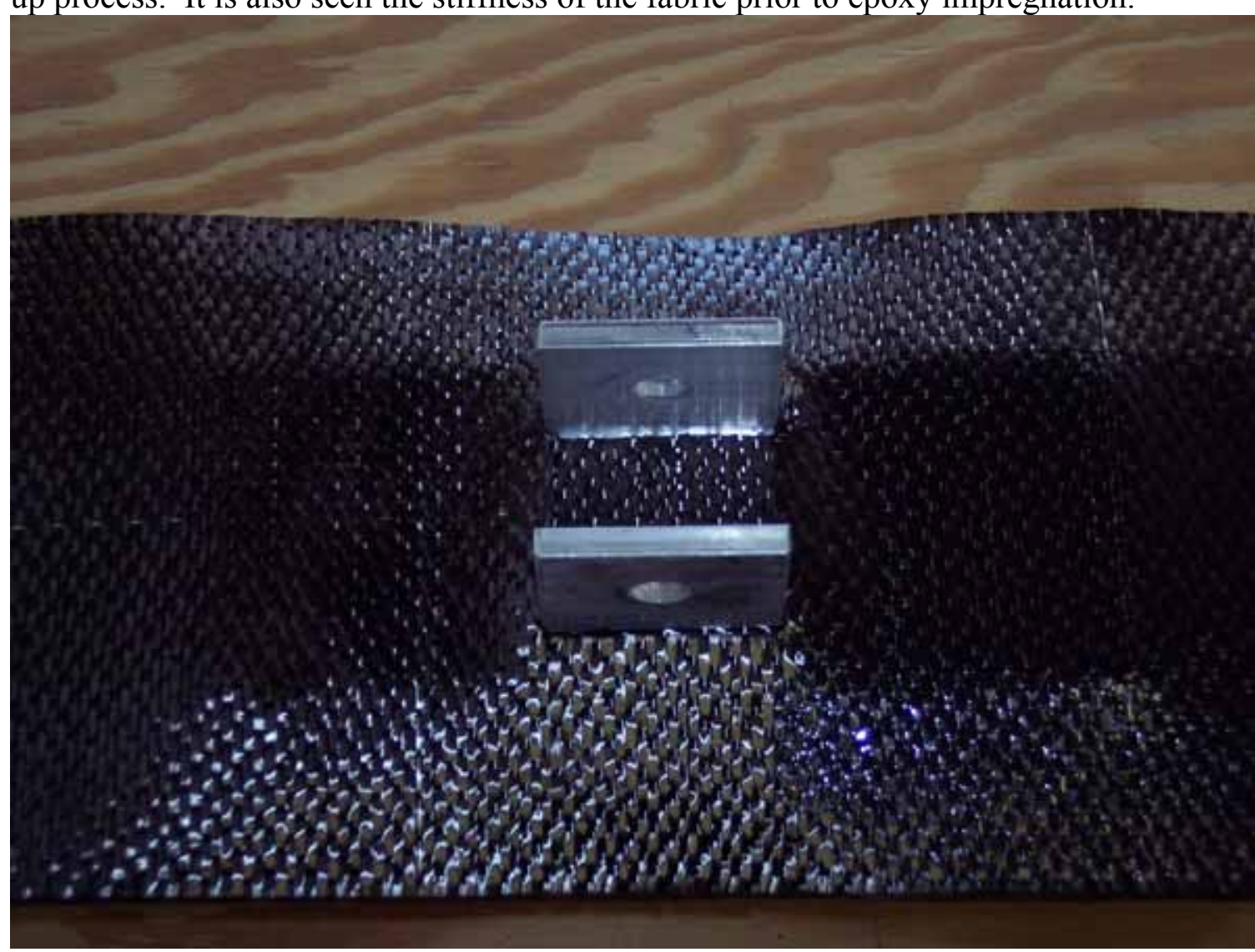

Fig. 24 Partially wetted carbon fabric during initial stage of lay-up process.

Complete impregnation and alignment of the fibers in the 0/90 directions was again ensured before the fabric layer of peel-ply was added. Fig. 25 below shows the layer of peel-ply saturated with the epoxy resin as it was conformed to the mold. The remaining steps for the bag molding cure process also remained the same as previous experiments so accurate comparisons can be made. 


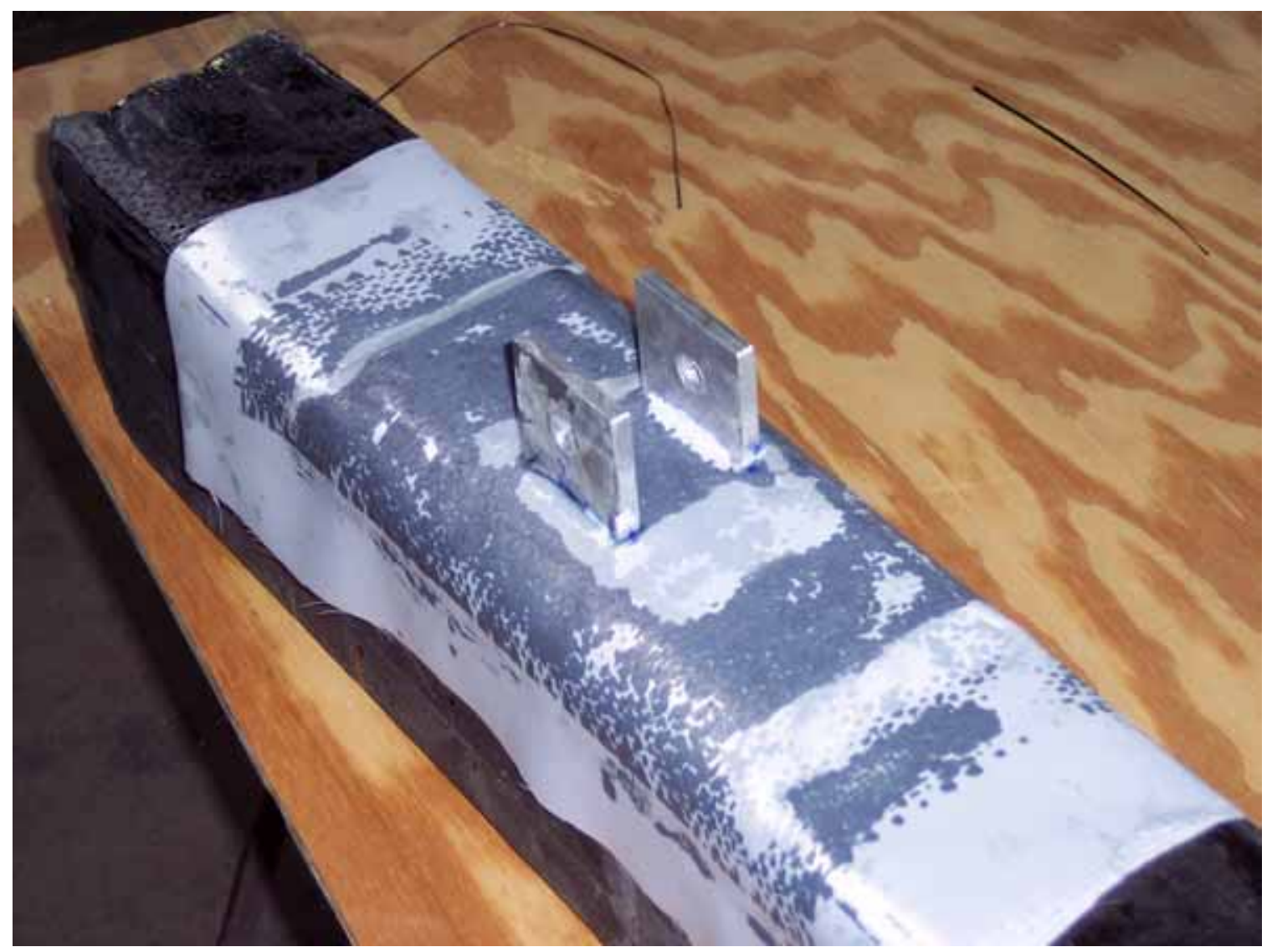

Fig. 25 Saturated peel-ply fabric.

Once cured, the new sample was secured and loaded under the same conditions as previous examples. The load slowly increased reaching $760 \mathrm{lb}$. before a snap was heard indicating interfacial separation between the aluminum and composite beam. Results have shown however, that only a portion of the interface has become separated at this point. As the load continued to increase, it reached 1,060 lb. when a drop of the load needle indicated major failure to where the carried load was redistributed to another area. This phenomenon in failure was linked to the aluminum/epoxy interface having no exterior damage visible. Once the load was transferred and continued to increase, it was at 1,200 lb. when composite sample deformation became visible. It was decided to continue the test in hopes to better understand interfacial reactions and ultimate failure. As deformation continued in the composite beam as well as the aluminum, strong evidence of interfacial matrix cracking was not again heard until the load reached 2,100 lb. This evidence further supports that the aluminum/epoxy interface will have remained adhered in some areas and capable of load carrying even after major debonding. At 2,200 lb. a picture was taken to illustrate the degree of sample deformation seen by its hour-glass shape in Fig. 26 below. It was at 2,410 lb. when fiber breakage occurred at a localized stress concentration caused by the method of bolting the sample to the frame. At this point the test must be stopped knowing once fiber breakage occurs, ultimate composite strength is typically reached. 


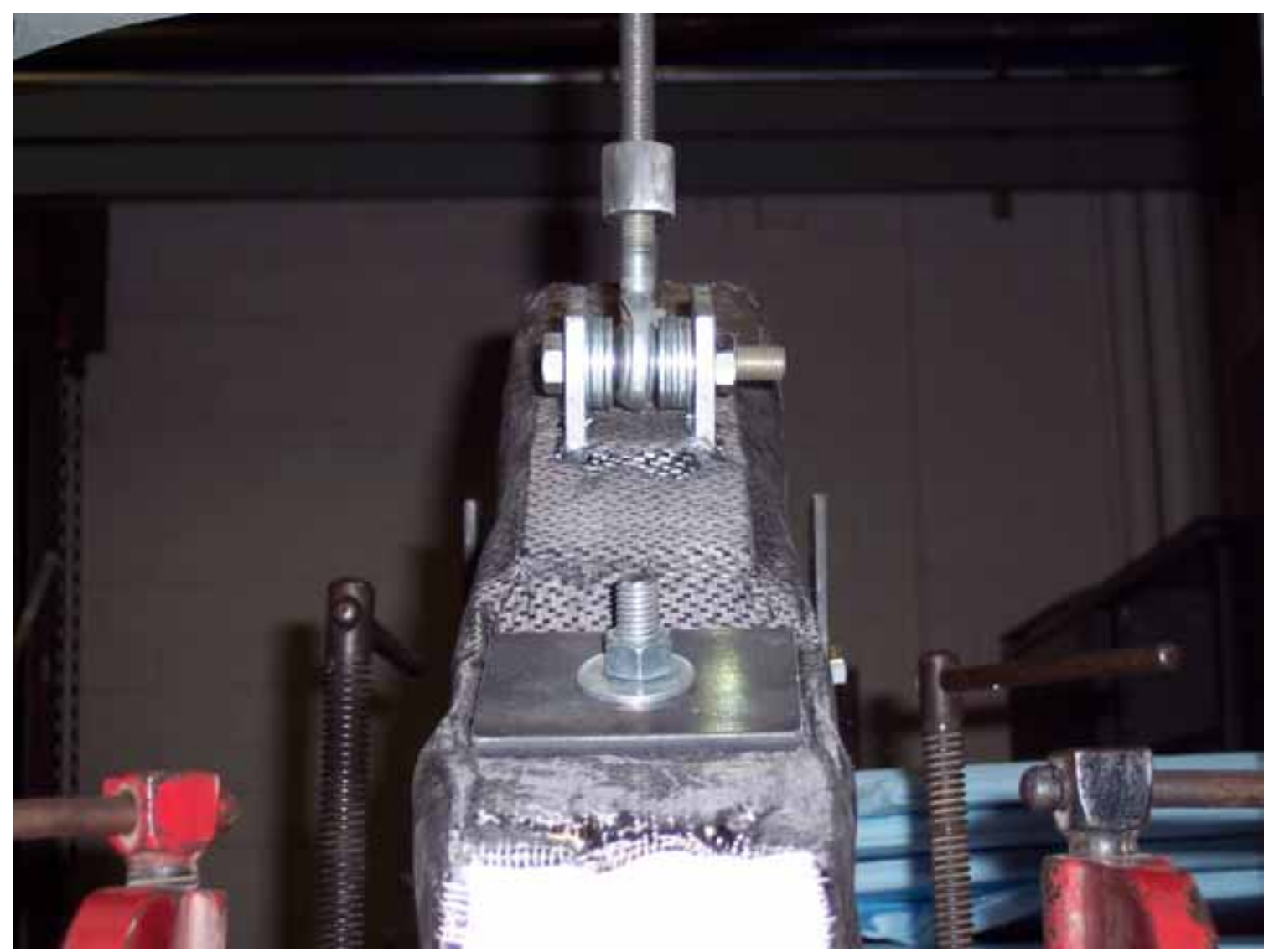

Fig. 26 Sample deformation at 2200 lbs.

Because this test was taken to such extreme failure, the characteristics of the fracture surfaces should give further evidence to the interfacial load distributions and reactions. Fibers were again cut away in order to completely separate the aluminum plate to observe the interface fracture surfaces. With the fibers removed, it can be seen in Fig. 27 the degree of deformation that occurred in the aluminum plate. The maximum deformation, seen to the right in the figure below, occurred on the downhill end of the plate in tension as expected. 


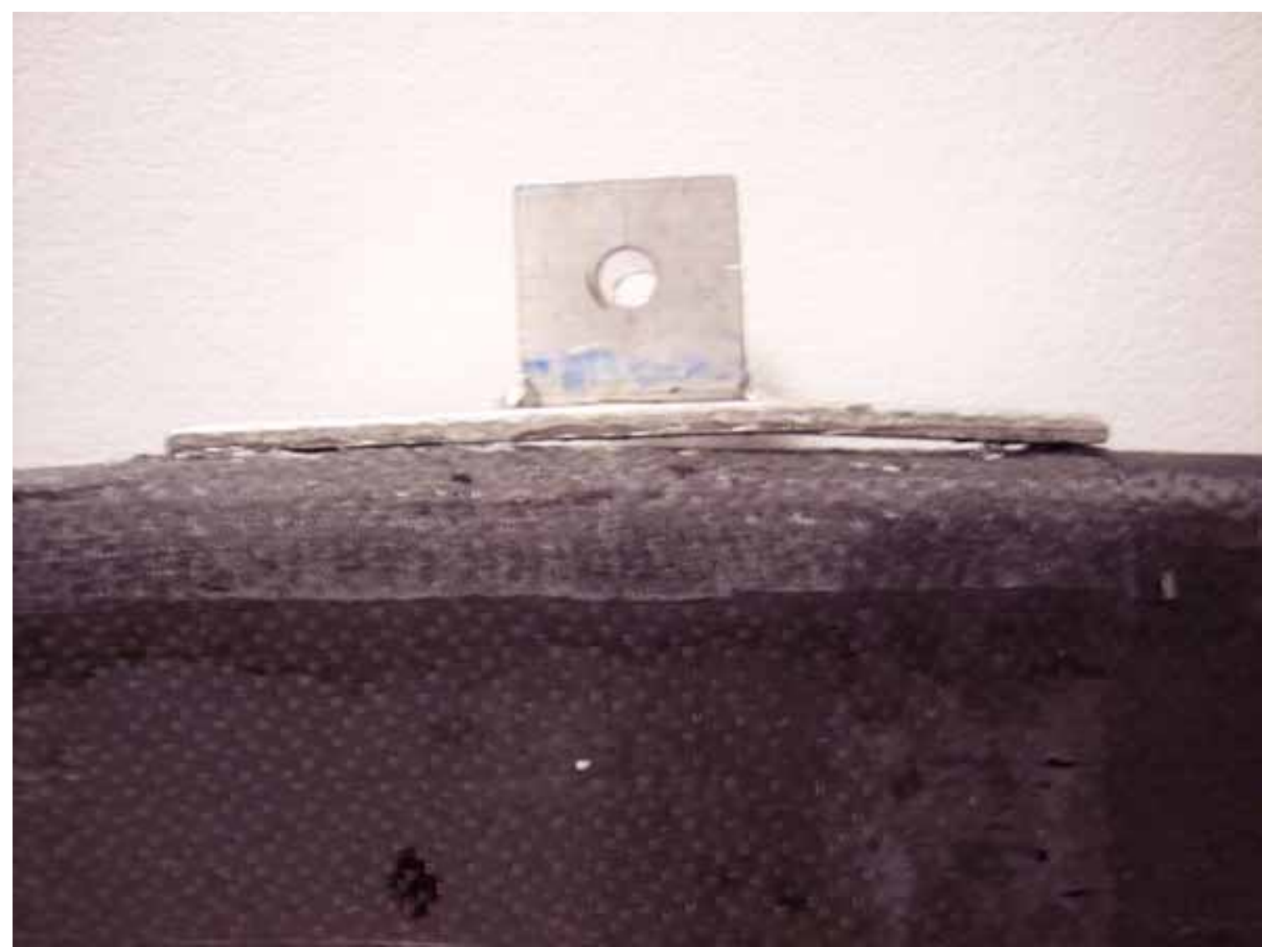

Fig. 27 Aluminum plate deformation.

Even with definite separation on the downhill side of the interface, once again it required force by hand to create complete separation. Again indicating the area of remaining aluminum/epoxy adhesion on the uphill sample end where the tensile effect load was lowest. The fracture surfaces immediately showed desirable results as well. The applied load appeared distributed much more effectively away from the weaker bond interface.

Analysis of the fracture surfaces shows additional support of the increase in interfacial bond strength through load distribution. As indicated before, the light and dark regions found on failure surfaces are assumed linked to the failure mechanism. There was a significant amount more of epoxy remained adhered to the aluminum plate than in previous experiments. Evidence of this can be seen in Fig. 28 showing the fracture surfaces after the splintered epoxy matrix was cleared away. Upon close inspection of the areas where epoxy remained adhered to the aluminum, it was also discovered that tiny splinters of carbon fiber were visible. This tells us that fibers were torn away during failure, an indication of a greater bond strength. 


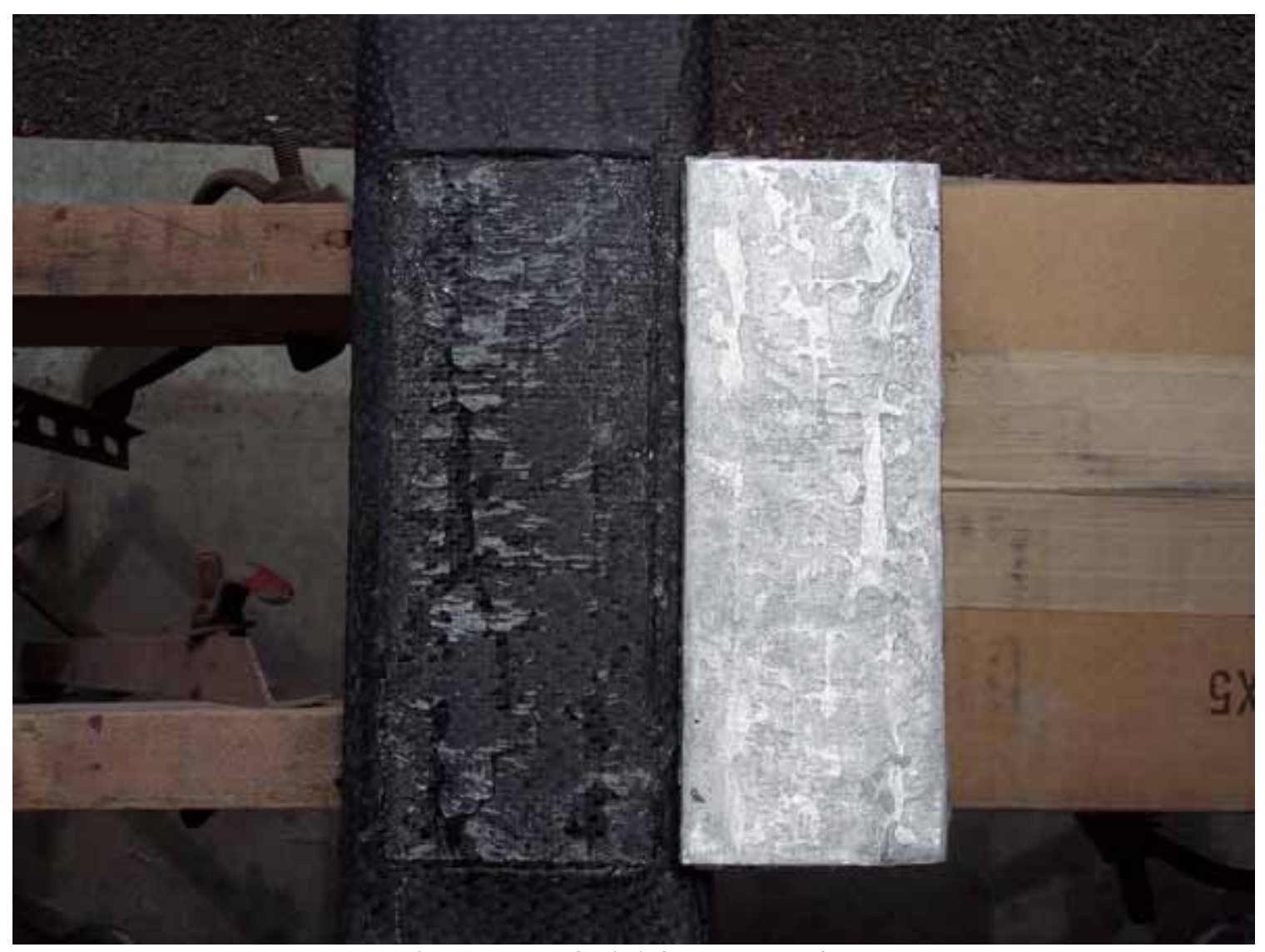

Fig. 28 Interfacial fracture surface.

For this test, broken splinters of epoxy matrix were discovered across the aluminum/composite interface and had to be cleared away before inspection. These splinters can be seen closely below in Fig. 29, which shows the composite interfacial fracture surface. This finding is assumed the result of the aluminum/composite beam deformation due to the extreme loading. After debonding had occurred, the 2,410 lb. load caused the epoxy on the fracture surfaces to splinter and break away. 


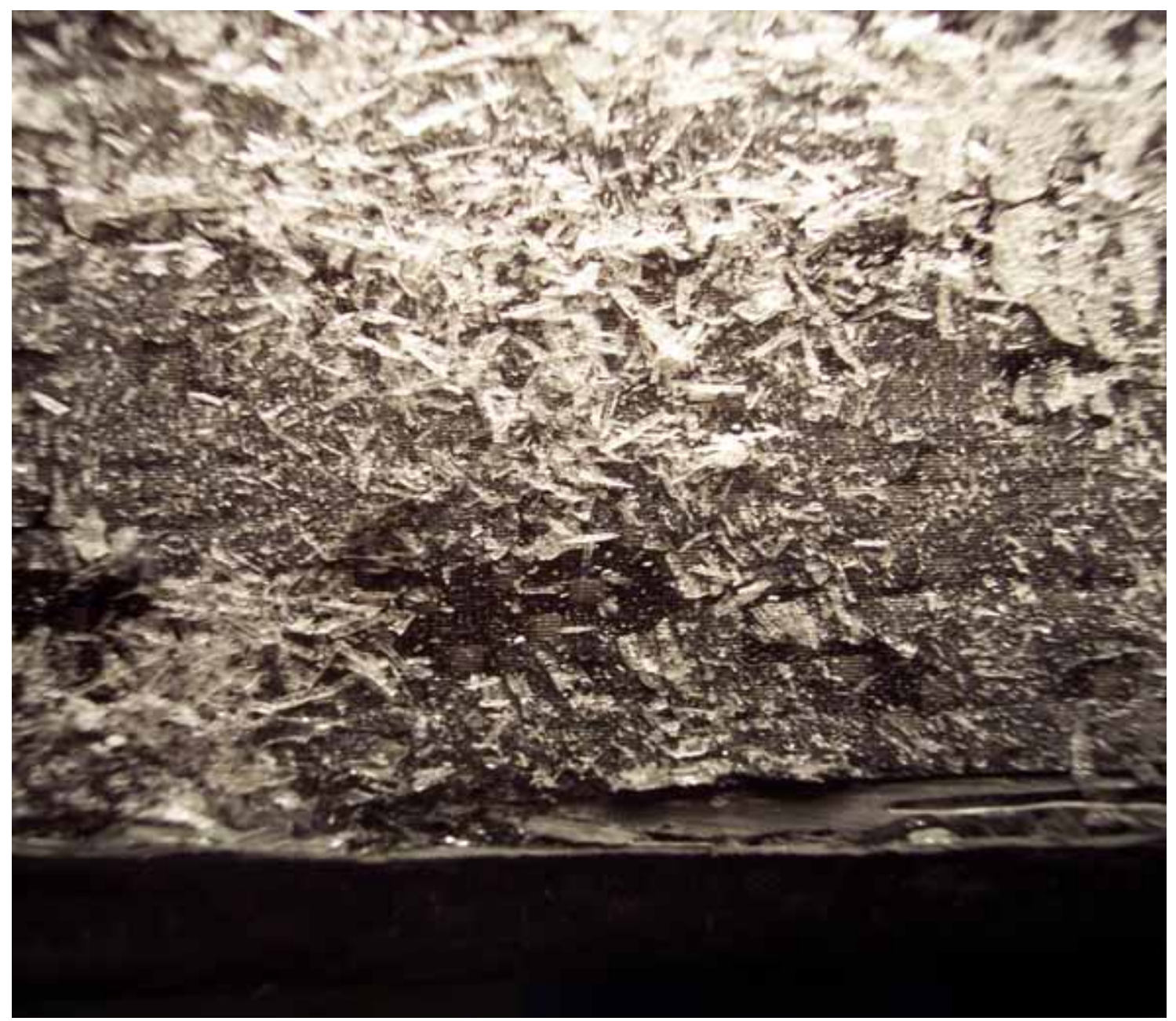

Fig. 29 Epoxy failure surface on the composite sample.

With the advancements made to this point, further research was dedicated to monitoring the strains and global deformation occurring across the composite during loading. With this knowledge, steps can be taken to further optimize the aluminum/epoxy bond strength. Using strain gages placed on the surface of the laminate wrap will give a better understanding of how the applied load (shock rebound) is transferred across the interface an into the composite beam during loading.

For the final two experiments, two samples were prepared under the same lay-up conditions as just previously discussed. However, one of the composite samples contained an additional $0^{\circ} / 90^{\circ}$ initial wrap around the foam beam mold. This was done in order to make advancements toward an optimal composite beam laminate configuration. By increasing the stiffness of the composite beam and reducing its deformation during testing, the result should be a strengthening of the interfacial bond.

In order to acquire this new data, a different test machine had to be used. The method for securing the sample and the load direction remained constant to maintain loading similarity to the previous experiments. An illustration of the similar loading conditions can be seen below in Fig. 30, which shows a sample just prior to loading. For both of these experiments, the load was applied from a MTS machine at a rate of 0.05 $\mathrm{in} / \mathrm{min}$. This low load rate is recommended for the data acquisition using the Vishay 
Micro-Measurement components. This load rate also allows for accurate monitoring of the strain behavior and failure patterns in the composite sample.

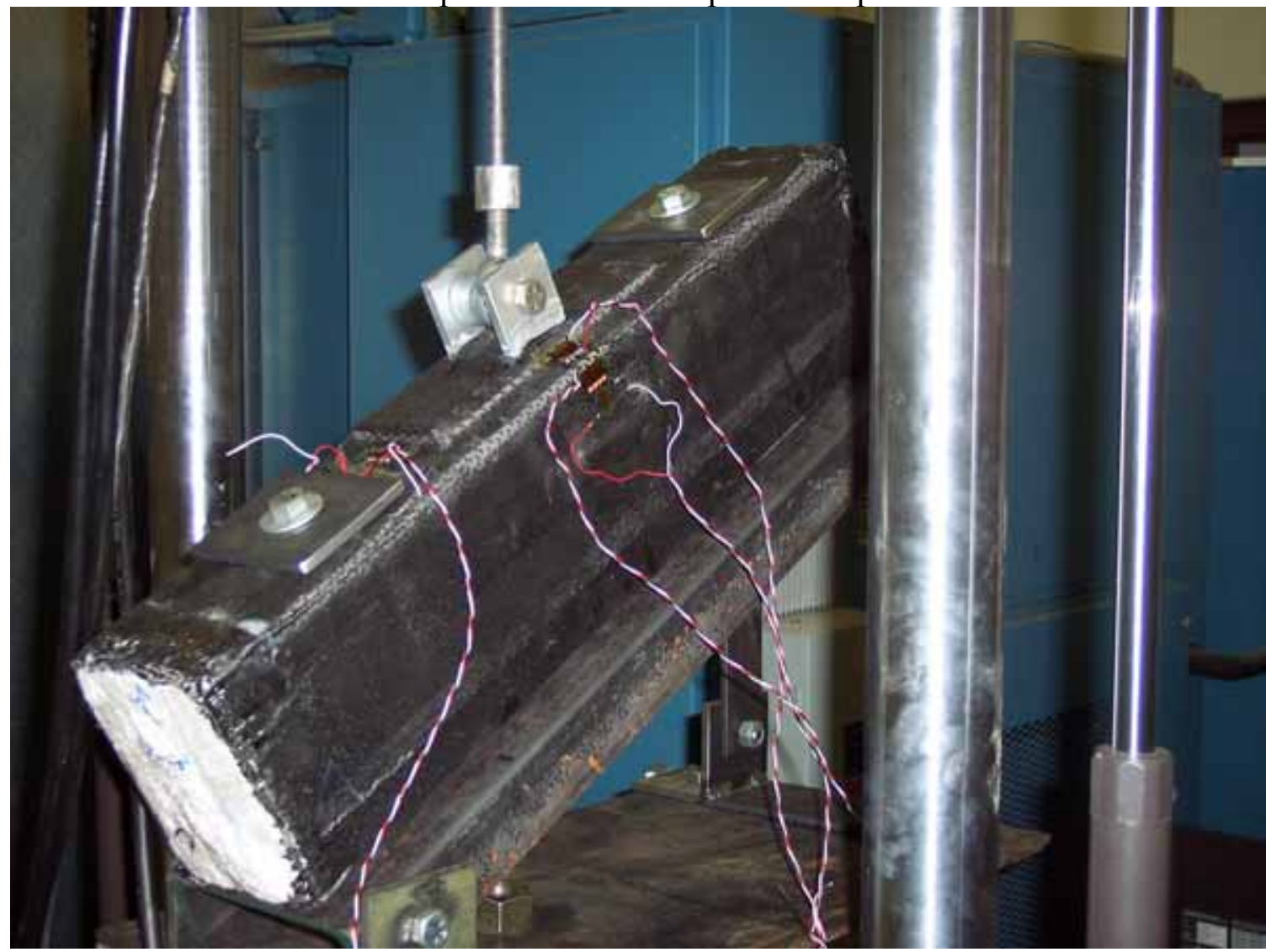

Fig. 30 Data acquisition experimental set-up.

The strain gages used were bidirectional capable of producing a strain reading in the $0 \% 90^{\circ}$ directions at each gage location. In both experiments, the gages were placed on the sample in the fashion as shown above, with the "top" gage located on the downhill side of the sample. The CEA-Series gage features a large copper solder tabs and a completely encapsulated grid for application ease. The self-temperature-compensation or (S-T-C) of the gage is $13 \mathrm{ppm} /{ }^{\circ} \mathrm{F}$. This was the recommended approximate thermal expansion coefficient of the structural material on which the gage is to be used. A gage resistance of $350 \mathrm{ohms}$ was used as opposed to the optional $120 \mathrm{ohms}$. The higher resistance gage was preferred to reduce heat generation for the same applied voltage across the gage and decrease leadwire effects and to improve signal-to-noise ratios in the gage circuit.

A comparably large strain gage was decided on to provide a strain reading over multiple fibers during testing. The gage used for these experiments allowed 3.125 yarns of carbon to be included in the representative volume element (RVE). The strain gage dimensions can be found in Table 4 below. 
Table 4 Strain gage dimensions.

\begin{tabular}{|c|c|c|}
\hline Property & U.S. Units (in) & SI Units $(\mathrm{mm})$ \\
\hline Gage length (each section) & 0.250 & 6.35 \\
\hline Overall length (complete pattern) & 0.450 & 11.43 \\
\hline Grid width (each section) & 0.290 & 7.37 \\
\hline Overall width (complete pattern) & 0.650 & 16.51 \\
\hline Matrix size $(\ell \times \mathrm{w}$ ) & $0.55 \times 0.74$ & $14.0 \times 18.8$ \\
\hline
\end{tabular}

In the first experimental test utilizing the strain gages, two separate bidirectional gages were bonded to the composite in an area closest to the aluminum/composite interface. The gages were placed here to monitor the strains found in the fibers directly attaching the aluminum plate. The strain behavior observed in this area will also give indication of interfacial failure modes and the load in which induces failure at this area. The arrangement of the strain gages for this experiment can be seen in Fig. 31. For future reference, this test will be noted as experiment 1 (EXP 1). It should also be noted the sample used in this experiment was the beam containing one less $0^{\circ} / 90^{\circ}$ laminate wrap around the foam core and therefore has the lower stiffness.

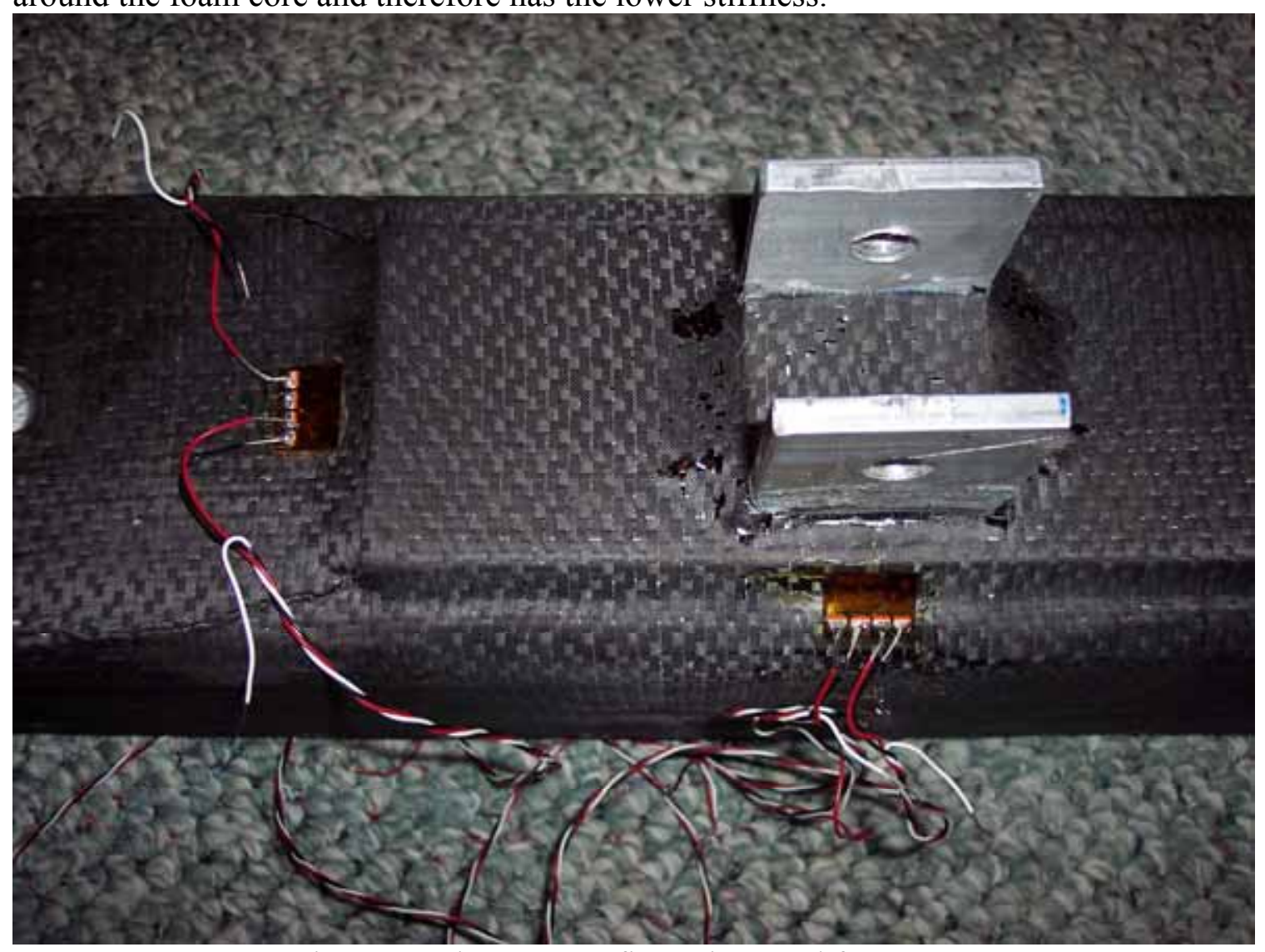

Fig. 31 Strain gage configuration used for EXP 1.

The gage matrix closest to the shock mount point seen above, will be defined as the "side" gages. The second gage matrix will be referred to as the "top" gages. The reference coordinate system can be defined in the photos shown above, Fig. 31 and 
below, Fig. 32, as the $0^{\circ}$ direction running from left to right and the $90^{\circ}$ direction from top to bottom. This can also be seen in Fig 41 and Fig 42.

In the second test sample we were looking for indication of the strain the composite beam would experience nearest the aluminum/epoxy interface. For this data, gage locations were moved but remained $0^{\circ} / 90^{\circ}$ oriented. Moving the gages around allows for failure monitoring in areas different than for EXP 1. Noted in the future as experiment 2 (EXP 2), the "side" and "top" gage grids were aligned along the same fiber tows running in the $90^{\circ}$ reference direction around the composite. The defined "top" set of gages was bonded to the fibers directly in contact with the aluminum plate underneath. The "side" gages were located in an area where there was no direct reaction to the aluminum/composite interface. However, this data will give indication of beam reactions in the composite that may be useful. The gage configuration used in EXP 2 can be seen below in Fig 32. Again note for EXP 2, there are four $0^{\circ} / 90^{\circ}$ laminates initially wrapped around the foam beam core. This additional layer is expected to strengthen the overall stiffness of the sample, strengthening the aluminum/epoxy interface.

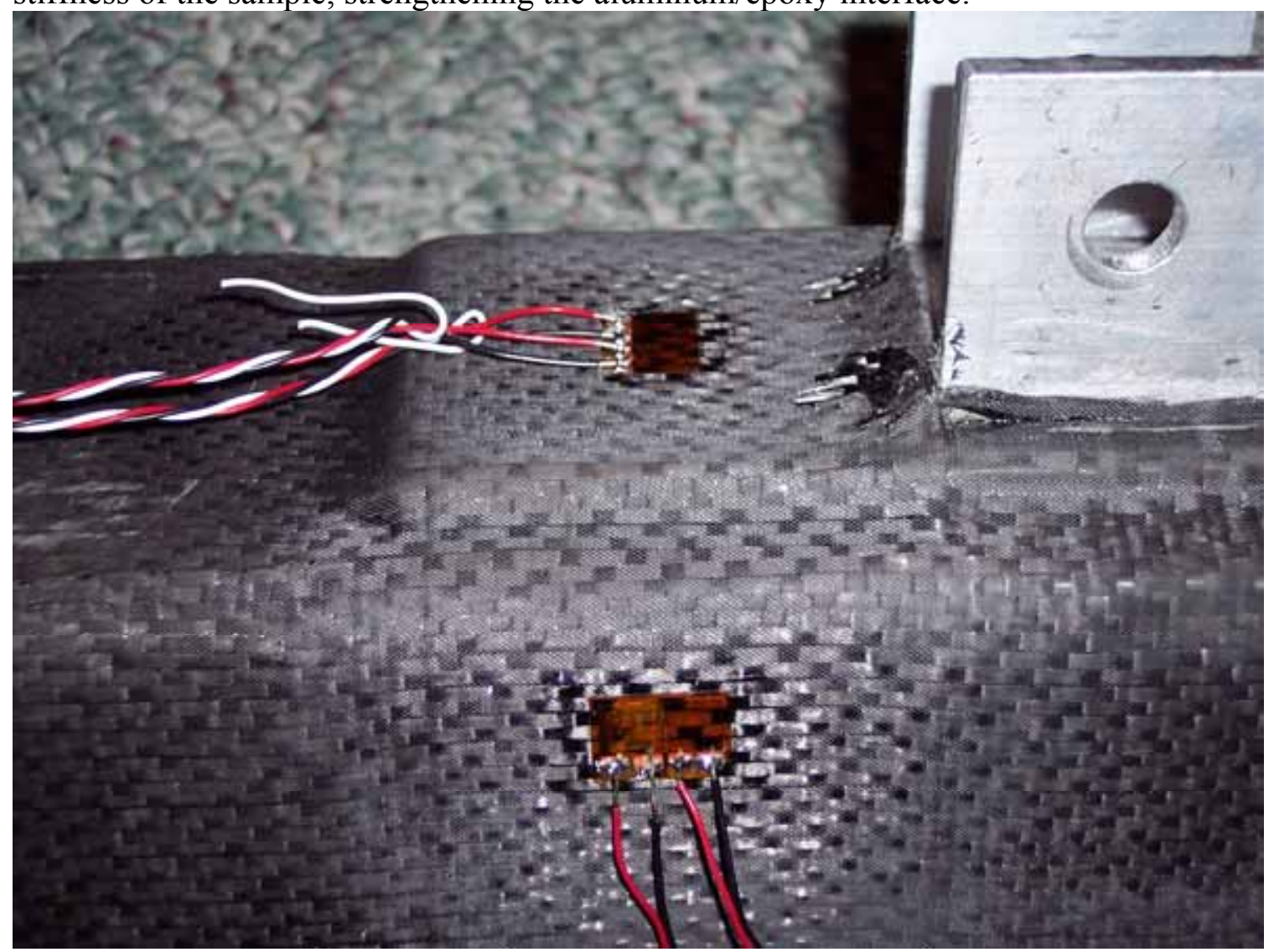

Fig. 32 Strain gage configuration used for EXP 2.

With the strain gages properly bonded and a secured sample in the test machine, the specified loading rate was applied to each sample. Two data points were collected per second in order to create the plots which follow. From these plots, conclusions can be made on just how the load is distributed through the aluminum plate, the aluminum/epoxy interface and into the composite beam sample. 
The plots in Fig. 33 seen below show the load in pounds in which it required to globally displace each sample in inches. The red line shows the results from EXP 1 and EXP 2 is represented in black. The steeper curve found from EXP 2 is our indication that the additional $0^{\circ} / 90^{\circ}$ fiber wrap did increase the overall strength of the sample as well as the aluminum/epoxy interface strength. For instance, it required $553 \mathrm{lb}$. to displace the sample $0.125 \mathrm{in}$. for EXP 2, whereas it required only $223 \mathrm{lb}$. to have the same effect in EXP 1 .

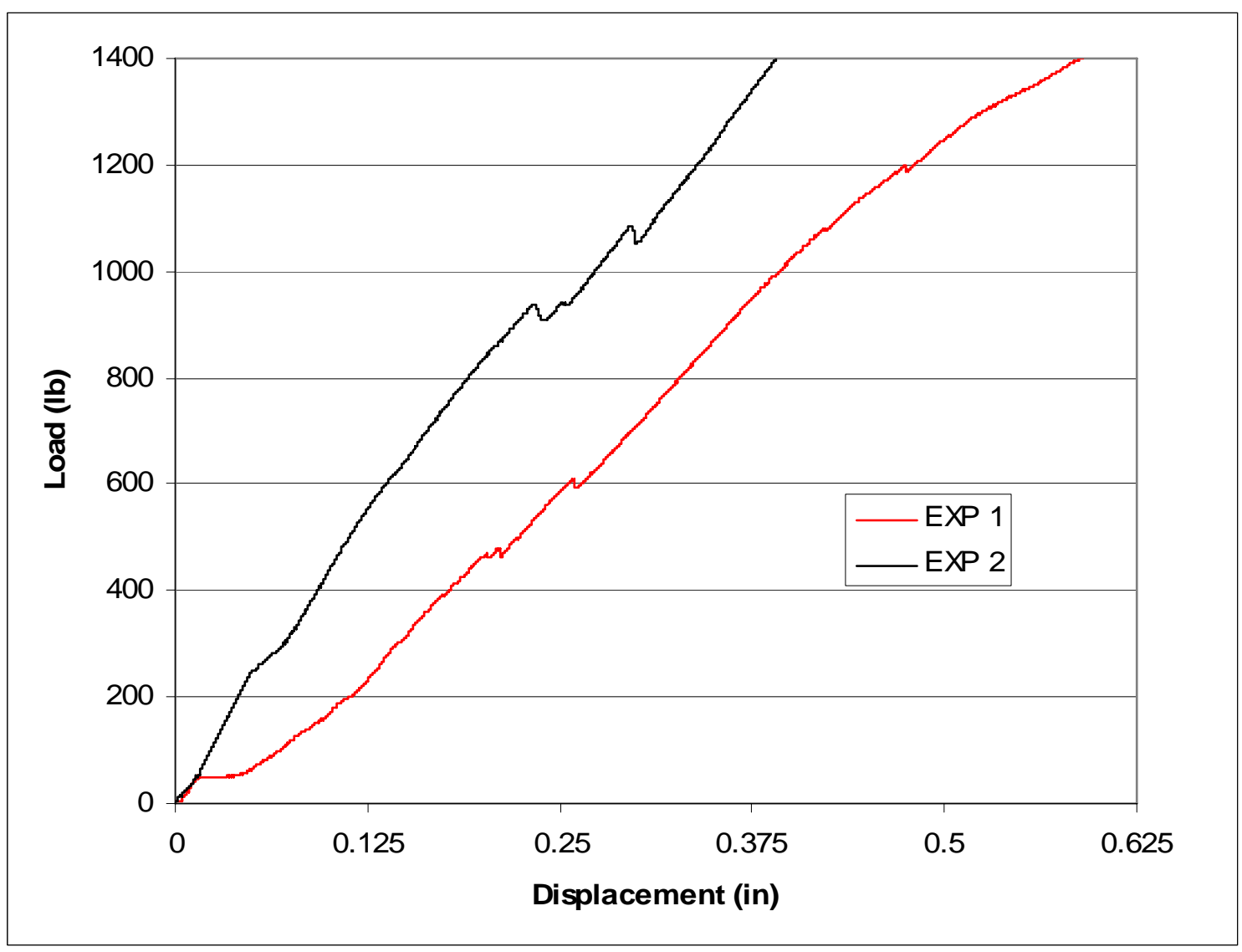

Fig. 33 Load vs. Displacement for EXP 1 and EXP 2.

The next thing to notice is the two obvious sudden failures that occurred in both experiments. These failures were found to be directly linked to the aluminum/epoxy debonding at the interface because this is considered the weakest link in the sample. The first sudden drop in the load curve indicates an initial separation in an area most likely concentrated in the applied load location. When this occurs, permanent debonding has occurred in this area at the interface. However, from previous experiments, it is known even after this initial separation, there are interfacial areas which remain adhered. The recovery of the load curve and the second sudden load decline can further illustrate these findings. It is at this second point of failure where it is assumed the previous area of debonding has rapidly expanded giving the results shown in the figure above. With a relatively steady load recovery after the second failure in both experiments, it is assumed the aluminum/epoxy interface at this point has little to no support in carrying further load increases. Data collected indicating failures in both experiments are found below in Table 5 which gives the load, the corresponding displacement and time values. 
Table 5 Failure data.

\begin{tabular}{|c|c|c|c|c|c|c|}
\hline & \multicolumn{3}{|c|}{ First Failure } & \multicolumn{3}{c|}{ Second Failure } \\
\hline EXP 1 & Load (lb) & Displacement (in) & Time (s) & Load (lb) & Displacement (in) & Time (s) \\
\hline peak & 480 & 0.214 & 457 & 611 & 0.263 & 560.5 \\
\hline valley & 463 & 0.216 & 460.5 & 592 & 0.264 & 563 \\
\hline recovery & 480 & 0.220 & 470 & 611 & 0.271 & 577.5 \\
\hline differences & 17 & 0.006 & 13 & 19 & 0.008 & 17 \\
\hline & \multicolumn{5}{|c|}{ First Failure } & \multicolumn{3}{c|}{ Second Failure } \\
\hline EXP 2 & Load (lb) & Displacement (in) & Time (s) & Load (lb) & Displacement (in) & Time (s) \\
\hline peak & 939 & 0.234 & 500.5 & 1087 & 0.296 & 632 \\
\hline valley & 908 & 0.239 & 510.5 & 1051 & 0.300 & 639.5 \\
\hline recovery & 939 & 0.256 & 547 & 1087 & 0.309 & 659.5 \\
\hline differences & 31 & 0.022 & 46.5 & 36 & 0.013 & 27.5 \\
\hline
\end{tabular}

From the data above, additional observations can be made about the aluminum/epoxy interface. The time in which it took the sample to recover after an interfacial failure indicates the severity of the debonding. For instance, in EXP 1 it only required 13 seconds for recovery to the peak load before failure. The displacement recorded during this time of first failure was 0.006 inches. For EXP 2 the first failure resulted in a 46.5 second complete recovery time, with 0.022 inches of displacement. These results would suggest the initial interfacial debonding in EXP 2 was much more severe most likely due to the almost $96 \%$ increase in required load just before first failure. An increase in debonded area during this more catastrophic failure would explain the 33.5 second increase in recovery time for EXP 2 over EXP 1 during first failure. This would also be the explanation for the increase in recovery time found during second failure as well.

Further indication of more severe interfacial damage due to higher loads can be represented by comparing the amount in which the load required to cause deformation dropped from peak to valley before recovery for each experiment during specific failure. For EXP 1 the difference in which the load drop, from peak to valley, increased from first failure (lower load) to second failure (higher load) was around $12 \%$. In EXP 2 the increase in load drop during first failure (31 lb.) compared to second failure (36 lb.) showed around a $16 \%$ increase. This increase in percentages further supports that the higher loads found in EXP 2 will cause more severe interfacial damage once debonding initiates, even though initiation occurs at an optimal higher load.

With an indicated two stage interfacial debonding failure for both experiments, it was examined to see if the strain results would indicate similar conclusions. Again, for EXP 1 first failure was recorded at $480 \mathrm{lb}$. and $611 \mathrm{lb}$. for second failure using the displacement plot. A comparison was made with the strain behavior during this indicated first and second recorded failure using Fig. 34 showing the strain vs. time results from the top $0^{\circ} / 90^{\circ}$ gage matrix in EXP 1 . 


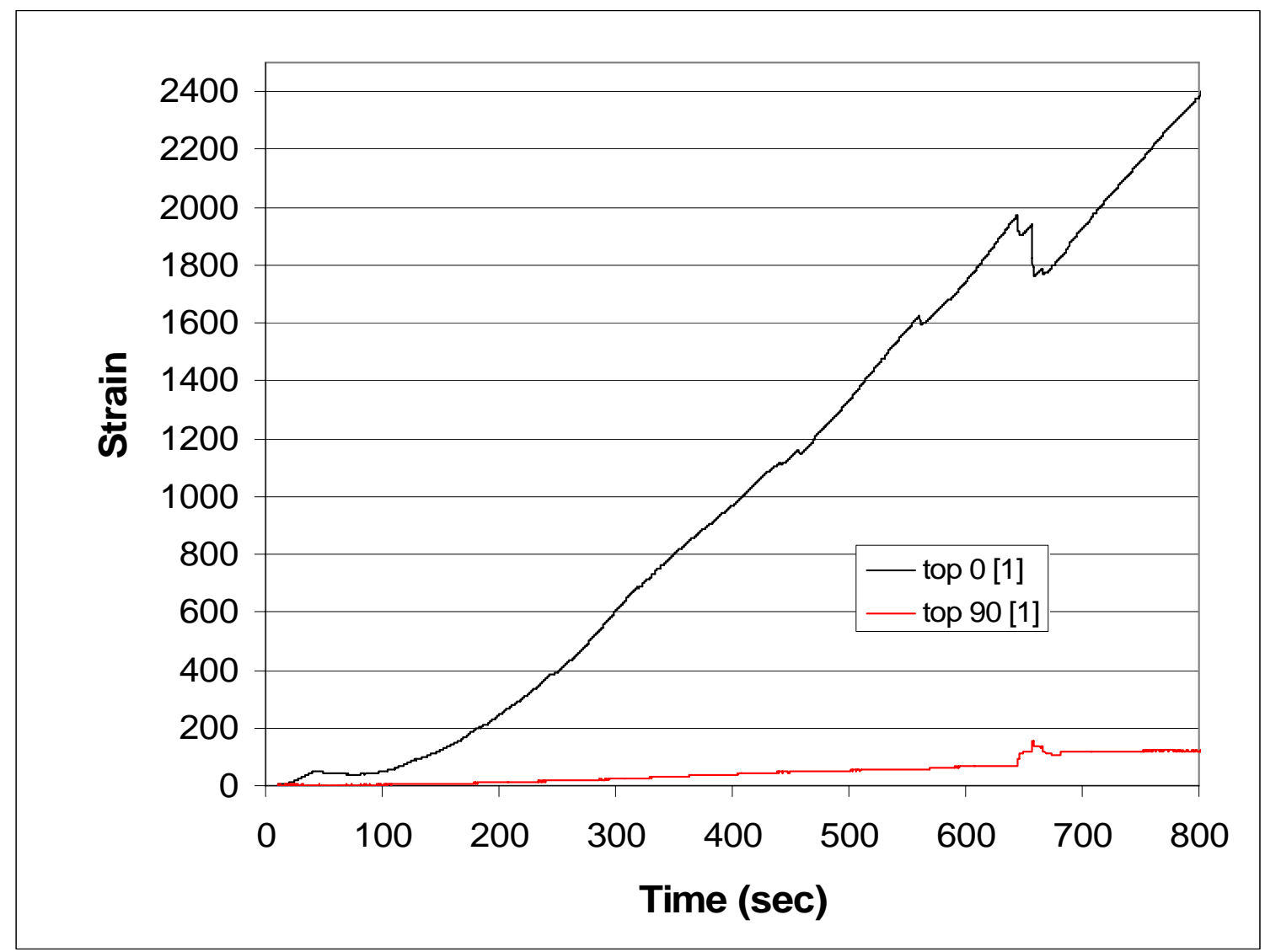

Fig. 34 EXP 1 Strain vs. Time at top gage location.

From the plots shown above, it can be seen the maximum amount of strain at this location occurs in the $0^{\circ}$ direction. The jumps in the recorded strain implying a strain reaction to the interfacial failures defined from the displacement plot does occur at the 480 and $611 \mathrm{lb}$. loads. These reactions are small in comparison to a third reaction observed, which is assumed to happen during a final major debonding stage. This major strain reaction did not occur in the top set of gages until $708 \mathrm{lb}$. where it was previously reported second debonding occurred at $611 \mathrm{lb}$. The stain decreased once it reached this load from $1973.9 \mu \varepsilon$ to $1921.9 \mu \varepsilon$ in the $0^{\circ}$ direction and increased from $70.238 \mu \varepsilon$ to $91.779 \mu \varepsilon$ in the $90^{\circ}$ within 0.5 seconds.

The delay in stain reactions observed is assumed to be the result of the gage location itself. The $611 \mathrm{lb}$. failure was recorded by the global displacement of the entire sample. Because the gages were not located in an area closest to where second debonding occurred, they were unable to immediately capture the reaction displayed by the global displacement plot. From these results it can be assumed debonding in the area of the $0^{\circ} / 90^{\circ}$ strain gages located on the downhill side of the aluminum/epoxy interface does not occur until around $708 \mathrm{lb}$., in which time the entire downhill area of the aluminum/epoxy interface is assumed to have become debonded for EXP 1.

The $0^{\circ} / 90^{\circ}$ strain reactions recorded for the same experiment for the side set of gages can be seen below in Fig. 35. The major strain reaction in the $0^{\circ}$ direction was recorded at $687 \mathrm{lb}$. where the stain decreased from $3674.5 \mu \varepsilon$ to $3252.6 \mu \varepsilon$. In the $90^{\circ}$ direction at a load of $621 \mathrm{lb}$. the strain began its decrease starting with a drop from 
$111.55 \mu \varepsilon$ to $92.565 \mu \varepsilon$ within a second. This strain reaction again does not directly correspond to the previously indicated debonding at $611 \mathrm{lb}$. It again is assumed that this strain reaction is only linked to the interfacial debonding localized around the gage locations and not where debonding initiates on a global scale.

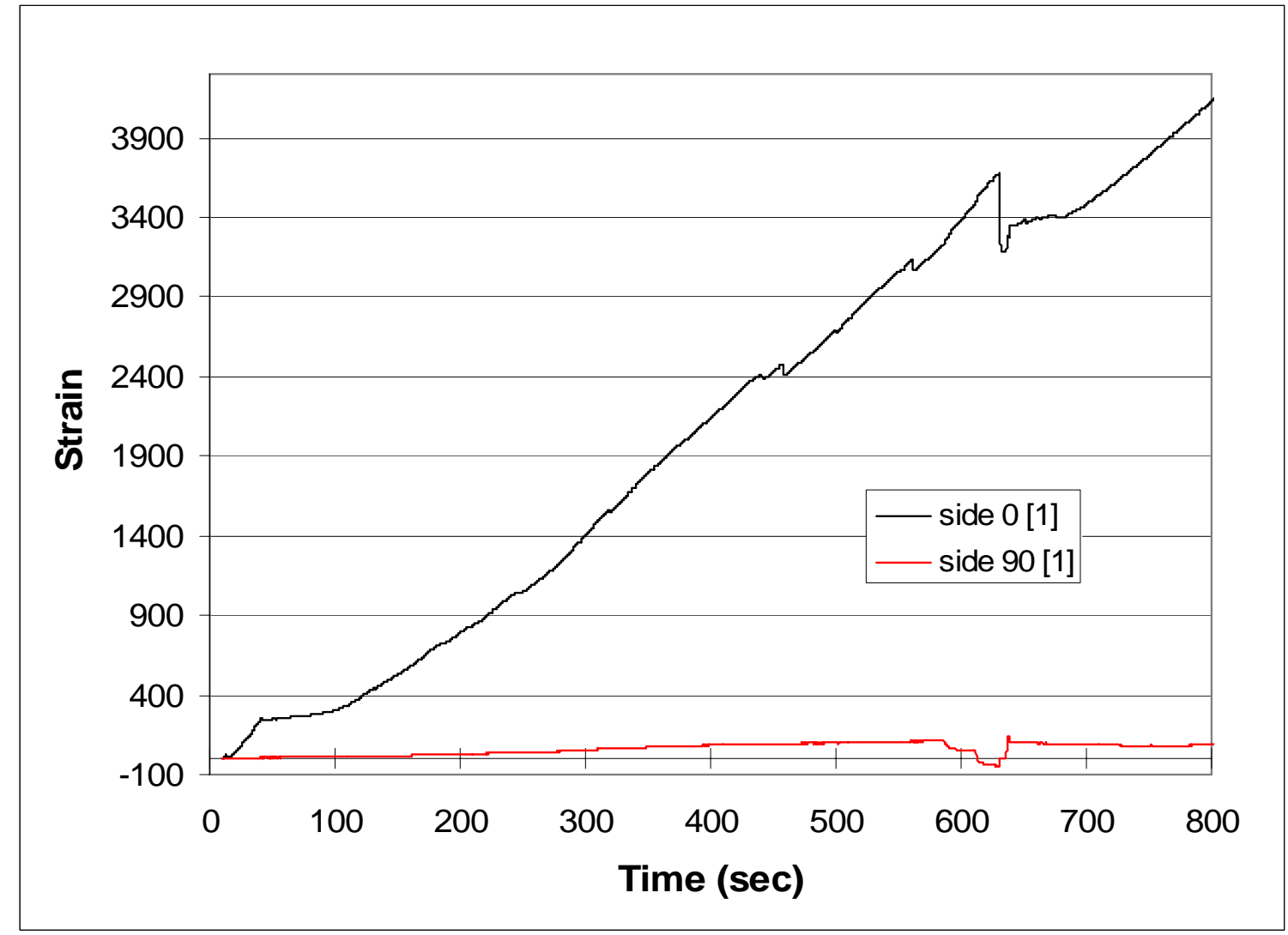

Fig. 35 EXP 1 Strain vs. Time at side gage location.

Further comparison between gage location shows it required $21 \mathrm{lb}$. less load to initiate interfacial debonding in the side gage location. This result is expected because again this $0^{\circ} / 90^{\circ}$ gage matrix is located closer to the point of applied load where it has been reported interfacial debonding initiates and then propagates outwards toward the location of the top gage matrix. This would explain why the side gage matrix experiences failure before the top gage matrix.

For EXP 2 the different location of the top strain gage matrix gave a much closer correlation to the indicated debonding failures displayed by the load vs. displacement curve. Stain vs. time plots for the $0^{\circ} / 90^{\circ}$ directions are seen below in Fig. 36. The first major strain reaction recorded for EXP 2 in the top set of gages was at $939 \mathrm{lb}$. where the stain decreased from $409.33 \mu \varepsilon$ to $408.38 \mu \varepsilon$ in the $0^{\circ}$ direction and from $194.53 \mu \varepsilon$ in to $194.06 \mu \varepsilon$ in the $90^{\circ}$ within 0.5 seconds. It was previously recorded at this same load (939 lb.) a jump in the load vs. displacement plot indicated first stage interfacial debonding. Furthermore, second failure indicated at $1087 \mathrm{lb}$. in the top $0^{\circ} / 90^{\circ}$ gages further corresponds to the previous failure observed in the EXP 2 displacement plot. At this load the strain decreased from $488.10 \mu \varepsilon$ to $487.63 \mu \varepsilon$ in the $0^{\circ}$ direction and from $220.32 \mu \varepsilon$ in to $219.38 \mu \varepsilon$ in the $90^{\circ}$. 


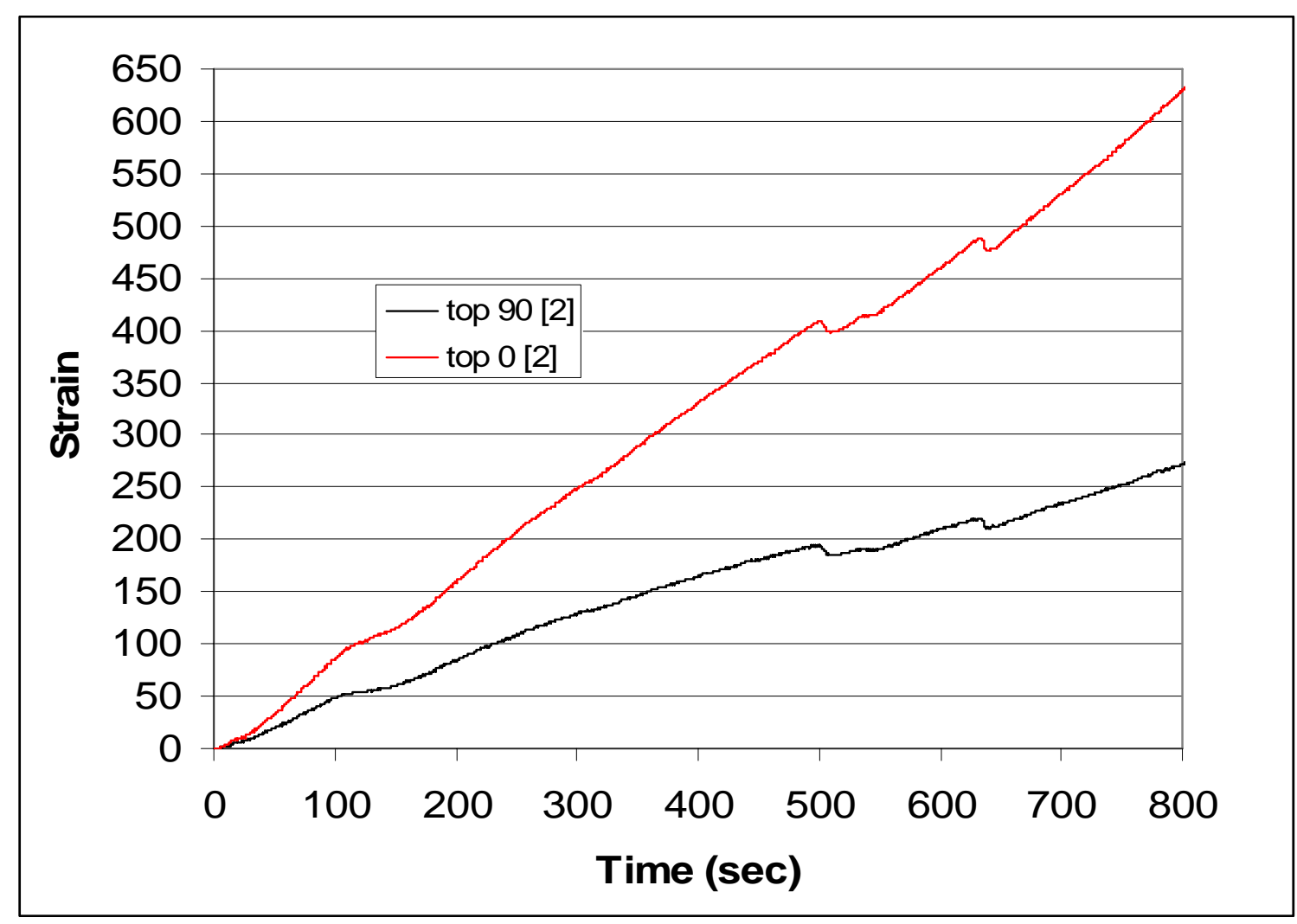

Fig. 36 EXP 2 Strain vs. Time at top gage location.

As discussed and illustrated, there is a directed correlation between acquired strain reactions in the top gage matrix and the global displacement for both stages of debonding failure in EXP 2. Again, the gage results are from a localized area directly over the aluminum/epoxy interface, so these strain results would indicate that the strain values given from the top $0^{\circ} / 90^{\circ}$ gages in EXP 2 are concurrent with the debonding stages that are observed by the jumps in the load vs. displacement plot for EXP 2.

It was found that the side gages for this experiment were too far removed from the attachment and were not useful in conclusions. Therefore, the next step was to cut away the fiber wrap over the aluminum, Fig. 37, in order to observe and make comparisons of the interfacial fracture surfaces. It is important to point out these last two experiments were not subjected to the extreme loading used in the previous experiment having the similar $0^{\circ} / 90^{\circ}$ laminate wrap over the aluminum plate. This was done in order to hopefully gain a better understanding of the debonding at the interface and not catastrophic failure of the sample. From the previous fracture surface with the matrix splintering, it was difficult to specify exactly what happened initially across the interface. 


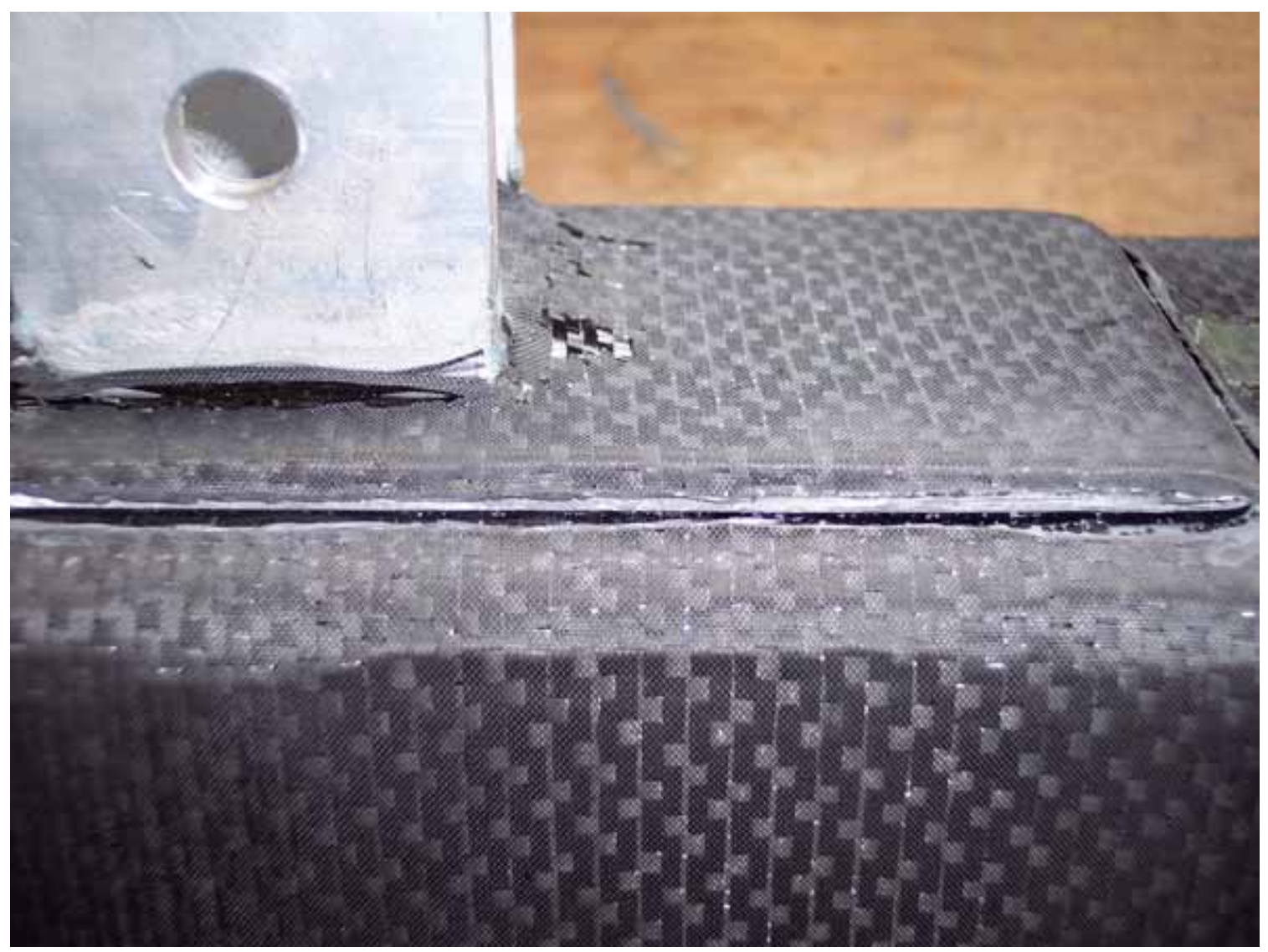

Fig. 37 Fibers cut away for inspection.

It required considerable amount more corner prying force to completely separate the aluminum/epoxy interface for these tests. This is a good indication that the facture surfaces observed from EXP 1 and EXP 2 can be assumed linked to initial debonding since it appears a significant bonded area remains at the interface after testing. Fracture surfaces from these experiments can be seen in the figures which follow. 


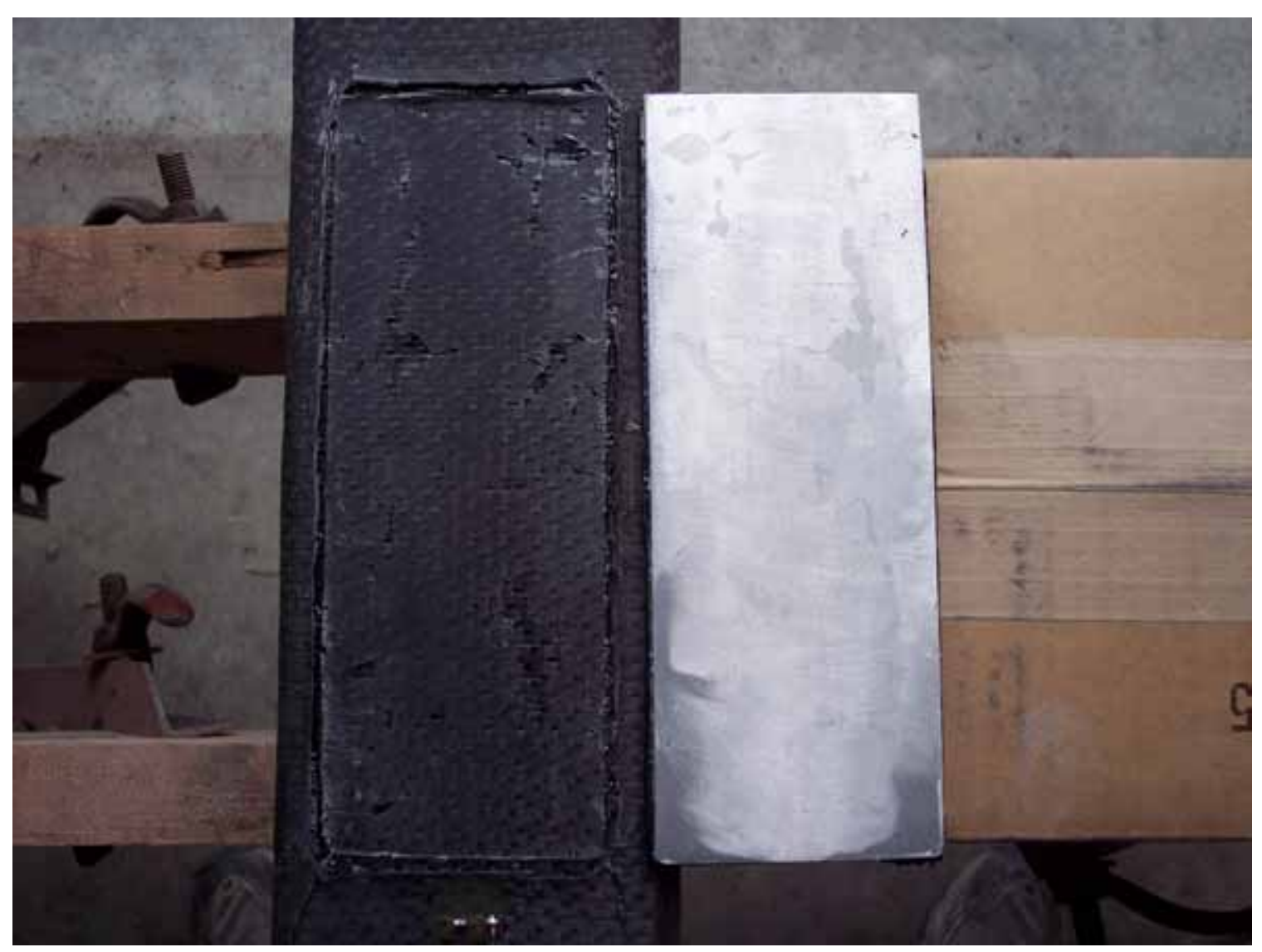

Fig. 38 EXP 1 Interfacial fracture surface.

The damage seen above appears more random than was expected. The dark regions on the composite surface again represent areas where epoxy remains adhered to the aluminum. Previously it was reported that these areas could be where the stress concentrations are the highest due to the applied load distribution. This assumption appears to again hold true, but it should also be considered the method used for complete separation. The prying action used at an aluminum corner completely changes the loading conditions to which cause final debonding.

The majority of the dark regions seem to be located on what would have been the uphill end, or the upper-half as seen above, during the sample test. This was also the end where the prying force was applied, the upper right corner seen above, to create separation in order to observe interfacial fracture surfaces. This evidence supports the assumption that the regions where epoxy remains adhered to the aluminum are linked to a concentration of load distribution. The large dark region seen on the downhill end would be a probable indication of initial failure. This is again a region that would see initial load concentration during testing and is most likely where debonding initiates. 


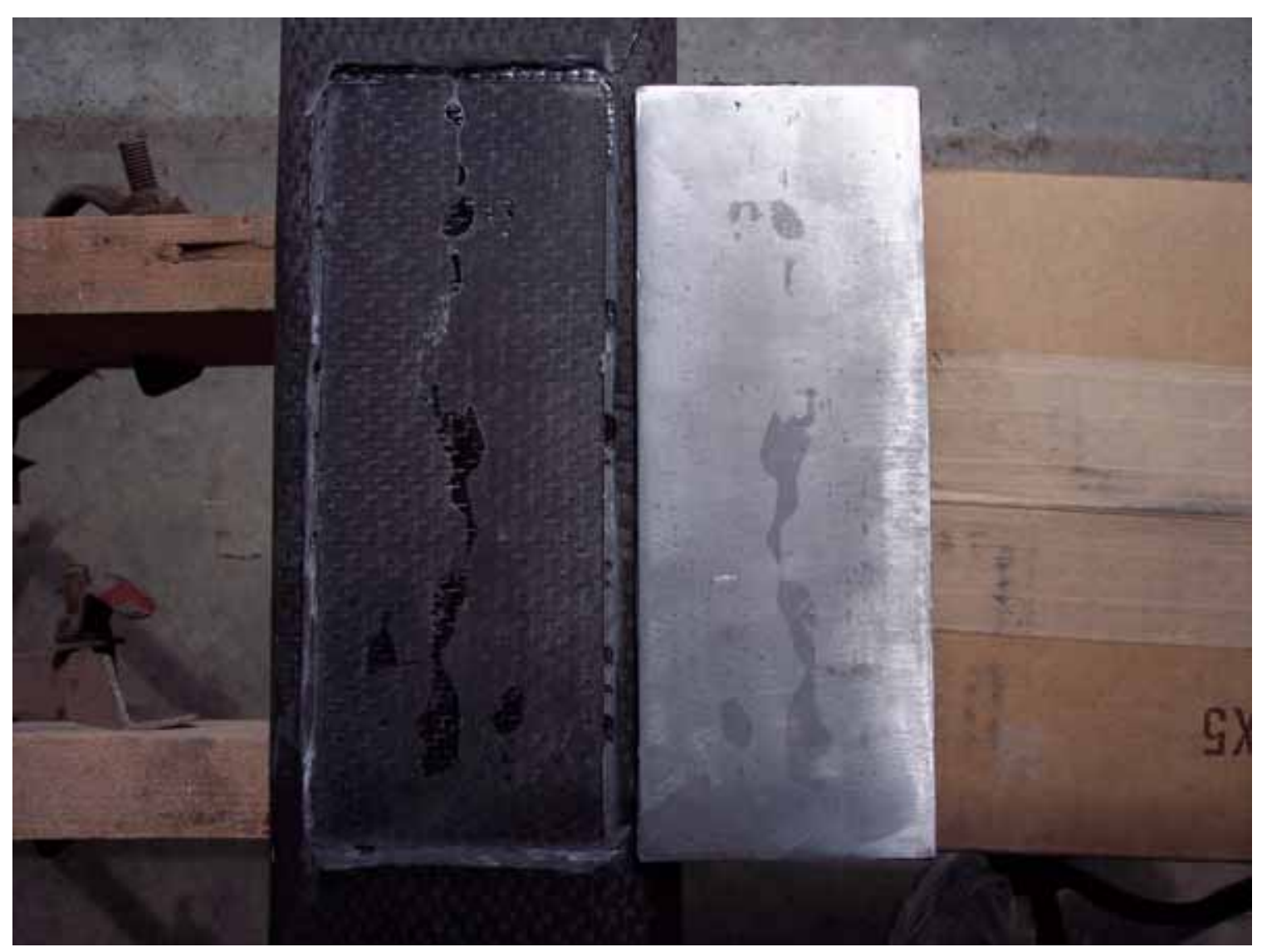

Fig. 39 EXP 2 Interfacial fracture surface.

The fracture surfaces for EXP 2 are seen in Fig. 39 above. From the previously illustrated strain gage plot there was an indication of two major failures during testing, the first at $939 \mathrm{lb}$. and the second at $1087 \mathrm{lb}$. As seen above, there are also two larger dark regions found along the center on the downhill end where major debonding is expected. This is also the general location of the top gage which was used to create the plot seen previously in Fig. 36. These results would further support the assumption that the jumps in the strain plots are linked to a sudden debonding at the interface where epoxy remains adhered to the aluminum.

\subsection{Experimental Verification}

It is necessary to now verify the assumptions made during the experimental discussion. A free body diagram (FBD) of the attachment surface will allow for recorded strain readings to be verified. FBD equations will be compared with experimental stains and give indication on what is happening in the $0^{\circ} / 90^{\circ}$ fibers at gage locations. This will allow for a relation between strain and debonding to be made.

As defined earlier, the applied load occurs at a $60^{\circ}$ angle relative to the top surface of the composite sample. This creates multiple loading conditions. The load transfer in the shear direction is found by multiplying the applied load by the cosine of the loading angle. Tensile load is found by multiplying the applied load by the sine of the loading angle. There is also the contribution of the moment which is created. A single equilibrium couple load can is used to represent this moment across the $8 \times 3$ in. bond 
interface using the equation; $\mathrm{P}=3 \mathrm{M} / 2 \ell$. Using these loading conditions, max stresses are defined in both the tension and shear directions across the adhesive bond area. This information will allow for conclusions to be drawn on the ultimate strength of the aluminum/epoxy adhesive bond.

The test defined earlier as experiment A, using the aluminum/epoxy adhesive bond as the only means of attachment, provides information on the stresses the bond alone can carry. Results showed complete bond failure and aluminum separation from the composite at $250 \mathrm{lbs}$. FBD equations were used as listed in the Appendix to create Table 6 found below.

Table 6 Calculated aluminum/epoxy interfacial failure data.

\begin{tabular}{|c|c|c|c|c|c|c|c|c|}
\hline F (lb) & $\mathrm{F}_{\mathrm{x}}(\mathrm{lb})$ & $\mathrm{F}_{\mathrm{y}}(\mathrm{lb})$ & M (lb.in) & $\mathrm{P}(\mathrm{lb})$ & $\begin{array}{c}\sigma_{\text {tension }} \\
\text { (psi) }\end{array}$ & $\begin{array}{c}\sigma_{\mathrm{M}} \\
(\mathrm{psi})\end{array}$ & $\begin{array}{c}\boldsymbol{\sigma} \\
(\mathrm{psi})\end{array}$ & $\begin{array}{c}\boldsymbol{\sigma}_{\text {shear }} \\
\text { (psi) }\end{array}$ \\
\hline 0 & 0 & 0 & 0 & 0 & 0 & 0 & 0 & 0 \\
\hline 10 & 5 & 8.66 & 6.88 & 1.29 & 0.36 & 0.43 & 0.79 & 0.21 \\
\hline 20 & 10 & 17.3 & 13.75 & 2.58 & 0.72 & 0.86 & 1.58 & 0.42 \\
\hline 30 & 15 & 25.9 & 20.63 & 3.87 & 1.08 & 1.29 & 2.37 & 0.63 \\
\hline 40 & 20 & 34.6 & 27.50 & 5.16 & 1.44 & 1.72 & 3.16 & 0.83 \\
\hline 50 & 25 & 43.3 & 34.38 & 6.45 & 1.80 & 2.15 & 3.95 & 1.04 \\
\hline 60 & 30 & 51.9 & 41.25 & 7.73 & 2.17 & 2.58 & 4.74 & 1.25 \\
\hline 70 & 35 & 60.6 & 48.13 & 9.02 & 2.53 & 3.01 & 5.53 & 1.46 \\
\hline 80 & 40 & 69.3 & 55.00 & 10.31 & 2.89 & 3.44 & 6.32 & 1.67 \\
\hline 90 & 45 & 77.9 & 61.88 & 11.60 & 3.25 & 3.87 & 7.11 & 1.88 \\
\hline 100 & 50 & 86.6 & 68.75 & 12.89 & 3.61 & 4.30 & 7.91 & 2.08 \\
\hline 110 & 55 & 95.3 & 75.63 & 14.18 & 3.97 & 4.73 & 8.70 & 2.29 \\
\hline 120 & 60 & 103.9 & 82.50 & 15.47 & 4.33 & 5.16 & 9.49 & 2.50 \\
\hline 130 & 65 & 112.6 & 89.38 & 16.76 & 4.69 & 5.59 & 10.28 & 2.71 \\
\hline 140 & 70 & 121.2 & 96.25 & 18.05 & 5.05 & 6.02 & 11.07 & 2.92 \\
\hline 150 & 75 & 129.9 & 103.13 & 19.34 & 5.41 & 6.45 & 11.86 & 3.13 \\
\hline 160 & 80 & 138.6 & 110.00 & 20.63 & 5.77 & 6.88 & 12.65 & 3.33 \\
\hline 170 & 85 & 147.2 & 116.88 & 21.91 & 6.13 & 7.30 & 13.44 & 3.54 \\
\hline 180 & 90 & 155.9 & 123.75 & 23.20 & 6.50 & 7.73 & 14.23 & 3.75 \\
\hline 190 & 95 & 164.5 & 130.63 & 24.49 & 6.86 & 8.16 & 15.02 & 3.96 \\
\hline 200 & 100 & 173.2 & 137.50 & 25.78 & 7.22 & 8.59 & 15.81 & 4.17 \\
\hline 210 & 105 & 181.9 & 144.38 & 27.07 & 7.58 & 9.02 & 16.60 & 4.38 \\
\hline 220 & 110 & 190.5 & 151.25 & 28.36 & 7.94 & 9.45 & 17.39 & 4.58 \\
\hline 230 & 115 & 199.2 & 158.13 & 29.65 & 8.30 & 9.88 & 18.18 & 4.79 \\
\hline 240 & 120 & 207.8 & 165.00 & 30.94 & 8.66 & 10.31 & 18.97 & 5.00 \\
\hline 250 & 125 & 216.5 & 171.88 & 32.23 & 9.02 & 10.74 & 19.76 & 5.21 \\
\hline
\end{tabular}

This low strength displayed by the bond alone is the reason additional steps were taken to improve the aluminum/composite attachment technique. Using the results from EXP 2 defined above, further calculations support the displayed strengthening of the 
bond. As previously stated, an indication of initial adhesion bond failure occurred at 939 lb. for this experiment. The calculated bond stresses for this load resulted in:

$$
\begin{aligned}
& \sigma_{\text {shear }}=19.56 \mathrm{psi} \\
& \sigma=74.23 \mathrm{psi}
\end{aligned}
$$

At this point it is assumed the fibers laminated over the aluminum plate transfer the additional 54.47 psi in tensile direction and 14.35 psi in the shear direction away from the aluminum/epoxy interfacial bond and into the composite beam.

To give indication of just how much this laminate wrap could withstand, conclusions were drawn using modified free body diagram equations. The moment stress was found using $\sigma_{\mathrm{m}}=\mathrm{Mc} / \mathrm{I}$. The additional stresses were calculated as mentioned above. Engineering values used in calculations for the laminate were taken from Table 7 below. These calculations can be found in the Appendix.

Calculations show for the given loading applications, it can be assumed fiber breakage in the laminate wrap will not occur until a $6,859 \mathrm{lb}$. load is reached. It is here where it is assumed only the area of fibers around the sides of the aluminum plate is carrying the additional load and the beam is supported, as seen in Appendix Fig. 2A. Here the ultimate shear strength of the laminate $(18,000 \mathrm{psi})$ will have been reached. At this load, the resulting tensile stress would only be $42,092.89 \mathrm{psi}$, where the ultimate tensile strength of the laminate is 322,000 psi.

Table 7 Typical epoxy composite properties.

(at room temperature)

\begin{tabular}{|c|c|c|}
\hline Properties & U.S. Units & SI Units \\
\hline Tensile strength & $322,000 \mathrm{psi}$ & $2,221 \mathrm{MPa}$ \\
\hline Tensile modulus & $20.5 \times 10^{6} \mathrm{psi}$ & $141 \mathrm{GPa}$ \\
\hline Flexural strength & $250,000 \mathrm{psi}$ & $1,725 \mathrm{MPa}$ \\
\hline Flexural modulus & $18.5 \times 10^{6} \mathrm{psi}$ & $128 \mathrm{GPa}$ \\
\hline Short-beam shear strength & $18,000 \mathrm{psi}$ & $124 \mathrm{MPa}$ \\
\hline Fiber volume & $62 \%$ & $62 \%$ \\
\hline
\end{tabular}

Calculations support that even with complete debonding at the aluminum/epoxy interface, the aluminum plate will remained attached to the composite until the fibers wrap begins to break away. The increase in max load required until failure is reached proves the advantage and the necessity of the reinforcement wrap. During fatigue, damage can accumulate to the point where the adhesive bond at the interface can no longer perform. However, the shock mount is not expected to catastrophically break away from the suspension member at this point, possibly leading to loss of vehicle control.

A comparison between the experimental strain and calculated strain is the next to be made. With the gages in EXP 1 being located on the fibers directly attaching the aluminum plate to the composite beam, only this area of fibers was used in FBD equations. The calculated tensile strain found in these fibers was represented in the side $90^{\circ}$ gage. This is expected, given the location of the gage directly under the point of applied tensile load $\mathrm{F}_{\mathrm{y}}$. The calculated shear strain was seen in the top $90^{\circ}$ gage. The equations which show these calculations are found in the Appendix. 
It was noted however the maximum amount of strain is found in the $0^{\circ}$ fiber directions for EXP 1. This result is linked the means for which the sample was bolted to the frame. The clamping force of the steel washer due to the applied load, created a load concentration in these gages. Data from the $0^{\circ}$ gages were found inconsistent with FBD calculations and were not plotted for this reason. The experimental vs. calculated strain plots for EXP 1can be found below in Fig. 40.

From the plots below, we can see the comparison of the side $90^{\circ}$ gage reading with the calculated tensile strain. Also seen is the close relation between the top $90^{\circ}$ gage and the calculated shear strain. In both cases, the calculated strain was found to be higher than the gage strain reading. This finding is supported knowing the bi-directional makeup of the fabric weave has the ability to transfer load across the laminate.

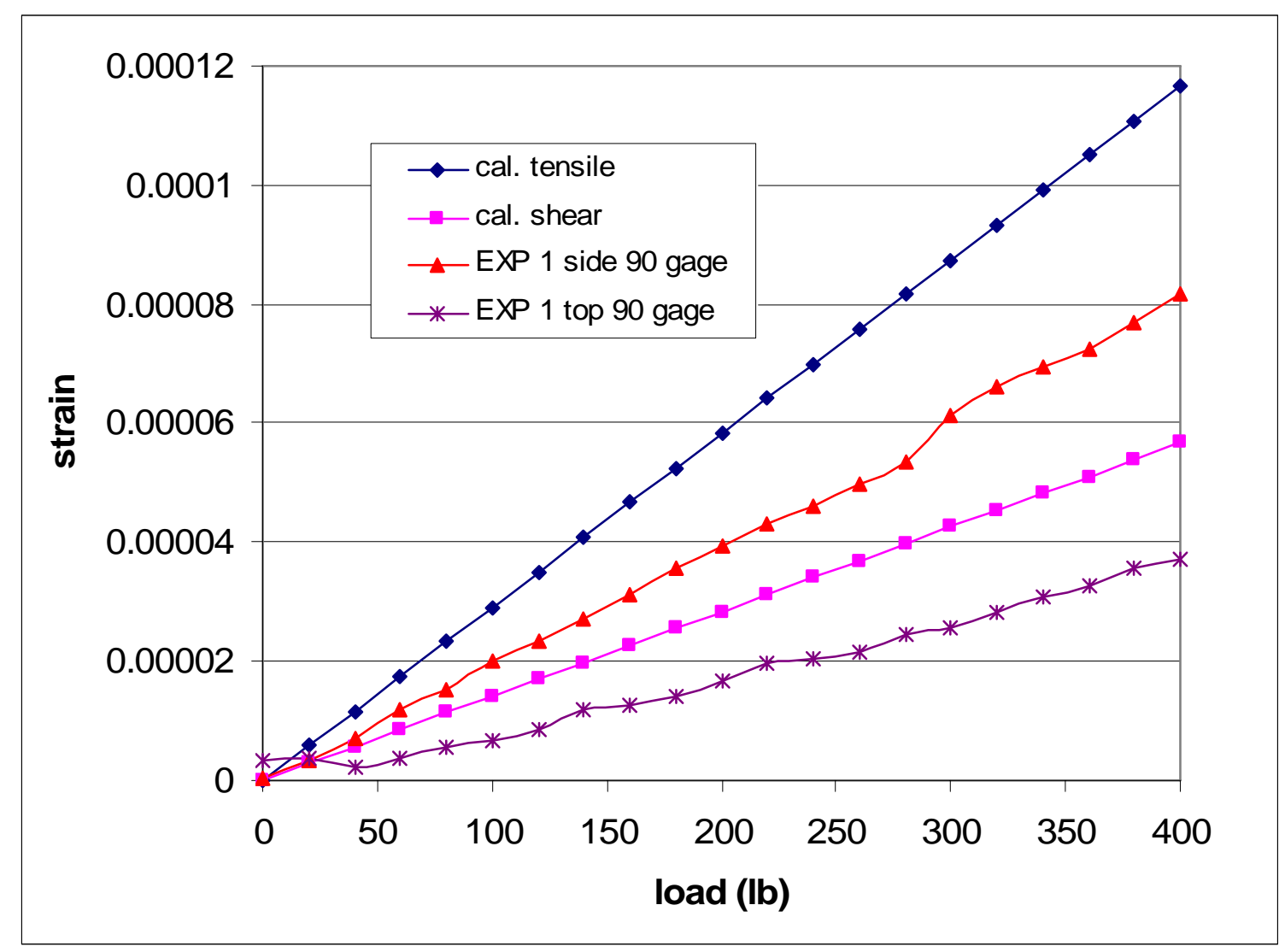

Fig. 40 EXP 1 strain vs. calculated strain. 
EXP 1 Strain gage configuration

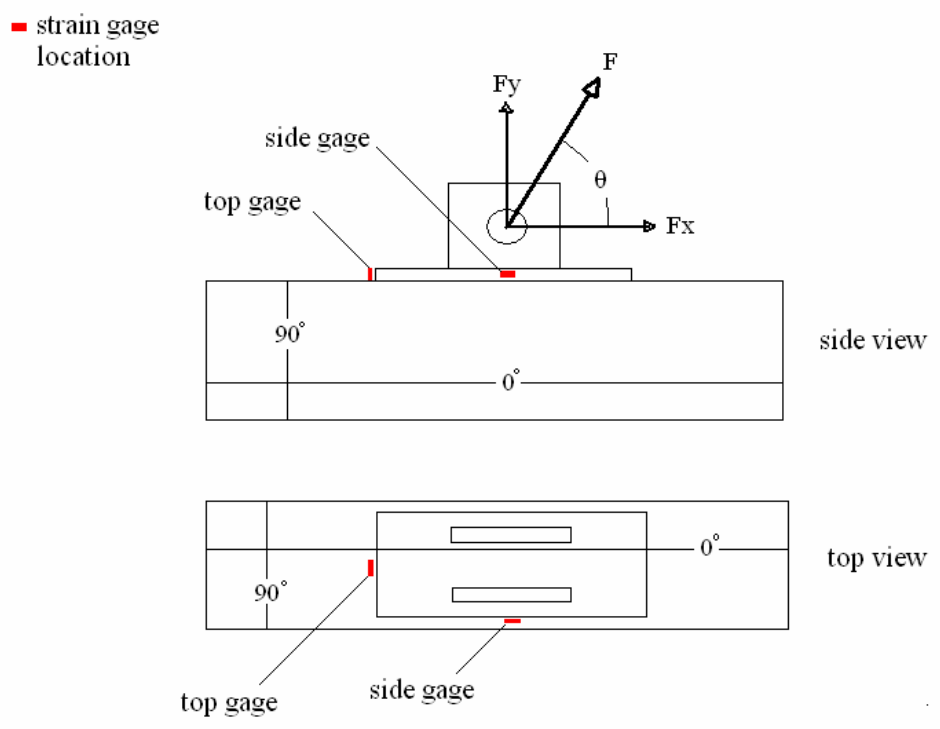

Fig. 41 Orientation of strain gages in EXP 1.

For EXP 2, we will treat the entire sample as a supported beam at the two bolt locations. In doing so, the top gage used for this experiment can be represented by FBD equations. A moment bending equation used to find the bending stress in the composite beam provided the plot of calculated bending strain found in Fig. 42 below. This calculated strain was plotted against the experimental results from the top gage in EXP 2 to make comparison.

It is seen from these EXP 2 plots, the strain readings in the top gage were less than the predicted calculated values found in the Appendix. This is again explained by the poisson effect due to the woven fiber laminate and the distribution of bending loads. In any case, fibers along the $0^{\circ}$ direction are expected to see the maximum of the applied bending load, and they do. As would be expected, the top $90^{\circ}$ gage for EXP 2 does show some of this calculated bending load. However, as seen, it is less strain due to bending than what the $0^{\circ}$ fibers experience. This illustrates the ability of loads to be transferred from fiber to fiber across the matrix. 


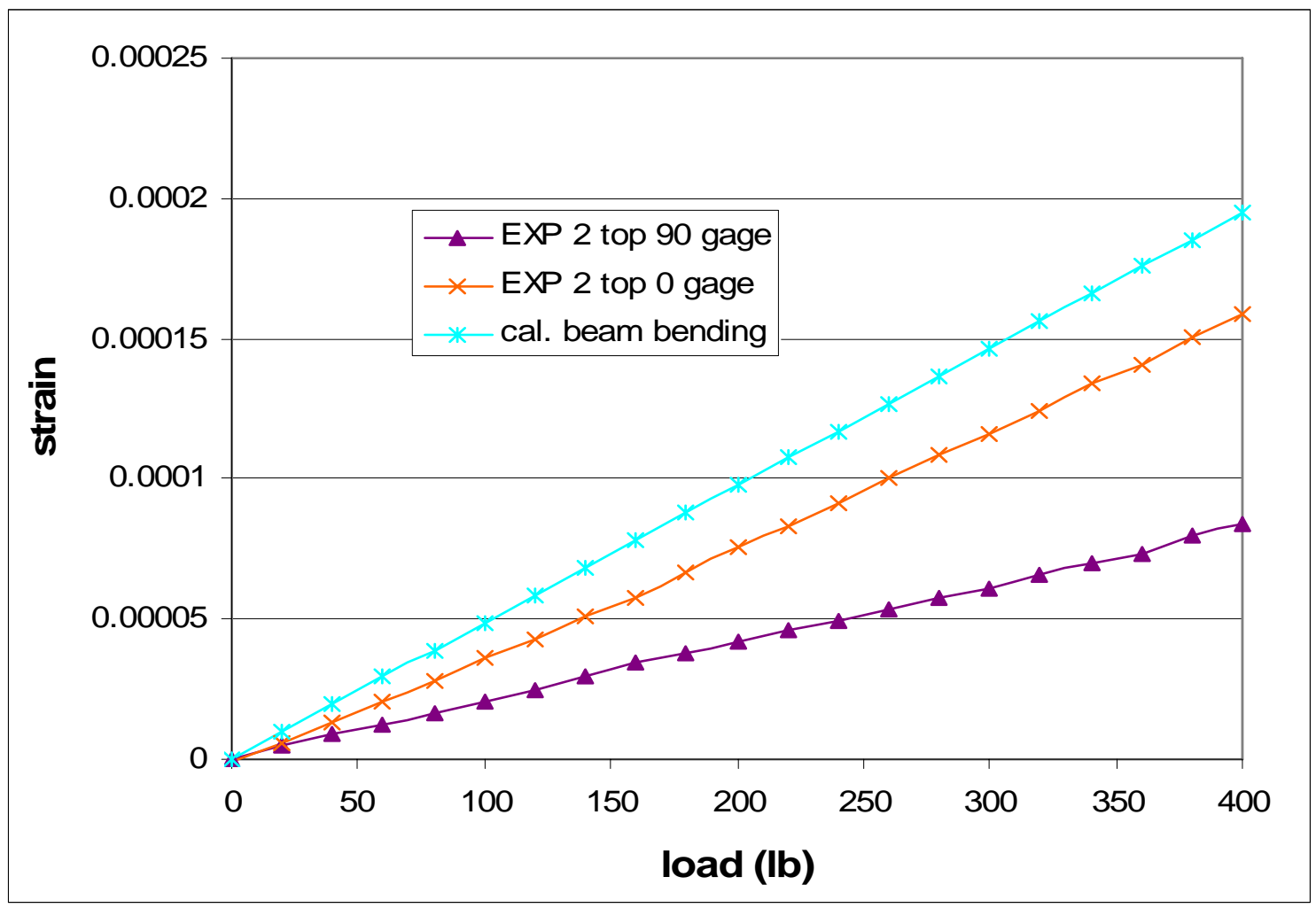

Fig. 42 EXP 2 strain vs. calculated strain.

EXP 2 Strain gage configuration

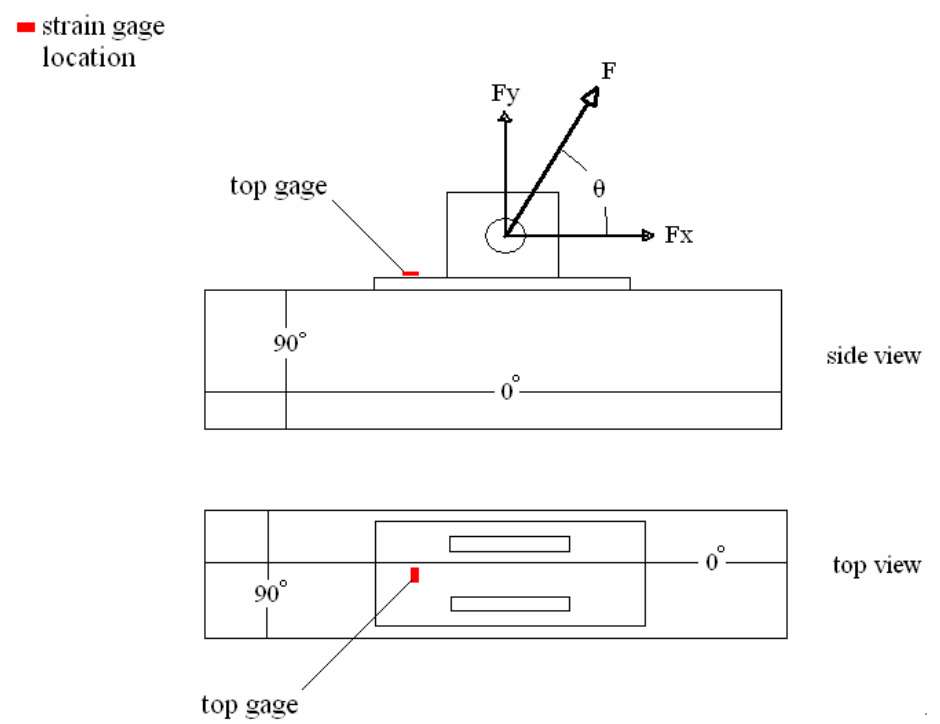

Fig. 43 Orientation of strain gage in EXP 2. 


\section{CHAPTER SEVEN}

\section{CONCLUSIONS}

An optimal composite suspension component would start with design. The design engineer must first know the magnitude of the loads in which the part will experience during operation. For suspension components, these loads can become extreme and sudden. With proper fiber alignment to withstand such loading and limit deformation, an optimal composite design can be reached.

For a design where an aluminum/composite interface is present there is an added complication. The bond strength between the aluminum and composite is assumed to be the weakest link and was researched. With the following suggestions, advancements can be made in strengthening this bond and making the use of carbon/epoxy hybrid composites even more appealing.

The type of loading the aluminum/epoxy interface experiences can determine a surface treatment that will best enhance the bond strength. Research suggests for a combined shear/tension load, the PAA coupled with silane treatment using a high temperature epoxy would be an optimal surface treatment for use in the experiment which was conducted. The effect of improving the interlocking mechanism is detailed in Section 4.3. Under wet conditions, further surface treatments may become necessary to limit the micro-battery effect outlined in Section 4.5.

From experimental results advancements were also made. The first was the indication that a stiffer composite sample will reduce interfacial deformation linked to debonding. As illustrated in Fig. 11, the mold was made by gluing three pieces of white foam board together. By wrapping each individual piece with a composite laminate, this will essentially create three composite beams in which are then bonded together as one. This new design will add tensile strength with two additional laminates running parallel through the mold.

It was found that laminating fibers over the aluminum plate tied into the sides of the composite sample will greatly strengthen the interfacial bond. For the experiment where there is no wrap, the failure stress in the glue was $\sigma_{\text {tension }}=19.76 \mathrm{psi}$ and $\sigma_{\text {shear }}=$ 5.21 psi. With the fiber wrap to transfer loads away from the epoxy interface, the stresses in the epoxy are reduced. This allowed for the applied load to reach $939 \mathrm{lb}$. before interfacial damage was seen. At this load the stresses seen are $\sigma_{\text {tension }}=74.23 \mathrm{psi}$ and $\sigma_{\text {shear }}=19.56$ psi. Because of this, upon lamination around the new mold design, it becomes important to align fibers in the sample corresponding to the load direction transferred from the aluminum plate. Further research should show, this sample stiffening effect to be very effective in not only strengthening the sample but the aluminum/epoxy interface as well.

Optimal design of the aluminum plate is also expected to have an expected obvious increase in interfacial bond strength. This assumption is linked to the idea of load transfer across the interface. An aluminum plate which has equal width dimensions to the composite sample it is bonded to will better transfer the applied load away from the weaker interface. The load will more directly transferred through the laminate wrap over the aluminum plate and down into the fibers which make up the composite sample. This will also increase the overall area of aluminum/epoxy adhesion. Furthermore, by 
smoothly tapering the two ends in the length direction of the plate, a more fiber dominate load transfer will result in greater bond strength. The overriding conclusion is to have a fiber configuration in the design that will best transfer the combined applied load away from the weaker interface. 


\section{REFERENCES}

1. Barbero E.J. (1999), Introduction to Composite Materials Design, Taylor and Francis, Philadelphia, PA.

2. MAE 593A Introduction of Materials Science class notes (fall 2004), Mechanical and Aerospace Engineering, West Virginia University, Morgantown, WV

3. MAE 593I Intermediate Materials Science 2 class notes (spring 2005), Mechanical and Aerospace Engineering, West Virginia University, Morgantown, WV

4. Odom E.M. and Adams D.F. (1982), Design and Fabrication of a Motorcycle Swingarm Utilizing Composite Materials, Society of Automotive Engineers, Inc. (820990)

5. Riegner D.A. and Hsu J.C. (1982), Fatigue Considerations for FRP Composites, Society of Automotive Engineers, Inc. (820698)

6. Friedman K., Ireland D. and Feraboli P. (2001), Strength Behavior of Metal-ToMetal and Metal-To-Composite Joints, Society of Automotive Engineers, Inc. (2001-01-3083)

7. Mallick P.K. (1981), Fatigue Consideration in the Design of Automotive Composites, Society of Automotive Engineers, Inc. (810326)

8. Mao H. and Mahadevan S. (2002), Fatigue damage modelling of composite materials, Journal of Composite structures, 405-410, Vol. 58, Iss. 4, Elsevier Science Ltd.

9. Lee S., Nguyen T. and Chuang T. (2003), Model of fatigue damage in strain-ratesensitive composite materials, Journal of Materials Research, 77-80, Vol. 18, No. 1.

10. Gilchrist M.D. and Curley L. (1999), Manufacturing and ultimate mechanical performance of carbon fibre-reinforced epoxy composite suspension push-rods for a Formula 1 racing car, Fatigue Fract. Engng. Mater. Struct. 22, 25-32, Blackwell Science Ltd.

11. Curtis P.T. and Dorey G. (1986), Fatigue of composite materials, IMechE conference publications, 297-306, Vol. 2.

12. Caceres A. (1998), Local Damage Analysis of Fiber Reinforced Polymer Matrix Composites, Dissertation, West Virginia University, Morgantown, WV. 
13. Berg K.R. and Plumer J. (1980), Can Composite Materials Compete in Vehicle Torsion Members?, Society of Automotive Engineers, Inc. (800484)

14. Chrstos J.P. (1991), A Simplified Method for the Measurement of Composite Suspension Parameters, S.A.E. Transactions Journal, 323-335, Vol. 100, No. 6.

15. Dragoni E. and Foresti F. (1998), Design of a single-sided composite swing arm for racing motorcycles, International journal of materials \& product technology, 411-420, Vol. 13, No. 3, Inderscience Enterprises Ltd.

16. Courtney T.H. (2000), Mechanical Behavior of Materials, $2^{\text {nd }}$ ed., McGraw-Hill Companies, USA.

17. Itou S. (2004), An experiment on stress intensity factors for an interface crack between epoxy and aluminum plates, International Journal of Fracture, 89-102, Vol. 125, Kluwer Academic Publishers.

18. Lu Y., Wu F., Xue G. and Wang X. (1994), Interfacial modification for an aluminum/epoxy resin laminated composite, Composite Interfaces, 265-274, Vol. 2, No. 4.

19. Schön J. (2004), Coefficient of friction for aluminum in contact with a carbon fiber epoxy composite, Tribology International, 395-404, Vol. 37, No. 5.

20. Albers R.G. and White S.R. (1992), The Effect of Surface Treatment on Enhancing the Interfacial Bond between Aluminum and Epoxy, Proceedings of the American Society for Composites...Technical Conference, 587-596.

21. Albers R.G. and White S.R. (1996), Experimental Investigation of Aluminum/Epoxy Interfacial Properties in Shear and Tension, The Journal of adhesion, 303-316, Vol. 55, Iss. 3.

22. Kenedi, P.P., Xavier, L.S., Amar de Aguiar, R.A., Sampaio, R.O., Carvalho de Queiroz, T.F. (2004), Modeling Different Configurations for a Frontal Suspension of an Off-Road Vehicle Mini-Baja, Society of Automotive Engineers, Inc. (2004-01-3437) 


\section{APPENDIX}

Equations for stress in epoxy.

... see Appendix Fig. 1A \& 2A

$\mathrm{F}=$ rebound load

$\mathrm{F}_{\mathrm{X}}=\mathrm{F} \cos \theta$

$\mathrm{F}_{\mathrm{y}}=\mathrm{F} \sin \theta$

$\mathrm{M}_{(\text {epoxy })}=\mathrm{d}\left(\mathrm{F}_{\mathrm{x}}\right)$

$\mathrm{P}=3(\mathrm{M}) / 2(\ell)$

$\sigma_{\mathrm{M}(\text { epoxy })}=4(\mathrm{P}) / \mathrm{w}(\ell / 2)$

$\sigma_{\text {tension(epoxy) }}=\mathrm{F}_{\mathrm{y}} / \mathrm{A}_{\text {epoxy }}$

$\sigma_{\mathrm{t}(\mathrm{epoxy})}=\sigma_{\mathrm{M}(\mathrm{epoxy})}+\sigma_{\text {tension(epoxy) }}$

$\sigma_{\text {shear(epoxy) }}=\mathrm{F}_{\mathrm{x}} / \mathrm{A}_{\text {epoxy }}$

$$
\begin{aligned}
& M_{\text {(epoxy) }}=1.375 \text { in. }\left(F_{x}\right) \\
& P=3\left(M_{(\text {epoxy })}\right) / 2(8 \text { in. }) \quad \text { (equil. couple load) } \\
& \sigma_{M(\text { epoxy })}=4(P) / 3 \text { in. }(4 \text { in. }) \\
& \sigma_{\text {tension(epoxy) }}=F_{y} / 24 \text { in. }^{2} \\
& \sigma_{\text {shear(epoxy) }}=F_{x} / 24 \text { in. }^{2} \quad \text {... see Table } 6
\end{aligned}
$$

Equations for stress and strain in carbon/epoxy wrap. ... see Appendix Fig. 1A \& 2A

$$
\begin{aligned}
& \mathrm{M}_{(\text {wrap })}=\mathrm{h}\left(\mathrm{F}_{\mathrm{x}}\right) \\
& \mathrm{I}_{\text {(wrap) }}=\left(\ell^{2} / 6\right)(3 \mathrm{w}+\ell) \\
& \mathrm{M}_{\text {(wrap) }}=1.125 \text { in. }\left(\mathrm{F}_{\mathrm{x}}\right) \\
& \sigma_{\mathrm{M}(\text { wrap })}=\mathrm{M} \mathrm{c} / \mathrm{I} \\
& \mathrm{I}_{\text {(wrap) }}=\left(8^{2} / 6\right)(3(3)+8) \\
& \sigma_{\mathrm{M}(\text { wrap })}=\mathrm{M}_{\text {(wrap) }}(4 \text { in. }) /\left(181.33 \mathrm{in}^{3}\right)(0.0086 \text { in. }) \\
& \sigma_{\text {tension(wrap) }}=\mathrm{F}_{\mathrm{y}} / \mathrm{A}_{\text {(wrap) }} \\
& \sigma_{\text {tension(wrap) }}=\mathrm{F}_{\mathrm{y}} /(22 \text { in. })(0.0086 \text { in. }) \\
& \sigma_{\text {(wrap) }}=\sigma_{M(\text { wrap })}+\sigma_{\text {tension(wrap) }} \\
& \sigma_{\text {shear(wrap) }}=\mathrm{F}_{\mathrm{X}} / \mathrm{A}_{\text {wrap }} \\
& \sigma_{\text {shear }(\text { wrap })}=F_{x} /(22 \text { in. })(0.0086 \text { in. })
\end{aligned}
$$

calculated tensile strain $=\sigma_{(\text {wrap })} / 20.5 \times 10^{6} \mathrm{psi}$ calculated shear strain $=\sigma_{\text {shear(wrap })} / 18.5 \times 10^{6} \mathrm{psi}$
... see Fig. 40

...see Fig. 40

Equations for bending stress and strain in composite beam.

$$
\begin{array}{ll}
\mathrm{M}_{(\text {beam })}=\left(\mathrm{F}_{\mathrm{y}} / 2\right)(\mathrm{m}) & \mathrm{M}_{(\text {beam })}=\left(\mathrm{F}_{\mathrm{y}} / 2\right)(6.5 \text { in. }) \\
\mathrm{I}_{(\text {beam })}=\left(\mathrm{n}^{2} / 6\right)(3 \mathrm{p}+\mathrm{n}) & \mathrm{I}_{(\text {beam })}=\left(6^{2} / 6\right)(3(4)+6) \\
\sigma_{\mathrm{M}(\text { beam })}=\mathrm{M} \mathrm{c} / \mathrm{I} & \sigma_{\mathrm{M}(\text { beam })}=\mathrm{M}(3 \text { in. }) /\left(108 \text { in. }^{3}\right)(0.0086 \text { in. }) \\
\text { calculated beam bending }=\sigma_{\mathrm{M}(\text { beam })} / 18.5 \times 10^{6} \mathrm{psi} & \ldots \text { see Fig. } 42
\end{array}
$$


Experiment Sample

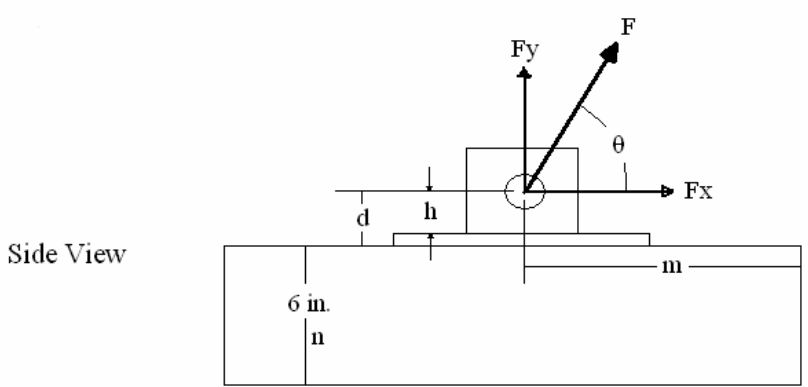

Top View

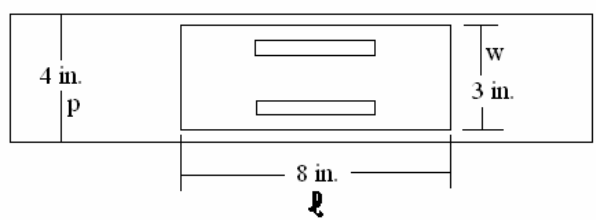

Fig. 1A Experiment sample. 
Area of fibers carrying load

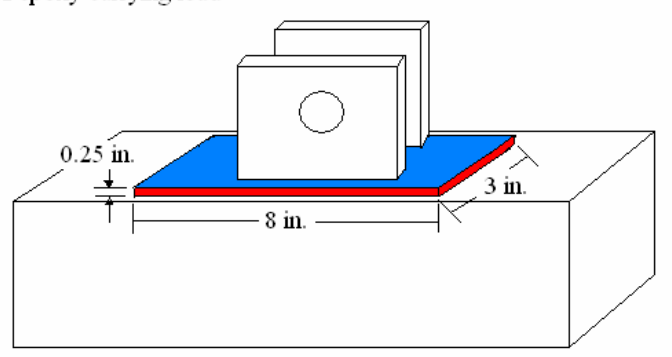

Fig. 2A Area under load. 